\title{
Is the Time Allocated to Review Patent Applications Inducing Examiners to Grant Invalid Patents?: Evidence from Micro-Level Application Data
}

\author{
Michael D. Frakes and Melissa F. Wasserman*
}

We explore how examiner behavior is altered by the time allocated for reviewing patent applications. Insufficient examination time may hamper examiner search and rejection efforts, leaving examiners more inclined to grant invalid applications. To test this prediction, we use application-level data to trace the behavior of individual examiners over the course of a series of promotions that carry with them reductions in examination-time allocations. We find evidence demonstrating that such promotions are associated with reductions in examination scrutiny and increases in granting tendencies, as well as evidence that those additional patents being issued on the margin are of below-average quality.

Evidence suggests that patents play an important role in both promoting innovative activity and shaping the direction of technological growth (Moser, 2004). In recent years, however, the patent system has come under voracious criticism (Burk \& Lemley, 2009). Critiques of the system has largely coalesced around one charge: the U.S. Patent and Trademark Office (Patent Office or Agency) is issuing too many invalid patents-i.e., patents on inventions that fail to

\footnotetext{
* Frakes: Associate Professor of Law, Northwestern University School of Law; Faculty Research Fellow, National Bureau of Economic Research; Fellow, Northwestern Institute for Policy Research (e-mail: mdf519@northwestern.edu). Wasserman: Associate Professor of Law; Richard and Anne Stockton Faculty Scholar; \& Richard W. and Marie L. Corman Scholar, University of Illinois College of Law. The work was funded in part by University of Illinois at Urbana Champaign Research Board, Award 12088 and the Cornell Institute for the Social Sciences Small Grant Award. We are grateful to Matt Berry at the National Center for Supercomputing Applications at the University of Illinois for collecting data from the Patent Office's PAIR database. We are grateful to Alberto Galasso for providing data on pairwise citations and for providing helpful comments. We are likewise grateful to Bhaven Sampat for providing data on examiner-driven citations. We thank Kevin Collins, Rochelle Dreyfuss, John Golden, Wendy Gordon, Paul Heald, Scott Hemphill, Mark Lemley, Ronald Mann, Alan Marco, Peter Molk, Lisa Ouellette, Jim Poterba, Arti Rai, Saurabh Vishnubhakat, Heidi Williams, and participants at the $14^{\text {th }}$ Annual Intellectual Property Scholar Conference, the Big Ten Untenured Conference, the Northwestern Law School Profs Talk, the $3^{\text {rd }}$ Annual Empirical Patent Law Conference, the Georgetown Law and Economics Workshop, the Northwestern Institute for Policy Research Workshop, the $9^{\text {th }}$ Annual Conference on Empirical Legal Studies, Patent Statistics for Decision Makers 2014, Tilburg Law and Economics Workshop, Works-in-Progress Intellectual Property, American Law and Economics Association 2015 Annual Meeting, Eighth Annual Searle Center Conference on Innovation Economics, 2015 Yale/Stanford/Harvard Junior Faculty Forum, faculty workshops at University of Texas School of Law, Indiana University Maurer School of Law, and the Washington University in St. Louis for useful comments.
} 
meet the patentability requirements (Jaffe \& Lerner, 2004). In board terms, a Pat6ent Office that is routinely granting patents on inventions that are already known or represent only a trivial advancement over current scientific understanding will tend to burden society with the deadweight losses associated with monopoly protection without reaping the benefits of spurred innovation (Nordhaus 1969). In addition, invalidly issued patents can be utilized by nonpracticing entities or "patent trolls" to opportunistically extract licensing fees from innovators, while also stunting follow-on discoveries in markets characterized by cumulative innovation (Scotchmer 1991, Sampat and Williams 2014, Galasso and Schankerman 2014).

Although commentators have suggested a plethora of reasons as to why the Agency may be biased towards allowing patents, there exists little compelling empirical evidence that any particular feature of the Patent Office actually induces the Agency to over-grant patents. ${ }^{1}$ Absent such evidence, policymakers are provided with little guidance as to how to address the root causes of the patent quality crisis. This paper begins to rectify this deficiency by addressing one feature of the Patent Office that scholars have identified as likely to influence an examiner's decision to grant a patent: the time allotted to review a patent application (Jaffe and Lerner, 2004). Because patent applications are presumed to comply with the statutory patentability requirements when filed, the burden of proving unpatentability rests with the Agency. That is, a patent examiner who fails to explicitly set forth reasons as to why the application fails to meet the patentability standards must grant the patent. To the extent that examiners are given insufficient examination time, one might expect them to conduct limited reviews of applications, leaving them in a weaker position to identify proper bases of rejections and thereby leaving them in a position where they must grant patents at elevated rates in light of this legal presumption of

\footnotetext{
1 See, however, Frakes and Wasserman (2013, 2015), which explore how the Patent Office's fee schedule, along with the Office's inability to finally reject a patent application, creates an incentive for a financially constrained agency to allow additional patents.
} 
validity. Much anecdotal evidence has been put forth to suggest that patent examiners indeed face binding examination time constraints, implicating such concerns. ${ }^{2}$

To more comprehensively test this simple hypothesis and challenge this anecdotal sentiment, we rely upon the fact that examination times decrease upon certain types of examiner promotion. Our basic empirical strategy is to follow individual examiners throughout the course of their careers and to track the evolution of their examination behavior-including their granting ratesas they experience promotions that diminish the amount of examination time at their disposal. Bolstering our ability to separate the effect of allocated examination time from other factors that may change generally upon promotion is the fact that examiner promotions and pay raises come in several varieties, some of which bear on examination times and some of which do not. Our identification strategy is further strengthened by the fact that the promotions of interest do not transpire lock-step with increases in years of experience, allowing us to decouple an experience effect from a promotion-of-interest effect, combined with the fact that applications are generally randomly assigned to examiners within technology groups.

To execute this empirical strategy, we estimate examiner fixed-effects specifications using novel, micro-level data on over 1 million patent applications disposed of between 2002 and 2012, merged with rich, examiner roster data received from the Patent Office pursuant to a series of Freedom of Information Act requests (FOIA). Our results suggest that as an examiner is given less time to review an application, the less active she becomes in searching for prior art, the less likely she becomes to make obviousness rejections (which are especially time-intensive

\footnotetext{
2 In an August 2010 report commissioned by the Patent Office to reassess the schedule by which they set examinationtime expectations (which we obtained pursuant to a Freedom of Information Act Request), the Manhattan Strategy Group stated the following:

Examiners consistently expressed the need for additional time. This was stated mostly in concern to not being able to do a high-quality examination and to avoid taking short-cuts. As one examiner in [Technology Center] 1700 explained, "when you add it up its not enough time to do a proper job on a case." A junior examiner expressed a similar sentiment, stating that "rather than doing what I feel is ultimately right, I'm essentially fighting for my life."
} 
exercises), and the more likely she becomes to grant the patent. Under the assumption that patent examiners who are allocated sufficient time to review applications will, on average, make the correct patentability determinations, our results suggest that the time allotments may be inducing patent examiners to grant invalid patents on the margin. Supporting the view that these marginal patents may be of questionable quality / validity, we find that examination-timereducing promotions are associated with a reduction in the frequency by which the inventors of U.S. issued patents are likewise successful in securing patent protection at the European Patent Office and the Japan Patent Office-two agencies following essentially similar patentability requirements but that expend greater resources per application than the U.S. Patent Office.

At first blush, it may not be surprising that the level of scrutiny afforded applications may, at some point, fall as allocated examination time becomes sufficiently strained. Importantly, our findings demonstrate that this is not merely a hypothetical scenario but instead that examiners appear to be operating at the point where time constraints indeed bind. That is, our results suggest that current reductions in time allocations upon promotion are hampering the ability of examiners to fully evaluate the merits of the given applications and thus ensure that only meritorious applications are granted. ${ }^{3}$ Moreover, we demonstrate that the magnitude of the resulting impact on examiner granting tendencies is substantial. As examination time is cut roughly in half (i.e., as an examiner rises from GS-7 to GS-14 along the General Schedule scale,

\footnotetext{
3 Temporal limits placed upon workers to complete specific tasks are naturally related to production targets enforced over specified measurement periods. Indeed, as discussed below and in the Online Appendix, the Patent Office's time allocations are effectuated via an examination quota system that is monitored bi-weekly and at quarter ends. Though our discussion focuses on the behavior of patent examiners at the U.S. Patent Office, the analysis contributes to a broader literature in personnel economics and human resource management on the productivity consequences of workload expectations and quotas and on the timing associated with measuring employee output. Notable examples of such studies include Asch (1990), Oyer (1998), Courty and Marshke (2004), Larkin (2014), and Chan (2015 a). The present investigation into the effects of time constraints on patent examiner behavior is likewise related to research bearing on the distortions in worker behaviors that may arise in connection with the time constraints that workers-e.g., physicians_-face near the ends of scheduled shifts. See, for example, Chan (2015 b). More broadly, this analysis is related to research on the distortionary effects of objective performance measures (Baker, Gibbons, and Murphy, 1994).
} 
controlling for changes in years of experience), our findings suggest that grant rates rise by as much as 10 to 19 percentage points, or by roughly 15 to 28 percent. $^{4}$

Despite a substantial literature in economics bearing on the patent system, ${ }^{5}$ the administrative process by which patent rights are initially established has received scant attention. To date, only a handful of studies have explored the dynamics of the Patent Office, primarily by investigating the role of examiner heterogeneity in explaining the outcomes of the patenting process (Cockburn, Kortum, \& Stern, 2003; Lichtman, 2004; Mann, 2014). These groundbreaking studies raise concerns of an inefficient and inequitable Patent Office, demonstrating that application outcomes are largely a function of the examiners that applicants randomly receive. However, these studies fail to explore arguably the most important outcome of this process - whether the examiner granted the patent—while also failing to examine whether a particular feature of the Patent Office influenced the examiner's behavior.

Lemley and Sampat (2012) arguably come closest to filling this gap in the literature, estimating a monotonically increasing relationship between years of examiner experience and examiner grant rates. Given the natural connection between experience and promotion, their analysis, as they note, likely captures some aspects of the impact of allotted examination time on grant rates; though, absent data on examiner promotions, they are unable to decouple an experience effect from an examination-time-allotment effect. Moreover, their analysis is largely cross-sectional in nature (observing 10,000 patent applications filed in January 2001), hindering their ability to distinguish between the effect of experience itself from either an examiner cohort

\footnotetext{
$4 \quad$ Notably, our findings also challenge the widely held belief that decreasing patent examiner attrition is vital to increasing patent quality (Jaffe \& Lerner, 2004).

5 This literature has ranged from analyses on how to value patent rights (Pakes, 1986; Jaffe et al., 1993; Harhoff et al., 1999; Hall et al., 2005), to studies exploring the effect of patents on innovation (Mansfield, 1986; Griliches, 1990; Cohen et al., 2000), to research on the ways in which patents are used and enforced once granted (Lanjouw and Lerner, 1997), among other investigations.
} 
effect or an examiner tenure effect. By tracking individual examiners over the course of a tenyear period, our fixed-effects specifications are able to overcome these concerns. While our focus is on understanding the impact of reductions in allocated examination time and not necessarily on the independent impacts of examiner experience, we note that the imposition of examiner fixed effects produces an inverse-U shape in the relationship between grant rates and experience, as opposed to the monotonically increasing relationship documented in Lemley and Sampat (2012). In other specifications that are in the spirit of a regression-discontinuity design, we find evidence suggestive of a strictly negative influence of experience (in years) on grant rates, combined with discrete jumps in grant rates upon the relevant promotions.

In the next section, we provide a background on the patent examination process and discuss our theoretical predictions. In Sections II and III, we describe our data and empirical methodology, respectively. Section IV presents results from our examiner fixed-effects analysis. Finally, Section V concludes.

\section{BACKGROUND AND THEORY}

\section{A. Description of Examination Process}

Every patent application filed with the Patent Office contains a specification, which describes the invention, and a set of claims that defines the metes and bounds of the legal rights the applicant is seeking. Moreover, to satisfy applicants' duty of candor under U.S. law, patent applications typically disclose to the Agency "prior art," that is previous patents, patent applications, or other publications, that are material to the patentability of the relevant invention.

Before an application enters examination, it is routed to an Art Unit, a group of eight to fifteen patent examiners who review applications in the same technological field. Upon arrival, the Supervisory Patent Examiner (SPE) of that Art Unit randomly assigns the application to a 
specific examiner. Occasionally, SPEs make non-random assignments, but in those instances, they do so not based on any characteristic that would affect the patentability of the application but instead, for instance, on an examiner's backlog of applications (Lemley \& Sampat, 2012). ${ }^{6}$

The assigned examiner assesses the patentability of the invention based on the criteria outlined in the Patent Act. Without making any reference to prior art, an examiner can deny a patent on the grounds that the claimed invention does not involve statutory subject matter (35 U.S.C. $\S$ 101), that the invention is not useful (35 U.S.C. §101) or that the application fails to satisfy the disclosure requirements (35 U.S.C. $§ 112$ ). In contrast, two other grounds for rejection-i.e., lack of novelty (35 U.S.C. $§ 102$ ) and obviousness (35 U.S.C. $§ 103)$-require the examiner to make a comparison of the claimed invention with the background art already known to the public. Before making this assessment, the examiner conducts her own prior art search to supplement that disclosed by the patent applicant. Because lack-of-novelty and obviousness rejections require this delicate prior art comparison (and underlying search), they are typically viewed as being more time consuming to perform than non-art-based rejections. Obviousness rejections are especially time intensive in this regard, even relative to novelty rejections. While novelty assessments require that examiners determine whether the claimed invention is covered by a single prior publication or patent, an obviousness determination requires an examiner to start with a prior art reference that covers only a portion of the invention and then piece together additional references or rely upon what is known to one of ordinary skill in the art in order to determine whether it would be "obvious" to modify any one of the cited prior art references to achieve the claimed invention.

\footnotetext{
6 We conducted a series of telephone interviews with former SPEs to confirm these details of patent examination assignment. Our interviews further substantiated that SPEs do not make any substantive evaluation of an application before assigning it to a particular examiner.
} 
After assessing the patentability of the claims, an examiner composes a "first office action" letter to the applicant that accepts or rejects them. Although some applications are allowed in their entirety upon first examination, more frequently, some or all of the claims fail to meet at least one of the patentability requirements, as the examiner will detail in the first office action letter. The applicant then responds by amending the claims or disputing the rejection. After the response, a patent examiner may issue a final rejection or allow the patent to issue. ${ }^{7}$

\section{B. Examination-Time Allocations}

A number of scholars have surmised that the time constraints facing patent examiners in assessing the patentability of claims are partly responsible for the Patent Office allowing too many invalid patents (Jaffe \& Lerner, 2004; Lemley, 2001; Lemley and Sampat 2012). Although it may take several years from filing a patent application for an applicant to receive a final patentability decision from the Patent Office, on average, an examiner spends only nineteen hours reviewing an application, including reading the patent application, searching for prior art, comparing the prior art with the patent application, writing a rejection, responding to the patent applicant's arguments, and often conducting an interview with the applicant's attorney (Frakes \& Wasserman, 2014). If, over these hours, examiners are unable to conduct a sufficient search of prior art and determine and articulate a proper basis of rejection in the relevant office action report, they are expected, under the law, to allow applications. In light of this legal presumption of validity, one might predict that a further tightening of time constraints will only cut the underlying search and evaluation period even shorter and cause examiners to error even further

\footnotetext{
$7 \quad$ After receiving a final rejection, an aggrieved patent applicant can restart the examination process by filing a continuation application, appeal the denied application to Patent Trial and Appeal Board, or abandon the application altogether.
} 
on the side of allowing additional patents on the margin that might have otherwise been rejected if given sufficient time. ${ }^{8}$

As explained in greater detail in the Online Appendix, the Patent Office sets expectations regarding the amount of time examiners should spend on applications. ${ }^{9}$ The number of hours allocated for review depends on both the technological field in which the examiner is working and on her position in the general schedule (GS) pay scale. A patent examiner in a more complex field is provided more hours to review an application than an examiner of the same grade who is working in a less complex field. The higher the pay grade of an examiner within a technology area the fewer number of hours the Patent Office extends to that examiner. A promotion to each subsequent pay grade is roughly equated to a ten to fifteen percent decrease in the number of allocated examination hours.

To demonstrate the degree to which time allocations scale with GS-level changes, we present in Table 1 the examination time expectations facing a patent examiner working in one of the most complex fields, artificial intelligence, and one of the least complex fields, compound tools.

$8 \quad$ That is, the underlying legal landscape leads to a simple prediction that time constraints will produce a bias towards granting, as opposed to producing symmetrical noise in the examination process. We acknowledge the possibility that certain examiners may decline to follow this legal presumption of validity when faced with time pressures and simply write up an illconceived and vague rejection. However, it is perhaps unlikely that reductions in the total amount of time allocated for the review process will incentivize non-compliant but nonetheless time-constrained examiners to issue more rejections of this particular nature. Mainly, it is important to acknowledge that preparing a notice of allowance (which essentially requires no justification) is still less time intensive to produce than even a vaguely worded and weak rejection. Furthermore, to the extent that examiners were to issue easily overcome rejections in non-final office actions, they might have little hope of dispensing with the application with finality; rather they would perhaps merely be inviting applicants to articulate proper responses, an event that will only require additional time outlays on the examiners' part at a future date. Finally, there may be reason to doubt why examiners would be inclined to disregard the legal presumption of validity in the first place and thus be motivated to issue rejections of this vague and weak variety. Such behaviors may be scrutinized during the evaluation processes they are put through at times. Moreover, rejections of this nature may more easily invite appeals by applicants, events that may likewise lead to certain repercussions for the associated examiners. All told, we predict that time constraints will cause examiners to error on the side of allowing more patents, as opposed to erring in both directions.

$9 \quad$ These time allotments have largely remained unchanged since 1976. The Patent Office has created new patent classifications as a result of new and emerging technology. Once the Agency has set the time allotments for a new technology these allocations also have largely remained unchanged. In 2010, however, the Patent Office increased the time allotments for every application by two hours. 
As demonstrated by this table, examiners operating at GS-level 14 are expected to review the same patent in approximately half that time of examiners operating at GS-level 7.

TABle 1: EXAmination Hours AllocAted to EXAMINER AS A FunCTION OF GS-LEVEL

\begin{tabular}{ccc}
\hline & $(\mathbf{1})$ & $(\mathbf{2})$ \\
\hline GS-level & Compound Tools & $\begin{array}{c}\text { Artificial } \\
\text { Intelligence }\end{array}$ \\
\hline GS-7 & 19.7 & 45.1 \\
GS-9 & 17.3 & 39.5 \\
GS-11 & 15.3 & 35.1 \\
GS-12 & 13.8 & 31.6 \\
GS-13 & 12.0 & 27.5 \\
GS-13, partial signatory & 11.0 & 25.3 \\
GS-14 & 10.2 & 23.4 \\
\hline
\end{tabular}

\section{C. $\quad$ Promotion Process}

Patent examiners are hired at different pay grades (GS-5, GS-7, GS-9, GS-11 or GS-12) depending upon their educational background and prior experience. Promotions at low pay grades typically (though not always) occur within a year for examiners that meet their workload expectations with few errors. An examiner's error rate is calculated by reviewing some subset of the examiner's work product to see if, for instance, the examiner fails to include all grounds of rejections that should have been made or if she includes unreasonable rejections. In contrast, promotions at the high pay grades (GS-12, 13, and 14) often require more time, as they generally involve the completion of additional testing or programs. ${ }^{10}$

While we contend that the most significant change associated with a promotion that bears on the examiner's decision to grant a patent application is the time allocated to review an

10 For instance, to be eligible for a GS-13 promotion, examiners must demonstrate legal competency by successfully complete training courses and passing written tests on subjects such as patent law, practice, and procedure. 
application, there is, upon promotion within GS-13 and to GS-14, also a change in the scrutiny of their work. Examiners at pay grades GS-13 and below must have their decisions reviewed by an examiner that has "full signatory authority." 11 Patent examiners at pay grades GS-13 may begin to work towards obtaining such authority by undergoing an evaluation period, which upon successful completion will result in a promotion to a patent examiner with "partial signatory authority." A GS-13 partial signatory promotion, though not associated with a change in the GS level, does entail a decrease in the examination time allotted to the promoted examiner and provides that examiner the ability to sign off independently on first office actions. Upon completing a second period of evaluation, a GS-13 partial-signatory patent examiner can be promoted to GS-14, a promotion which provides the examiner with full signatory authority or the right to sign off on all aspects of an application independently. The fact that variations in scrutiny of this nature do not occur upon all examination-time-reducing promotions is an important component to our identification strategy, as discussed in Section IV below. ${ }^{12}$

To our knowledge, nothing else changes upon GS-level promotions that would affect the manner in which examiners conduct their examination. For instance, the basic structure of overtime and bonuses remains constant upon GS-level promotions as does the ways in which examiners earn work credits, in which event one would not expect examiners to face enhanced financial incentives to grant patents (to the extent that they ever face such incentives) upon promotions to higher grade levels. We confirmed that GS-level promotions are not associated

\footnotetext{
11 Even though these "junior" examiners do most of the work on the application they are listed as secondary examiners on the application.

12 Although the determinants of GS-13 partial-signatory and GS-14 promotions are similar to lower level promotionsmeet workload expectations with few errors - the evaluation period is more formalized with these higher-level promotions. That is, unlike lower-level promotions, examiners who wish to be eligible for signatory authority must affirmatively agree to participate in an evaluation period in which a larger portion of their work product is reviewed for clear errors than if they had not agreed to participate in the signatory authority program.
} 
with such changes through our review of examiner compensation materials made available by the Patent Office and through our interviews with former SPEs.

\section{Hypothesis}

We assume that, when given sufficient time, examiners will conduct their examination practices in line with proper patentability standards. However, binding time constraints may force examiners of this otherwise competent disposition to decrease the degree to which they search prior art, decrease their ability to extend meaningful obviousness rejections and thus increase the propensity by which they grant patents. We surmise that examiner promotions of the variety that decrease the amount of time expected to review applications will only tighten these constraints and intensify such outcomes.

\section{DATA}

Most prior investigations into the determinants of examiner behavior have explored only issued patents (for example, Cockburn, Kortum, and Stern, 2003). Among other things, a sampling frame of that nature is insufficient to capture arguably the most important decision that an examiner must make: whether or not to grant the given patent application. Moreover, when prior studies have considered application-level data, they have done so only with respect to a subset of applications at one snapshot in time, ${ }^{13}$ which is insufficient to account for sources of examiner heterogeneity that may bias the analysis. To overcome these deficiencies and to facilitate a rich examiner-fixed-effects design, we collected individual application data from the Patent Office's Patent Application Information Retrieval (PAIR) database on all 1.4 million utility patent applications that were filed on or after March, 2001 and that reached a final

\footnotetext{
13 For example, Lemley and Sampat (2012) consider only 10,000 applications filed in January of 2001.
} 
disposition-i.e., excluding ongoing applications—by July 2012. The Online Appendix provides more specifics regarding the construction of this sample.

Though especially rich in content, the PAIR database is not readily suitable for a comprehensive, machine-readable analysis of granting practices considering that the data is divided into separate webpages for each individual application, with each webpage providing information via numerous tab delimited and portable document format (pdf) files. Because of the nontrivial nature of this data collection we utilized the National Center for Supercomputing Applications at the University of Illinois to amass and coordinate information contained across the $1+$ million different webpages. Specifically, we collected information on the status of the application as well as other information about the prosecution process, including, among others, the patent examiner charged with reviewing the application and the basis of any rejection associated with the application (e.g., obviousness).

Critical to our analysis is determining the experience (in years) and the GS-level for each of the 9,000 examiners represented in our analytical file. For these purposes, we match the examiner field in the PAIR data with the two sets of examiner rosters received pursuant to separate FOIA requests, one of which dates back to 1992 to facilitate the identification of experienced examiners at the beginning of our sample. We describe these rosters and this matching process (including our handling of "fuzzy" name matches) in greater detail in the Online Appendix. We likewise provide a breakdown in the Online Appendix of the percentage of applications reviewed by examiners in each of the relevant GS-levels and experience groups considered below. The greatest percentages are accounted for by the higher GS-levels (GS-level $12+)$ considering that examiners spend considerably more time at such ranges. Finally, we treat the individual who did the majority of work on the application as the examiner charged with 
reviewing that application: (1) the non-signatory examiner, when both a non-signatory and an examiner with signatory authority are associated with an application, or (2) the signatory examiner, when only one examiner is associated with an application.

For each application in our sample, we relate examiner characteristics, including their pay grade and experience level, to whether or not the application was granted, our key outcome of interest. All told, 68 percent of the applications disposed of over this time period were granted (see Table 2). ${ }^{14}$ To form our second set of outcome measures, we determine whether the given application had at least one claim rejected during examination based on each of the following statutory bases: $§ 101$ (lack of patentable subject matter, lack of utility, double patenting), § 102 (lack of novelty), 103 (obvious), and $\S 112$ (failure to meet the disclosure requirements). To the best of our knowledge, we are the first to report the bases of rejections for any substantial sample of patent applications. ${ }^{15}$ Details regarding the process utilized to collect the rejectiontype data can be found in the Online Appendix. The likelihood that a given application received each of the indicated types of rejections in the sample are as follows: (1) 11 percent, $\S 101$; (2) 56 percent, § 102; (3) 72 percent, § 103; and (4) 35 percent, § 112.

To proxy for how intensively examiners are searching for prior art, we focus on the sample of patents issued over the above-specified time period (as distinct from the sample of applications over this time period) and collect information on the share of prior art references listed in each

14 Continuation applications, as distinct from the now more common RCEs, are counted as a rejection / abandonment of the original application and the filing of a new application within the PAIR database (RCEs, which keep the same serial number and stay with the same examiner, are not treated as new applications). Accordingly, this 68 percent rate does not necessarily capture the percentage of original applications that are ultimately allowed considering that some continuation applications may successfully issue. It is important to note that this is merely a classification issue-i.e., do these events contribute or not contribute to the Patent Office's grant rate? Our focus is largely on exploring the relationship between the grant rate, however it is defined, and certain characteristics of the examiners.

15 Cotropia, et al., 2013, however, have previously reported rejection data for 1,554 patents issued in 2007. 
issued patent that emanate from the examiner rather than the applicant. ${ }^{16}$ Previous investigations have reported that examiners are more likely to rely upon prior art they discovered during their own search, rather than art disclosed by an applicant, to reject a patent application (Cotropia, Lemley, and Sampat, 2013).

TABLE 2. SUMMARY STATISTICS

\begin{tabular}{lc}
\hline & \\
\hline & 0.678 \\
Incidence of Granted Patent & $(0.467)$ \\
& 0.717 \\
Incidence of Any Obviousness Rejection & $(0.450)$ \\
Share of Rejections based on Obviousness & 0.454 \\
& $(0.283)$ \\
Share of Prior Art Citations Originating from Examiner & 0.546 \\
Incidence of U.S. Patent being Allowed by both EPO and JPO (among Patent & $(0.369)$ \\
Family Sample) & 0.442 \\
Incidence of U.S. Patent being Allowed by EPO (among Patent Family & $(0.497)$ \\
Sample) & 0.604 \\
Incidence of U.S. Patent being Allowed by JPO (among Patent Family & $(0.490)$ \\
Sample) & 0.637 \\
Incidence of Large-Entity Applicant & $(0.481)$ \\
Incidence of Foreign Priority (at EPO or JPO) & 0.734
\end{tabular}

Statistics are from the collection of applications in the Patent Office's s PAIR database that reached a final disposition and that were published in the PAIR records between March, 2001 and July, 2012. Statistics bearing on EPO and JPO allowance rates are from the subset of patents that were granted out of this initial set of applications and whose applicant's likewise sought patent protection at the EPO and JPO.

A final set of outcome measures considered in the analysis below is meant to reflect on the quality of the patents issued by the Patent Office. As explained in Section IV, we assess these outcomes by looking at a set of inventions that sought protection at each of the U.S. Patent

16 This measure includes patent and non-patent prior art (and foreign prior art), though the results presented below are robust to just focusing on patent prior art. Several studies have used the share of references listed in an issued patent originating from the applicant or examiner as a proxy for the extent to which the party in question (examiner or applicant) searched the prior art (Lemley and Sampat, 2012; Sampat, 2010; Alcacer et al., 2009). 
Office, the European Patent Office (EPO) and the Japan Patent Office (JPO) and observe whether patents issued in the U.S. were allowed or rejected at the EPO and/or JPO. We obtained this information using the Triadic Patent Family database maintained by the Organization for Economic Co-operation and Development.

\section{METHODOLOGY}

To explore how patent examination practices change upon promotions that leave examiners with less examination time, we estimate the following:

$$
\begin{aligned}
G R A N T_{\text {aikt }}= & \alpha+\boldsymbol{\gamma}_{\mathbf{i}}+\boldsymbol{\lambda}_{\mathbf{t}}+\boldsymbol{\partial}_{\mathbf{k t}}+\boldsymbol{\beta}_{1}\left(\mathbf{G S}_{i t}\right)+\boldsymbol{\beta}_{\mathbf{2}}\left(\mathbf{E X P E R}_{i t}\right) \\
& +\boldsymbol{\beta}_{3} \mathbf{X}_{\text {aikt }}+\varepsilon_{\text {aikt }}
\end{aligned}
$$

where $a$ indexes the individual application, $i$ indexes the individual examiner, $k$ indexes the technology associated with the application and $t$ indexes the year in which the application is disposed of by the examiner. GRANT aikt indicates whether or not the given application was allowed by the examiner. Year fixed effects are captured by $\boldsymbol{\lambda}_{\mathbf{t}}$. $\mathbf{G S}_{\mathbf{i t}}$ represents a set of dummy variables capturing the incidence of the examiner assigned to the underlying application falling into each of the general schedule (GS) pay-grade levels. GS it also includes separate categories for GS-13 without partial signatory authority and GS-13 with partial signatory authority, considering that this unique within-GS-level promotion likewise carries with it reductions in examination-time expectations. The ability to draw upon a within-GS-level change in the time allotment extended to examiners provides us with an opportunity to challenge the argument that the analysis may be purely driven by factors changing with GS-level promotions other than examination time allocations. 
Furthermore, included in some specifications, EXPER it $_{\text {captures a set of dummy variables for }}$ the incidence of the relevant examiner falling into a range of experience-level categories $(0-1$ years, 2-3 years, etc.), where experience is signified by the number of years (in 2-year bins) at the time of the application's disposition that the relevant examiner has been with the Patent Office. In other specifications, as discussed in detail in Section IV, we nest experience within GS-level categories and thus create dummy variables capturing a series of experience categories within each GS-level. In a robustness check, we include a set of technology-by-year fixed effects, $\boldsymbol{\partial}_{\mathbf{k t}}$ (using the 37 technology subcategories set forth in Hall et al., 2001), to alleviate concerns that examiners may be reassigned to different technologies as they ascend to higher pay-grades and that such reallocation schemes may change over time (e.g., with fluctuating economic conditions). ${ }^{17}$ Other specifications include various individual characteristics of the applications, $\mathbf{X}_{a i k t}$, including the entity size status of the applicant (large versus small), the length of time being the filing and the disposition of the application (and its square), and the foreign priority status of the application (previous filings at the EPO and JPO).

Importantly, a set of examiner fixed effects are captured by $\boldsymbol{\gamma}_{\mathbf{i}}$. Such fixed effects help address concerns that more experienced examiners and higher GS-level examiners are fundamentally different from their more junior counterparts, for reasons beyond mere differences in seniority and promotion levels-e.g., concerns that examiners who have reached higher grade levels and thus who have been successful in attaining promotions may be those with a stronger inherent

\footnotetext{
17 We aggregate to the Hall et al. subcategory level (37 groups) in forming these technology-by-year fixed effects-as opposed to using the much finer grained U.S. Patent Office "classes" (over 500 groups) - for computational ease. These technology-year fixed effects also address concerns that the Patent Office may execute more promotions during times in which application filings are elevated in particular technologies, events that may also impact observed grant rates. We alternatively alleviate this concern in Column 2 of Table 3 by estimating specifications that include technology-year-specific filing counts as a control while using the finer-grained Patent Office classes as the basis for technology groupings. In this alternative specification, we also include Patent Office class fixed effects to account for fixed differences across such groups. As demonstrated by Column 2, the inclusion of class fixed effects and class-year filing counts leads to virtually no change in the estimated coefficients of the grade level dummies.
} 
disposition towards granting in the first place, along with concerns that more experienced examiners may also differ from less experienced examiners simply because they elected to stay at the Patent Office.

\section{RESULTS}

\section{A. Grant-Rate Analysis}

1. Primary Results

We begin our exploration into the effects of allotted examination time-as identified by the occurrence of certain examiner promotions-by plotting the evolution of grant rates observed over the course of a given examiner's career as they rise in the ranks. More specifically, in Figure 1, we plot results from a regression of the incidence of an application being granted on a set of dummy variables capturing each of the relevant examiner pay grades, in addition to a set of year fixed effects and examiner fixed effects (see Column 1 of Table 3 for the tabular regression results underlying this figure). ${ }^{18}$ Figure 1 suggests that the grant rates increase with each gradelevel promotion, including increases as given examiners initially ascend to GS-level 13 and subsequently ascend to GS-level 13 with partial signatory authority. We find that as an examiner moves from GS-level 7 to GS-level 9, they increase their grant rates by 3.8 percentage points (or by roughly 6 percent). As the examiner ascends even higher in ranks and thus as the examiner receives less and less time to review her applications, this increase in grant rates continues

\footnotetext{
18 Standard errors are clustered at the examiner level to account for autocorrelation over time in examiner-specific residuals. In unreported regressions, we also cluster at the NBER technology sub-category level (37 technologies). Estimated standard errors only rise slightly in this instance-e.g., from 0.009 on average throughout Column 1 of Table 2 to 0.010 on average throughout that Column. Given computational considerations in light of the over-1-million observations and nearly 9,000 examiner fixed effects, we elect to estimate linear probability models throughout. We note, however, that the pattern of results we present are virtually unchanged when we instead take a 10-percent random sub-sample of examiners and estimate conditional logit specifications (available upon request from the authors).
} 
monotonically until the point at which her grant rate at GS-level 14 is 18.6 percentage points (or nearly 28 percent) higher than it was when she was at GS-7.

Figure 1: Relationship between Examiner GS Levels and Grant Rate

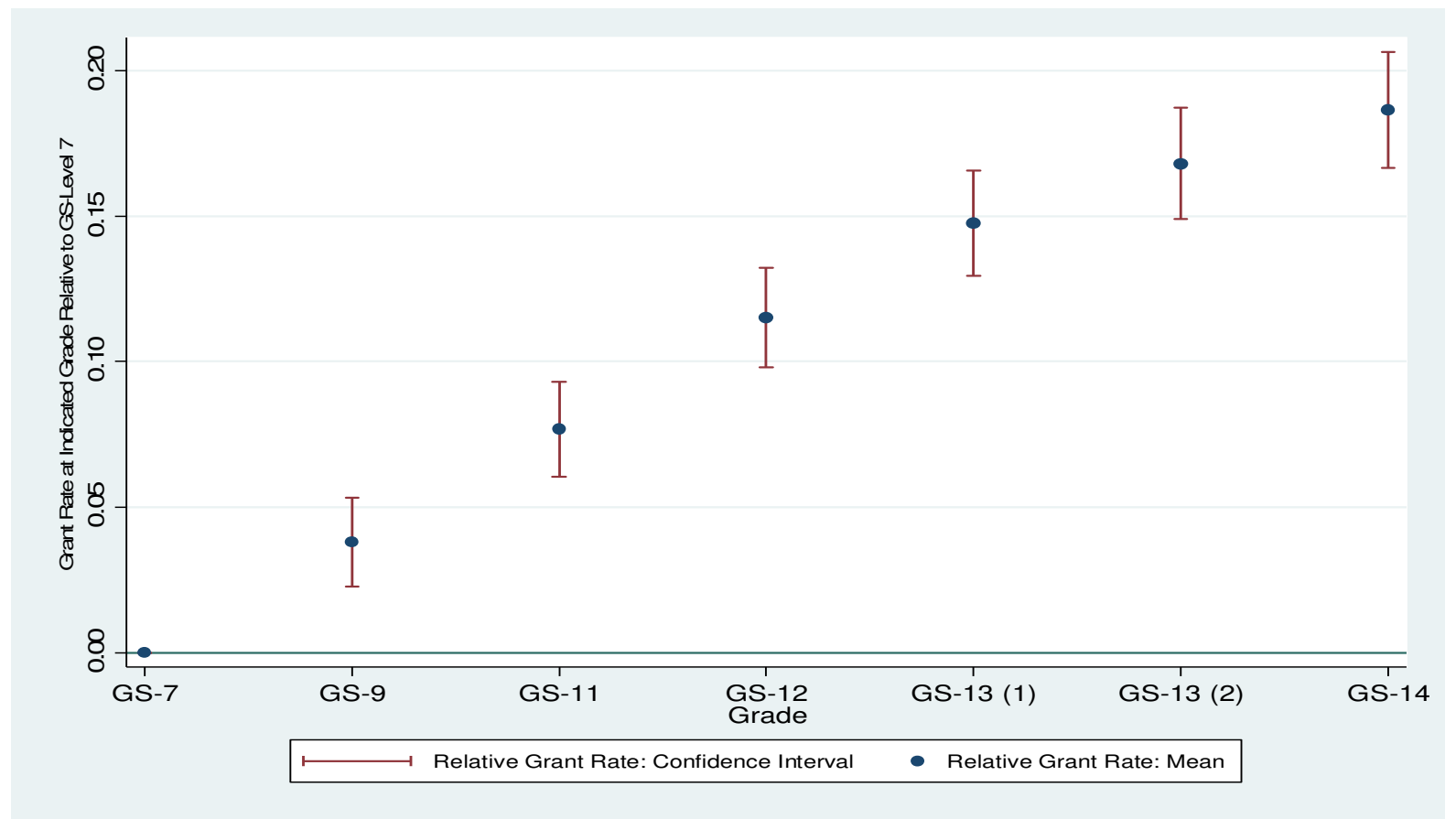

Notes: this figure presents results from a regression of a dummy variable indicating a granted application on dummy variables representing each General Schedule level between 7 and 14, including both GS-13 with and without partial signatory authority. The dummy variable for GS-level 7 is omitted, representing the reference group. The vertical bars represent $95 \%$ confidence intervals for the estimated coefficients. Regressions include examiner and year fixed effects. Standard errors are clustered at the examiner level. 


\section{TABLE 3. RELATIONSHIP BETWEEN GRANT RATES AND EXPERIENCE AND GRADE LEVELS OF THE ASSOCIATED PATENT EXAMINER}

\begin{tabular}{|c|c|c|c|c|c|c|}
\hline & $(1)$ & (2) & (3) & (4) & $(5)$ & $(6)$ \\
\hline Omitted: GS-7 & & & & & & $\begin{array}{l}\text { (omitted: } \\
\text { GS-11) }\end{array}$ \\
\hline GS-9 & $\begin{array}{c}0.038^{* * * *} \\
(0.008)\end{array}$ & $\begin{array}{c}0.036^{* * *} \\
(0.008)\end{array}$ & $\begin{array}{c}0.026^{* * *} \\
(0.007)\end{array}$ & $\begin{array}{c}0.036^{* * * *} \\
(0.008)\end{array}$ & $\begin{array}{c}0.017 \\
(0.020)\end{array}$ & - \\
\hline GS-11 & $\begin{array}{c}0.077^{* * * *} \\
(0.008)\end{array}$ & $\begin{array}{c}0.076^{* * *} \\
(0.008)\end{array}$ & $\begin{array}{c}0.033^{* * *} \\
(0.008)\end{array}$ & $\begin{array}{c}0.072^{* * *} \\
(0.008)\end{array}$ & $\begin{array}{c}0.026 \\
(0.020)\end{array}$ & - \\
\hline GS-12 & $\begin{array}{c}0.115^{* * *} \\
(0.009)\end{array}$ & $\begin{array}{c}0.112^{* * *} \\
(0.009)\end{array}$ & $\begin{array}{c}0.049^{* * *} \\
(0.009)\end{array}$ & $\begin{array}{c}0.104^{* * *} \\
(0.008)\end{array}$ & $\begin{array}{c}0.060^{* * * *} \\
(0.023)\end{array}$ & $\begin{array}{c}0.031^{* * *} \\
(0.005)\end{array}$ \\
\hline GS-13 & $\begin{array}{c}0.148^{* * * *} \\
(0.009)\end{array}$ & $\begin{array}{c}0.141^{* * *} \\
(0.009)\end{array}$ & $\begin{array}{c}0.066^{* * *} \\
(0.010)\end{array}$ & $\begin{array}{c}0.127^{* * *} \\
(0.009)\end{array}$ & $\begin{array}{c}0.068^{* *} \\
(0.025)\end{array}$ & $\begin{array}{c}0.062^{* * * *} \\
(0.007)\end{array}$ \\
\hline $\begin{array}{l}\text { GS-13 (with partial } \\
\text { signatory authority) }\end{array}$ & $\begin{array}{c}0.168^{* * * *} \\
(0.010)\end{array}$ & $\begin{array}{c}0.159^{* * *} \\
(0.010)\end{array}$ & $\begin{array}{c}0.084^{* * *} \\
(0.011)\end{array}$ & $\begin{array}{c}0.149^{* * * *} \\
(0.010)\end{array}$ & $\begin{array}{c}0.076^{* * *} \\
(0.027)\end{array}$ & $\begin{array}{c}0.083^{* * * *} \\
(0.009)\end{array}$ \\
\hline GS-14 & $\begin{array}{c}0.186^{* * * *} \\
(0.010)\end{array}$ & $\begin{array}{c}0.177 * * * \\
(0.010)\end{array}$ & $\begin{array}{c}0.103^{* * * *} \\
(0.011)\end{array}$ & $\begin{array}{c}0.165^{* * * *} \\
(0.010)\end{array}$ & $\begin{array}{c}0.104^{* * *} \\
(0.031)\end{array}$ & $\begin{array}{c}0.097^{* * * *} \\
(0.011)\end{array}$ \\
\hline \multicolumn{7}{|c|}{ Omitted: 0-1 Years Experience } \\
\hline 2-3 Years Experience & - & - & $\begin{array}{c}0.073^{* * *} \\
(0.004)\end{array}$ & - & - & - \\
\hline 4-5 Years Experience & - & - & $\begin{array}{c}0.077^{* * *} \\
(0.006)\end{array}$ & - & - & - \\
\hline 6-7 Years Experience & - & - & $\begin{array}{c}0.072^{* * * *} \\
(0.007)\end{array}$ & - & - & - \\
\hline 8-9 Years Experience & - & - & $\begin{array}{c}0.057 * * * \\
(0.009)\end{array}$ & - & - & - \\
\hline $\begin{array}{l}\text { 10-11 Years } \\
\text { Experience }\end{array}$ & - & - & $\begin{array}{c}0.045^{* * *} \\
(0.010)\end{array}$ & - & - & - \\
\hline $\begin{array}{l}\text { 12-13 Years } \\
\text { Experience }\end{array}$ & - & - & $\begin{array}{c}0.027^{* * *} \\
(0.012)\end{array}$ & - & - & - \\
\hline 14+ Years Experience & - & - & $\begin{array}{l}-0.001 \\
(0.015)\end{array}$ & - & - & - \\
\hline $\mathrm{N}$ & 1158689 & 1158689 & 1158689 & 990940 & 48936 & 274285 \\
\hline $\begin{array}{l}\text { Examiner and Year } \\
\text { Fixed Effects? }\end{array}$ & YES & YES & YES & YES & YES & YES \\
\hline $\begin{array}{c}\text { Patent Office Class } \\
\text { Fixed Effects? }\end{array}$ & NO & YES & NO & NO & NO & NO \\
\hline $\begin{array}{l}\text { Application Controls } \\
\text { and Technology-by- } \\
\text { Year Fixed Effects? }\end{array}$ & NO & NO & NO & YES & NO & NO \\
\hline $\begin{array}{l}\text { Balanced Sample of } \\
\text { Examiners from } \\
\text { GS-7 to GS-14? }\end{array}$ & NO & NO & NO & NO & YES & NO \\
\hline $\begin{array}{l}\text { Balanced Sample of } \\
\text { Examiners from } \\
\text { GS-11 to GS-14 }\end{array}$ & NO & NO & NO & NO & NO & YES \\
\hline \multicolumn{7}{|c|}{$\begin{array}{l}{ }^{*} \text { significant at } 10 \% ;{ }^{* *} \text { significant at } 5 \% ;{ }^{* * *} \text { significant at } 1 \% \text {. Standard errors are reported in parentheses and } \\
\text { are clustered to correct for autocorrelation within given examiners over time. Each observation is a given } \\
\text { application from the PAIR database that reached a final disposition and that was published in the PAIR records } \\
\text { between March, } 2001 \text { and July, } 2012 \text {. The specification in Column } 5 \text { includes applications only from those } \\
\text { examiners that started the sample period at GS-7 and ascended to at least GS-14 over the sample period. The } \\
\text { specification in Column } 6 \text { includes applications only from those examiners that started the sample period at GS-11 } \\
\text { and below and ascended to at least GS-14 over the sample period, focusing only those applications that they } \\
\text { disposed of while at GS-11 through GS-14. Technology-by-year effects are based on the } 37 \text { Hall et al. (2001) } \\
\text { technology sub-categories, while the technology fixed effects used in Column } 2 \text { are based on Patent Office } \\
\text { Classes. Column } 2 \text { also includes technology class-year-specific application filing counts as a covariate. }\end{array}$} \\
\hline
\end{tabular}


Essential to our analysis is the separation of the effects stemming from grade-level promotions and from the acquisition of additional years of experience within the Agency. Note from the outset that while such events naturally correlate with each other, they do not do so perfectly. That is, examiners do not always receive promotions lockstep with experience, allowing us to separately identify these forces. This is especially true from GS-12 onwards when examiners begin to routinely spend multiple years (to varying degrees) at the respective grade. ${ }^{19}$ By including year fixed effects in a specification with examiner fixed effects, this initial specification is identifying the impacts of GS-level changes while accounting for the influence of individual examiners moving across experience levels (in year increments). This observation stems from the well-known point (Heckman and Robb 1985) that age (experience) effects have become determined when one has estimated both year effects and cohort effects (which derive from individual effects). ${ }^{20}$ However, we acknowledge that this initial specification does not allow us to distinguish the contribution of year effects from experience effects. In certain specifications estimated below, we take further steps to achieve this separation (see below).

Examiner behavior may change over time under a range of theories. For instance, with more years of experience, examiners may become better at identifying allowable subject matter. On the other hand, it could be the case that examiners simply lessen their scrutiny as time goes by in the Patent Office due to an increased tendency to shirk. To the extent that any such stories are even present in the first place-which we address more directly below-the above findings demonstrate a distinct jump in grant rates that occurs upon GS-level promotion independent of any pattern of grant rates that examiners exhibit over time itself. Considering that the key

19 Over 75 percent of examiners who have reached the stage of GS-level 14 stay at that grade level over a year, with over 20 percent staying for at least 8 years. On the other hand, only 16 percent of examiners who have been at GS-level 7 stay at that grade beyond 1 year.

20 Behind this problem is the identity: calendar year $=$ year of birth (cohort) + age. 
channel by which the act of promotion may theoretically impact subsequent examination behavior stems from its effect on the time allotted for examination (as discussed above), these results provide greater confidence that (1) time constraints may be binding on examiners and (2) that tightening such constraints may leave examiners with less time to adequately challenge the patentability of applications. ${ }^{21}$ We further support this contention below with even richer methods of decoupling experience from promotions and with investigations into examiner search efforts and rejection patterns. Beforehand, however, we briefly discuss the relationship that we nonetheless estimate between grant rates and an increase in examiner experience in years.

\section{Experience Effects}

Though our focus is mainly on examination time allocations, it would be of interest to identify the effects of experience independently in order to more fully evaluate the determinants of examiner behavior. As above, it is not possible to distinguish year effects from annual experience effects in specifications that include individual examiner intercepts, absent additional normalization restrictions on the parameterization of the year or experience effects that break the identity between them. In our primary approach to isolating the independent impacts of experience, we estimate specifications that achieve the necessary restrictions by specifying

\footnotetext{
21 We acknowledge that some examiners may attempt to increase their chances of promotion by granting more permissively as a general matter of course, either because such behavior may facilitate the processing of a greater number of applications or in light of the financial interests of the Agency in over-granting patents (Frakes and Wasserman 2013). Our fixed effects methodology is designed to place inherent granting tendencies aside-including those stemming from promotion-seeking behavior - and instead focus on within-examiner changes in behaviors over the course of a career. For a story of this nature to explain the results, it would have to be the case that promotion-seeking behavior elevates in intensity upon each promotion. Cutting against this latter theory are the drops in grant rates that we observe within particular GS levels over time, as we discuss below.
} 
examiner experience dummies into two-year blocks-i.e., 0-1 years of experience, 2-3 years of experience, etc. ${ }^{22}$

In Column 3 of Table 3, we present results from this attempt to separately estimate GS-level, year and experience effects, where we focus on presenting the GS-level and experience dummy coefficients, leaving year effects as a nuisance control. In Figure 2, we plot the estimated coefficients of the experience group dummies from this specification, finding an inverse-U relationship between examiner experience (in years) and grant rates. Grant rates do increase by close to 8 percentage points as an examiner moves from $0-1$ to $2-3$ years of experience. The grant rate effectively stays at this level through 5 years of experience and thereafter begins to fall, until the point at which the grant rate at 14+ years of experience is identical to the $0-1$ year experience level.

These U-shaped experience findings build upon Lemley and Sampat's (2012) prior observation that grant rates increase monotonically with experience in years. Lemley and Sampat acknowledge the possibility that the monotonic relationship they estimate does not represent a true experience effect at all but instead captures either the promotion-related time-allocation story of focus in our analysis or an alternative story of selective retention-i.e., a tenure effect in which those senior examiners that elect to stay at the Patent Office differ fundamentally from

22 By specifying experience groups in this manner, it is no longer the case that experience dummies would be perfectly collinear with year dummies as would be the case with both yearly experience group dummies and year effects. For instance, consider a set of applications reviewed in 2002 by some examiners who began with the Patent Office in 1997 and others who began in 1996, among a much richer sample of applications covering multiple years and cohorts. How can we attribute the information from these particular applications to an estimation of cohort, year and experience effects across this broader sample? By creating a group comprising those with 5-6 years of experience and using these observations to contribute to an estimation of the intercept for this group, we retain the ability to contribute information to separately identify a 1996 cohort effect and a 1997 cohort effect. With enough statistical power, having broken this identity, one can identify the separate influence of each such mechanism. See de Ree and Alessie (2011) for a discussion as to how specifying age effects in blocks breaks the age + cohort $=$ year identity. We note that this approach is not without consequence, since we are implicitly assuming that experience effects follow a grouping of this nature-i.e., that 5-year experience examiners and 6-year experience examiners are alike. We note, however, that our results generalize to alternative normalization restrictions, including the use of 3- or 4-year experience bins or to the use of a 0-1 year experience bin along with yearly experience dummies thereafter. In each case, we continue to document an inverse-U pattern (results available upon request). 
those that leave the office earlier. Lacking data on examiner GS levels and observing only a cross section of applications at a point in time, Lemley and Sampat are unable to fully rule out these possibilities, though, they do include some examiner tenure controls to alleviate selective retention concerns. Though not emphasized in their analysis, the cross-sectional sampling frame also leaves them unable to separate the effect of gaining experience in years-a true experience effect-from an examiner cohort effect, where this latter influence captures fundamental differences in examination behavior (perhaps due to initial training or cultural idiosyncrasies) among those who began their careers with the Patent Office in different calendar years. ${ }^{23}$

By controlling for examiner GS levels and individual examiner effects, we are, unlike the prior literature, able to target the association between examiner experience and grant rates while accounting for cohort, tenure and promotion-related effects. In the Online Appendix, we demonstrate that the monotonic relationship between experience and grant rates documented by Lemley and Sampat is likely driven by the promotion-related time-allocation effects (depicted in Figure 1) and by examiner cohort effects - that is, all else equal, inherent granting tendencies have fallen with subsequent examiner cohorts (beginning with high grant rates for those starting in the 1990s). Once controlling for these other influences, experience effects themselves appear to follow the inverse-U shape depicted in Figure 2. have higher grant rates than those with 2 years of experience, it is difficult to determine whether that finding is attributable to the act of gaining 6 additional years of experience or from the fact that those who started working for the Patent Office in the early 1990s have higher inherent granting tendencies relative to those starting in the late 1990s-e.g., due to difference in initial hiring conditions over such periods and due to the importance of initial conditions in developing enduring practice styles. 
Figure 2: Relationship between Examiner Experience Groups and Grant Rate, Controlling for GS Level

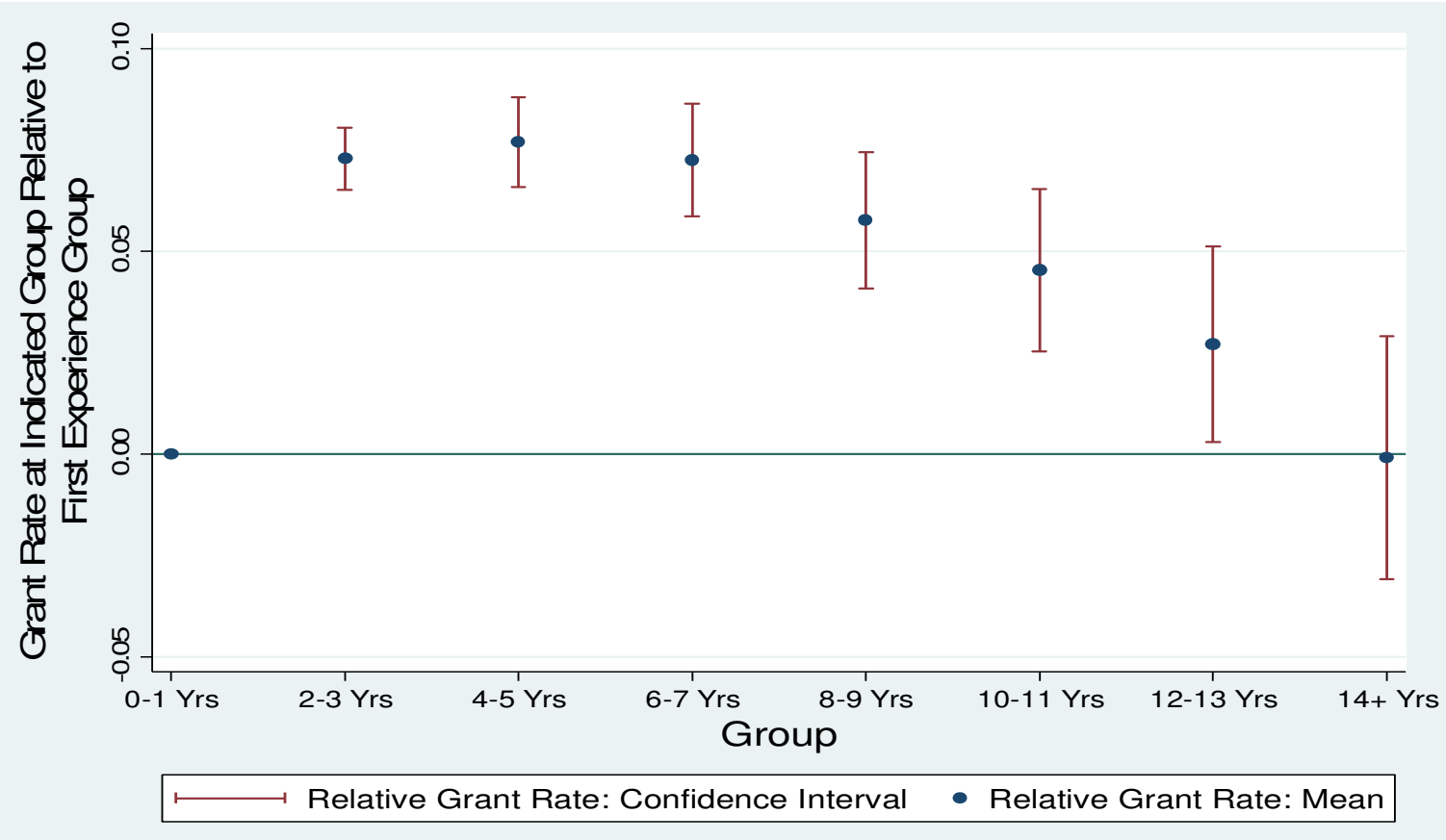

Notes: this figure presents results from a regression of a dummy variable indicating a granted application on dummy variables representing each General Schedule level between 7 and 14, including both GS-13 with and without partial signatory authority, along with dummy variables representing the incidence of 8 different experience (in years) groups. This figure presents the coefficients of the experience group dummies only. The vertical bars represent 95\% confidence intervals for the estimated coefficients. Regressions include examiner and year fixed effects. Standard errors are clustered at the examiner level.

\section{Within-Grade Experience Effects}

In this sub-section, we take an alternative approach to separating grade-level effects from experience effects. Instead of simply estimating the overall impacts of being at the Patent Office for a given number of years, we nest experience years within grade levels. In other words, we estimate specifications that include a series of dummy variables capturing the presence of specific years within specific grade levels-e.g., 0-1 years in GS-13, 2-3 years in GS-13, 0-1 years in GS-14, 2-3 years in GS-14 etc. This approach allows us to more comprehensively 
follow the course of a hypothetical examiner over the various stages of a career and thus better visualize the independent and discontinuous impacts of examination-time-reducing promotions. For this analysis, we focus only on those examiners in GS-12 and above considering that the majority (though not all) of those within lower grade levels achieve promotions within their first year at those grades, providing little ability to reliably track the evolution of grant rates over years while at GS-7, 9 or 11.

Figure 3: Relationship between Grant Rate and Increases in Experience Years within Distinct Grade Levels

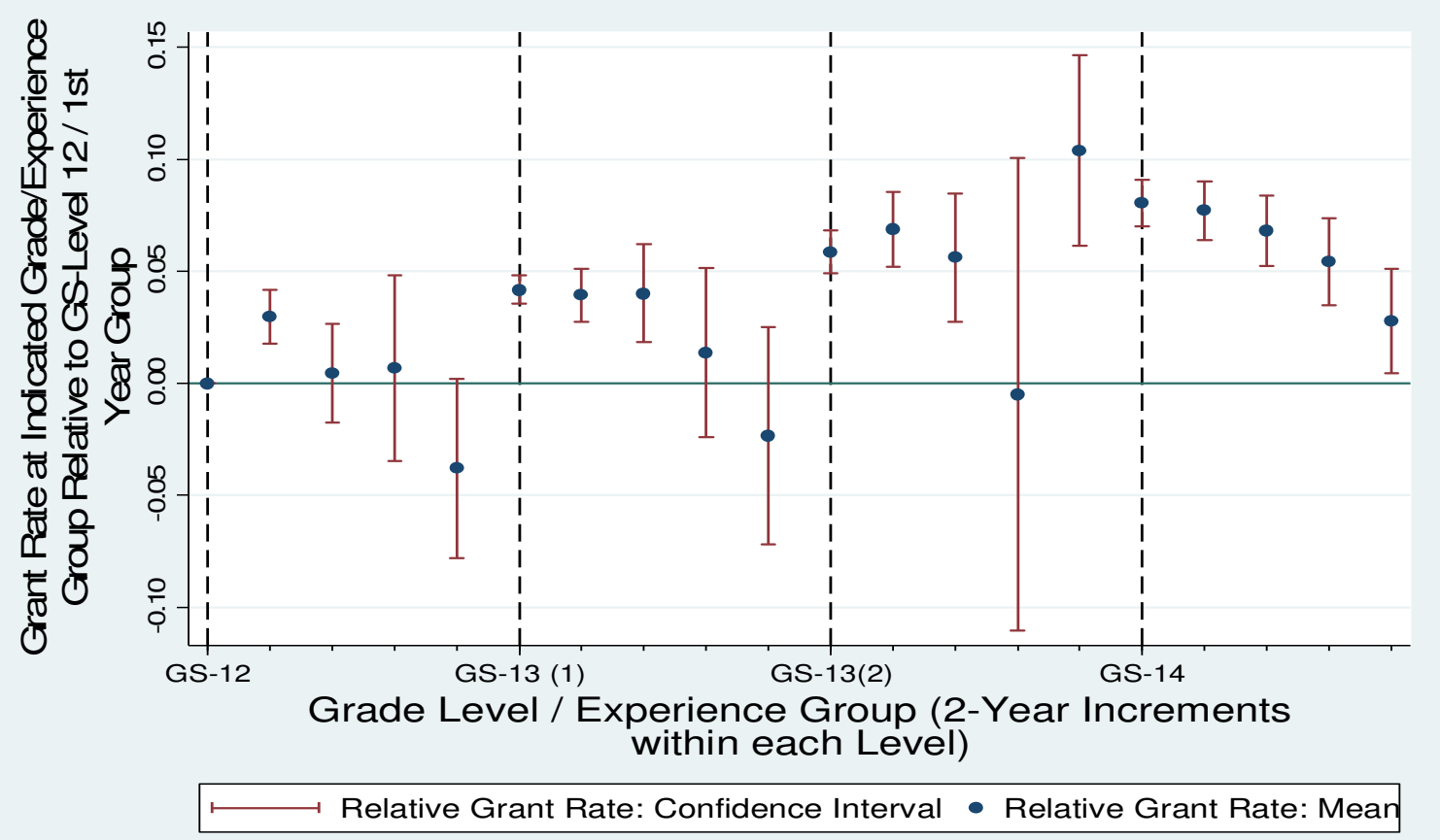

Notes: In the specification underlying this figure, we regress a dummy variable indicating a granted application on a series of dummy variables capturing specific experience years within each grade level, beginning at GS-level 12 . We track examiners for 1-2, 3-4, 5-6, 7-8 and 9+ years within GS level 12 and then the same within each of GSlevel 13 without signatory authority, GS-level 13 with signatory authority and, finally, GS-level 14. Specifications include both examiner and year fixed effects. Standard errors are clustered at the examiner level.

Figure 3 plots the results of this exercise, presenting the coefficients of each of these separate dummy variables, with the $0-1$ year period at GS-12 serving as the omitted reference group. The 
results only further solidify the contention that examination practices change upon the occurrence of career events that are associated with reductions in the time allocated to examiners. Upon each such promotion, the observed grant rate jumps. Importantly, these promotion-level increases do not appear to be mere reflections of continuing trends in grant rates over the duration of an examiner's tenure at the specific grades, which might otherwise suggest a simple experience-level story or which might otherwise suggest a selection story in which the Patent Office elects to promote examiners at points in time in which the examiners begin to grant at elevated rates. ${ }^{24}$ Consider, for instance, GS-level 14, a level in which examiners spend on average 4.5 years upon reaching. While the grant rate jumps distinctly once one enters this GS level (to a degree that is 8 percentage points higher than the reference period), the grant rate actually begins to fall thereafter. In the period represented by her $9^{\text {th }}$ year and beyond at GS-14, her grant rate is over 5 percentage points below the initial GS-14 grant rate. If the grant rate had incrementally continued to rise over such years, especially at levels commensurate with those experienced upon grade level changes, it would instill less confidence in an interpretation of the results as emanating from reductions in the amount of time at the disposal of examiners.

$24 \quad$ In the Online Appendix, we provide even further support against the possibility that the Patent Office elects to promote given examiners once their grant rates hit certain elevated points, a possibility that could otherwise explain the initial findings in Figure 1. Specifically, we find that those examiners that are promoted quickly within the Agency-and whose work appears to be most valued by the Patent Office-actually have lower inherent grant rates relative to those who rise more slowly in the ranks. 
Figure 4: Relationship between Grant Rate and Increases in Experience Years within Distinct Grade Levels, Conditional on Examiner Starting at least Below GS-12 During Sample Window

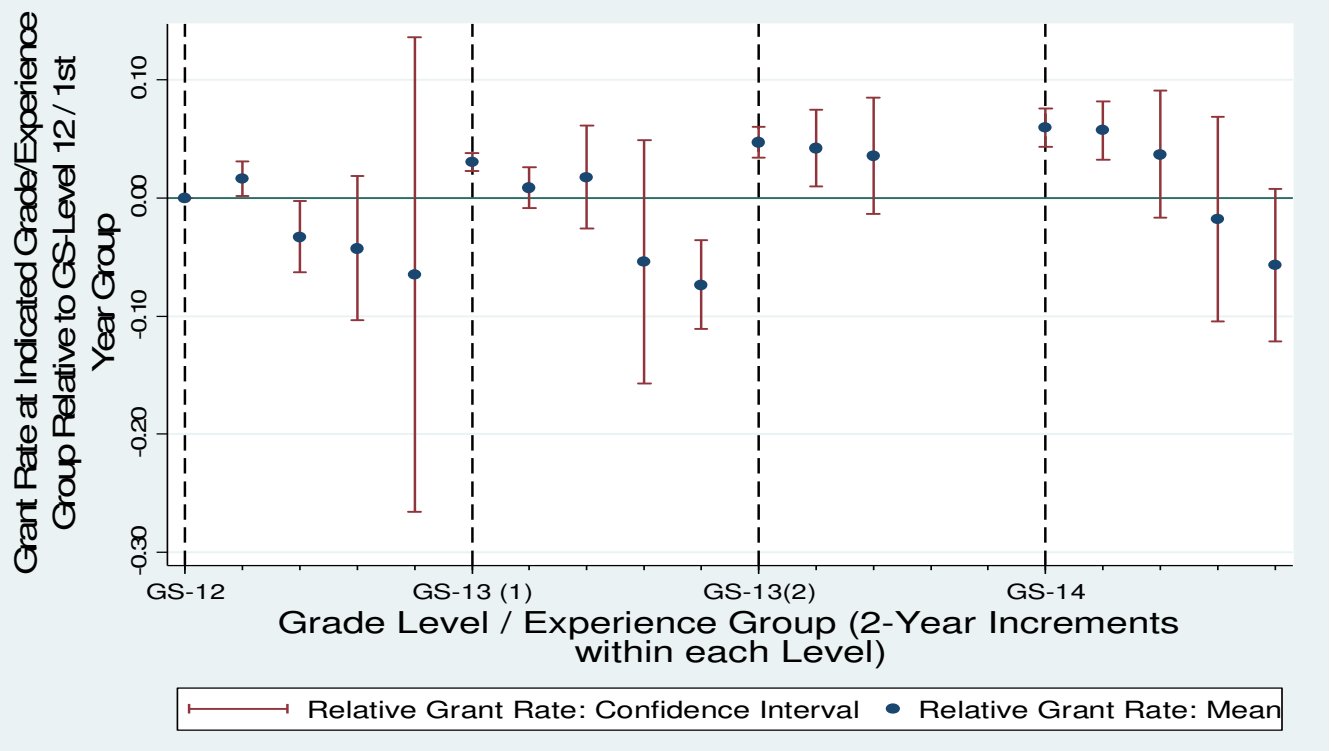

Notes: this figure replicates that of Figure 3, except that it excludes examiners that start the sample period at GS-12 and higher (that is, it excludes those examiners whose pre-sample-period tenures within the relevant grade are unobservable). Within this restricted sample, there are no observations (and thus no reported results) for examiners in the $4^{\text {th }}$ and $5^{\text {th }}$ period groups within the second GS-13 category.

Indeed, if anything, this picture depicts a story in which experience (in years) alone ultimately corresponds to a reduction in granting tendencies, as opposed to the monotonically increasing relationship observed between grade levels and grant rates (further illuminating the various forces underlying the positive relationship found in Lemley and Sampat, 2012). With respect to each of the four given promotion categories considered in Figure 3, the grant rate ultimately begins to fall over time as one stays within the respective category long enough. These drops in grant rates with experience are periodically corrected by successive promotions of the sort that leave examiners with diminished examination time. If anything, the declines in grant rates observed over the temporal dimension of Figure 3-that is, over the increases in years within the various grade levels_-perhaps suggest a story in which examiners in general learn over time how 
to form more effective bases of rejection (thus contributing to falling grant rates), only to have this learning process interrupted by occasional promotions that diminish the amount of time they have to derive such rejections (thus re-elevating grant rates).

In discussing Figure 3, it also bears mentioning that examiners may continue to receive salary increases throughout their tenure at each GS-level. The presence of such alternative types of promotions - that is, within-GS-level increases in salary that are tied only to experience-are further helpful for our analysis in providing support against an argument that the findings set forth in Figure 1 are attributable merely to any increases in income associated with GS-level promotions (if that were the case, grant rates would tend to rise throughout all of Figure 3 ). ${ }^{25}$

\section{Caveats}

To be sure, our identification of GS-level effects as distinct from experience effects in Figure 1 and Table 3 is drawn from the experiences of those examiners that happen to stay within those GS levels for some time before being promoted. For low GS levels, this group of examiners is more select. It is unclear whether such local findings generalize to the quick risers within the Agency. Nonetheless, the same pattern of grant-rate increases upon promotion is present as we proceed to higher and higher grade levels, where it is more common for examiners to spend multiple years within given GS levels, lending some confidence to a more general story.

Similar concerns arise for the case of the within-GS-level declines in grant rates over time observed in Figure 3. After all, only a small minority of examiners at GS-12 and 13 stay at those grades over the full course of years depicted. Perhaps the most conservative way to interpret our results is that with respect to at least some examiners-that is, those that happen to achieve

25 Examiners are promoted to different "steps"-e.g., Step 1 at GS-12, Step 2 at GS-12, etc. These step promotions generally transpire with increases in experience over time, as distinct from merit based promotions, and generally entail a meaningful increase in salary level. For instance, a GS-level 14 at "Step 5" is paid \$128,941 while a GS-level 14 at Step 10 is paid $\$ 147,900$. 
promotions relatively more slowly - the effects of increased temporal experience on grant rates appears to generally be negative. For those other examiners that experience early promotions more rapidly, it is difficult to say what role experience plays as distinct from GS-level changes during these early years. Nonetheless, such quick risers at least stay for a long time at GS-14 at which point their grant rates do indeed fall with more years of experience.

\section{Sample Balance}

A related concern stems from the sample imbalance in the above specifications. Take Figure 1 for instance. Though examiners in our sample experience on average nearly 4 of the 7 possible promotions depicted in this figure and though the relevant GS-level coefficients are identified by actual within-examiner changes in grade levels for at least some subset of examiners (as opposed to across-examiner comparisons), the underlying specification does not follow all examiners throughout each of the indicated grade levels. Nonetheless, in Columns 5 and 6 of Table 3, we present results of a balanced-sample analog of Column 1/Figure 1 in which we follow a more select group of examiners that experience each of the indicated promotions. The findings parallel those presented above.

Figure 3 poses similar concerns insofar as some examiners are entering the sample period during the course of the trajectory envisioned by this figure. In Figure 4, we arguably achieve better balance by estimating a similar specification but conditioning on those examiners that enter the sample period at least below GS-12, allowing us to observe how examiners proceed along the pathway inherent in Figure 3 as they enter the GS-12+ range from the outset. In the Online Appendix, we present results from yet additional specifications that aim to achieve sample balance in tracing examiner behavior throughout the course of their careers. 


\section{Other Robustness Checks and Alternative Specifications}

Covariates and Technology Effects. We further challenge the above grant-rate results through a range of additional robustness exercises. For instance, we demonstrate in Column 4 of Table 3 that the above findings remain nearly unchanged when we include certain application-level controls (indicated in Section III above), along with the inclusion of technology-by-year fixed effects (Column 4 of Table 3). Further, in the Online Appendix, we estimate specifications identical to that underlying Figure 1 separately for each of the 37 different Hall et al. (2001) technology sub-categories. This exercise demonstrates that the increase in grant rates associated with the promotions of interest manifests itself in each of the 37 different technologies (as opposed to being driven by a small subset of technologies). ${ }^{26}$ As such, time constraints appear to be binding across the board within the Agency.

Falsification Exercise. In Table A9 of the Online Appendix, we conduct a falsification test in which we estimate the relationship between the promotions of interest and two characteristics of the underlying application with respect to which the examiner has no ability to alter (and with respect to which we have data): (1) whether or not the incoming application was previously filed with the EPO and JPO and (2) whether or not the applicant is a large or small entity (as such terms are used by the Patent Office to set application fees). We find no meaningful or statistically significant changes in foreign priority rates as examiners ascend grade levels. From GS-level 11 onwards, we find that the incidence of a large-entity applicant remains virtually flat

26 With respect to a few of those 37 groups, grant rates initially fall after the first promotion but then rise thereafter. Of course, in those latter instances, the grant rates are still rising over the range where the methodology can best separate a time allocation effect from an experience in years effect. Bear in mind that differences across technologies in the need for examination hours (because of differences in underlying levels of complexity of the art) are already reflected in the allocation schedules. This fact makes it difficult to form ex ante predictions that promotion-related tightening of time constraints will have greater impacts in some technologies relative to others. We also caution that little should be drawn from the observation of declining grant rates upon early promotions in those few instances where it is observed considering that the affected technologies_e.g., Drugs—are generally complex fields where the vast majority of examiners enter the affected Art Units at GS11 or 12 . 
(with only a minor increase in this incidence as examiners move from GS-7 to GS-9 and then from GS-9 to GS-11). These results lend further confidence to the contention that applications are randomly sorted, especially in the grade levels of most interest for our analysis (where it becomes easier to separate experience effects from grade-level effects).

GS-15 Examiners. For the reasons set forth in the Online Appendix, we exclude those few applications examined by GS-15 examiners from the primary analysis $(<3$ percent of all applications). While published, official records regarding the scaling of time allotments upon promotions suggest that GS-15 examiners should be given even less time than GS-14 examiners to review applications, the examiner-level time allotment information we received from the Patent Office suggested that this may not be the case for many of the GS-15 examiners. In spite of this discrepancy, we estimate specifications in the Online Appendix that include these GS-15examined applications and assume that GS-15 examiners are indeed given less time for review, as the official schedules suggest they should. As demonstrated by Figures A5 and A6, we continue to estimate the same pattern of results with this inclusion. ${ }^{27}$

\section{B. Analysis of Rejection Patterns}

\section{Obviousness}

A key prediction set forth above is that examiners will begin to perform fewer and fewer rejections based on the argument that the proposed claims are obvious-an especially time intensive analysis - upon the occurrence of promotions that leave them with less and less allocated examination time. We now attempt to illuminate the above grant-rate findings by

27 The Online Appendix presents results of certain additional robustness checks, including, among others, the estimation of specifications that control for the incidence of a request-for-continued examination (RCE) associated with the application, which is a device used by applicants to continue the examination process in the face of an examiner's final rejection. 
testing this secondary hypothesis and exploring the effects of promotions on the incidence of obviousness rejections among the underlying applications.

One limitation of the data that we collected for this analysis, as novel as it is, is that we simply capture the incidence of any obviousness rejection without knowing the full force of such rejection. Does it simply cover one claim or many claims? Is it easy to overcome or difficult? Such questions cannot be adequately resolved with the data collected. With this limitation in mind, we first take an approach where we do not view obviousness rejections in an absolute sense, but instead specify the dependent variable as the ratio of obviousness rejections to total rejections, more specifically the incidence of an obviousness rejection divided by the sum of the incidence of the following types of rejections: obviousness, lack of novelty, lack of patentable subject matter/utility, and failure to satisfy the disclosure requirements. Though each of the variables underlying this ratio suffer from the above limitation, this measure at least provides us with a sense of the relative effort spent on obviousness rejections. In Columns 1 and 2 of Table 4, we replicate the basic specifications estimated in Table 3 but use this obviousness share measure as the dependent variable. The results depict a monotonically strengthening decline in this obviousness rejection share upon the promotions of interest, suggesting a story in which examiners begin to spend less and less of their efforts on time-intensive obviousness analyses upon promotions that leave them with less and less time at their disposal. ${ }^{28}$ separately, further illuminating the pattern of results presented in Column 1 of Table 4. 
TABLE 4. RELATIONSHIP BETWEEN EXAMINATION SCRUTINY METRICS AND GRADE AND EXPERIENCE LEVELS OF ASSOCIATED EXAMINERS

\begin{tabular}{|c|c|c|c|c|}
\hline & $(1)$ & $(2)$ & (3) & (4) \\
\hline & \multicolumn{2}{|c|}{$\begin{array}{c}\text { SHARE OF REJECTIONS BASED } \\
\text { ON OBVIOUSNESS }\end{array}$} & \multicolumn{2}{|c|}{$\begin{array}{c}\text { SHARE OF PRIOR ART } \\
\text { CITATIONS FROM EXAMINER }\end{array}$} \\
\hline \multicolumn{5}{|l|}{ Omitted: GS-7 } \\
\hline GS-9 & $\begin{array}{l}-0.001 \\
(0.004)\end{array}$ & $\begin{array}{l}-0.000 \\
(0.004)\end{array}$ & $\begin{array}{c}0.004 \\
(0.007)\end{array}$ & $\begin{array}{c}0.002 \\
(0.006)\end{array}$ \\
\hline GS-11 & $\begin{array}{l}-0.006^{*} \\
(0.004)\end{array}$ & $\begin{array}{l}-0.004 \\
(0.004)\end{array}$ & $\begin{array}{l}-0.009 \\
(0.007)\end{array}$ & $\begin{array}{l}-0.003 \\
(0.007)\end{array}$ \\
\hline GS-12 & $\begin{array}{l}-0.024^{* * *} \\
(0.004)\end{array}$ & $\begin{array}{c}-0.020 * * * \\
(0.005)\end{array}$ & $\begin{array}{l}-0.027^{* * *} \\
(0.007)\end{array}$ & $\begin{array}{l}-0.012^{*} \\
(0.007)\end{array}$ \\
\hline GS-13 & $\begin{array}{l}-0.028 * * * \\
(0.005)\end{array}$ & $\begin{array}{l}-0.024^{* * *} \\
(0.005)\end{array}$ & $\begin{array}{c}-0.038^{* * *} \\
(0.007)\end{array}$ & $\begin{array}{l}-0.013 * \\
(0.008)\end{array}$ \\
\hline $\begin{array}{l}\text { GS-13 (with partial signatory } \\
\text { authority) }\end{array}$ & $\begin{array}{l}-0.035^{* * *} \\
(0.005)\end{array}$ & $\begin{array}{c}-0.031 * * * \\
(0.005)\end{array}$ & $\begin{array}{l}-0.048^{* * * *} \\
(0.008)\end{array}$ & $\begin{array}{c}-0.018^{* *} \\
(0.008)\end{array}$ \\
\hline GS-14 & $\begin{array}{c}-0.050 * * * \\
(0.005)\end{array}$ & $\begin{array}{c}-0.046^{* * *} \\
(0.006)\end{array}$ & $\begin{array}{l}-0.051^{* * *} \\
(0.008)\end{array}$ & $\begin{array}{l}-0.020 * * \\
(0.008)\end{array}$ \\
\hline \multicolumn{5}{|l|}{ Omitted: 0-1 Years Experience } \\
\hline 2-3 Years Experience & - & $\begin{array}{l}-0.007^{* * * *} \\
(0.002)\end{array}$ & - & $\begin{array}{c}-0.018 * * * \\
(0.004)\end{array}$ \\
\hline 4-5 Years Experience & - & $\begin{array}{l}-0.006^{*} \\
(0.004)\end{array}$ & - & $\begin{array}{l}-0.035^{* * *} \\
(0.005)\end{array}$ \\
\hline 6-7 Years Experience & - & $\begin{array}{l}-0.007 \\
(0.005)\end{array}$ & - & $\begin{array}{l}-0.045^{* * * *} \\
(0.007)\end{array}$ \\
\hline 8-9 Years Experience & - & $\begin{array}{l}-0.010^{*} \\
(0.006)\end{array}$ & - & $\begin{array}{l}-0.043^{* * *} \\
(0.008)\end{array}$ \\
\hline $\begin{array}{l}\text { 10-11 Years } \\
\text { Experience }\end{array}$ & - & $\begin{array}{l}-0.009 \\
(0.007)\end{array}$ & - & $\begin{array}{l}-0.039 * * * \\
(0.010)\end{array}$ \\
\hline $\begin{array}{l}\text { 12-13 Years } \\
\text { Experience }\end{array}$ & - & $\begin{array}{l}-0.010 \\
(0.009)\end{array}$ & - & $\begin{array}{l}-0.034^{* * *} \\
(0.011)\end{array}$ \\
\hline $14+$ Years Experience & - & $\begin{array}{l}-0.009 \\
(0.010)\end{array}$ & & $\begin{array}{l}-0.018 \\
(0.014)\end{array}$ \\
\hline $\mathrm{N}$ & 884857 & 884857 & 643838 & 643838 \\
\hline \multicolumn{5}{|c|}{$\begin{array}{l}{ }^{*} \text { significant at } 10 \% ;{ }^{* *} \text { significant at } 5 \% ; * * * \text { significant at } 1 \% \text {. Standard errors are reported in } \\
\text { parentheses and are clustered to correct for autocorrelation within given examiners over time. Each } \\
\text { observation in Columns } 1 \text { and } 2 \text { is a given application from the PAIR database that reached a fina } \\
\text { disposition and that was published in the PAIR records between March, } 2001 \text { and July, 2012. Each } \\
\text { observation in Columns } 3 \text { and } 4 \text { is from a subset of those applications that culminate in an issued } \\
\text { patent. }\end{array}$} \\
\hline
\end{tabular}


Figure 5: Relationship between Share of Rejections based on Obviousness and Increases in Experience Years within Distinct Grade Levels

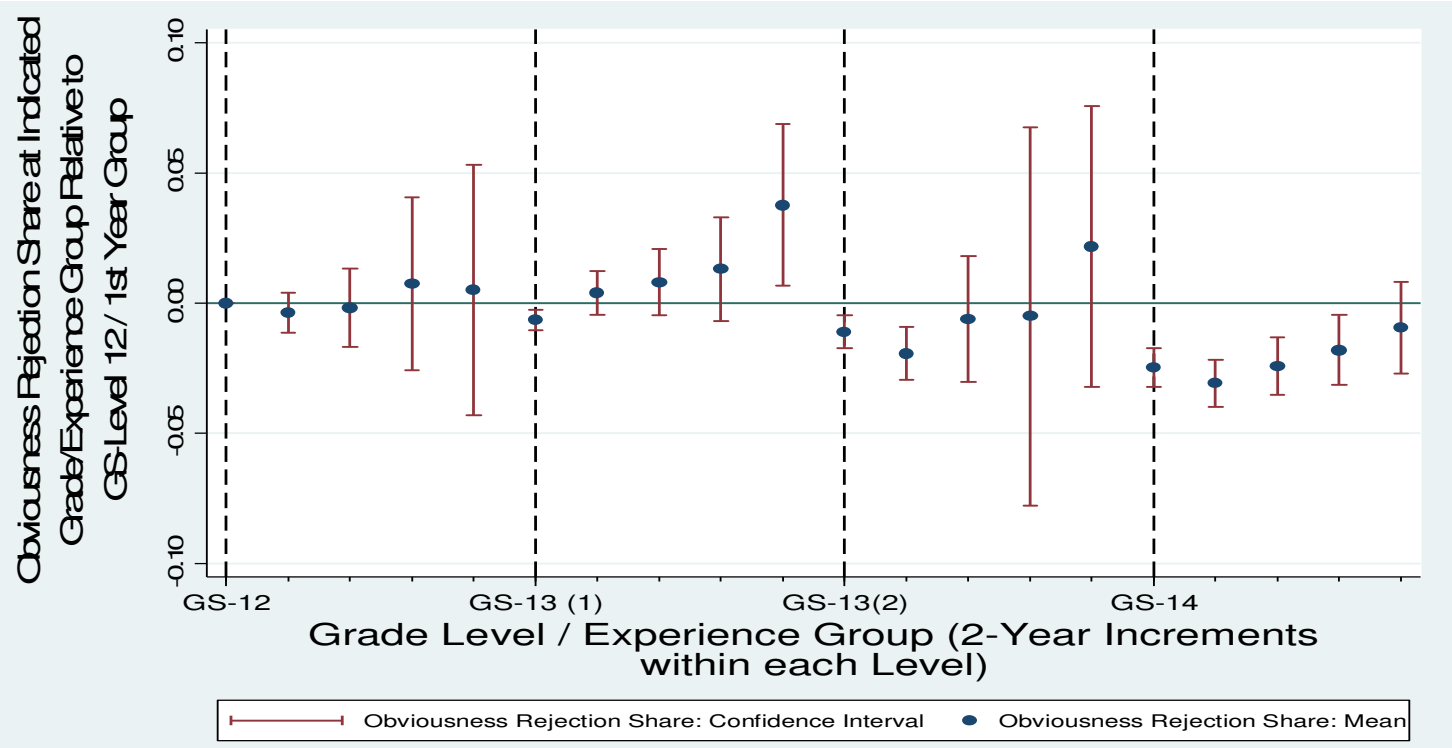

Notes: this figure replicates that of Figure 3 except that it replaces the incidence of an application being granted with the share of rejections for the application constituting an obviousness rejection as the dependent variable.

Figure 6: Relationship between Incidence of any Obviousness Rejection and Increases in Experience Years within Distinct Grade Levels

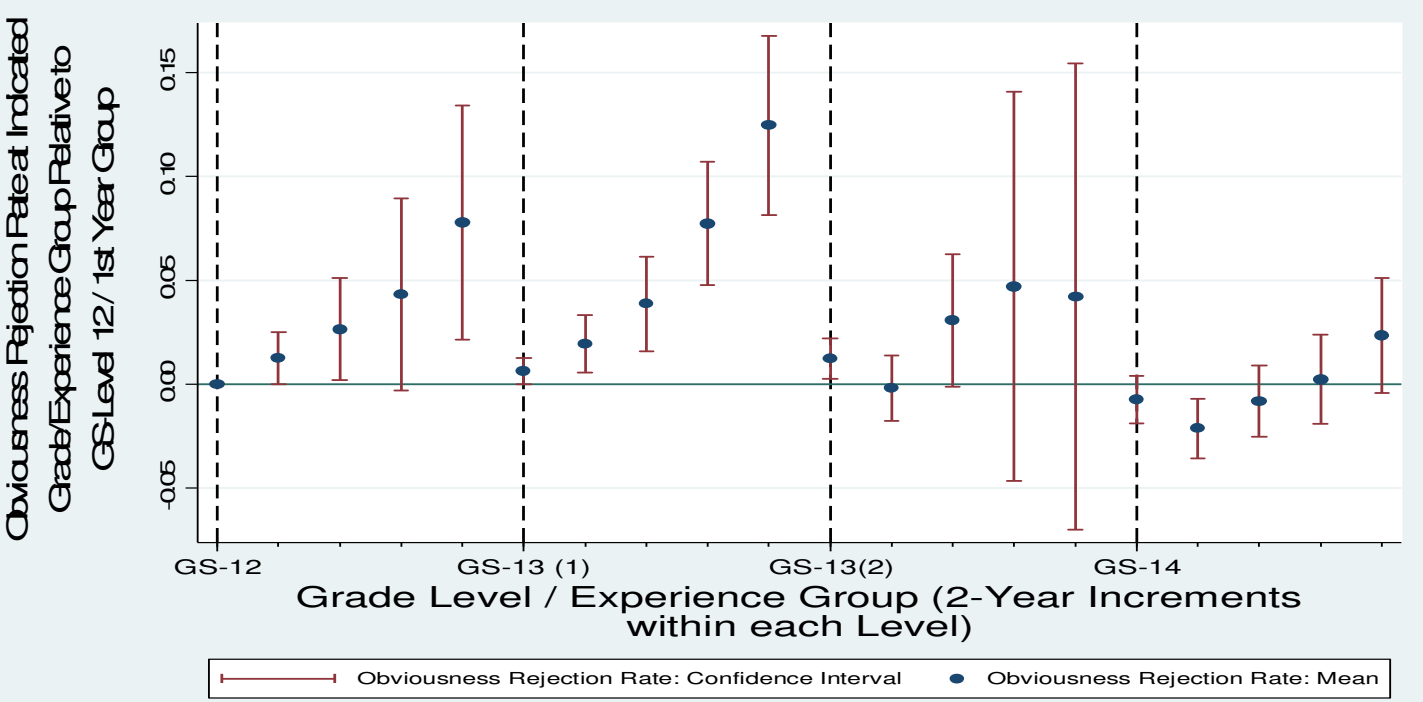

Notes: this figure replicates that of Figure 3 except that it replaces the incidence of an application being granted with the incidence of an application experiencig an obviousness rejection as the dependent variable. 
In Figure 5, we follow the approach of Figure 3 and track how the share of obviousness rejections evolves as an examiner increases in tenure over time within particular grades. Complementing the observation in Figure 3 of jumps in grant rates upon promotions, we observe corresponding drops at such moments in obviousness rejection efforts. Further complementing Figure 3, which demonstrates a general trend to decrease grant rates over time within given grade levels, Figure 5 likewise demonstrates a corresponding tendency over the time dimension to increase the share of obviousness rejections. As before, this may be consistent with a learning story in which examiners get better and better at forming obviousness determinations over time. Periodically, however, examiners will experience promotions that cut short the time they have to make such rejections, at which moments, the rates by which they are able to form obviousness rejections fall back down. We note that examiners may experience a learning curve with respect to other types of rejections as well (e.g., novelty). The obviousness share measure employed in Figure 5 effectively normalizes the analysis by any such general rejection-learning trends, focusing instead on the relative degree of obviousness scrutiny. In Figure 6, we attempt to explore this learning-disruption story in a more absolute sense and replace the obviousness rejection share as the dependent variable with the incidence of any obviousness rejection itself. The results depict an even starker increase in rejection behavior over time followed by large drops upon examination-time-reducing promotions.

\section{Implications of Obviousness Analysis for Grant-Rate Findings}

As discussed in Section I, once an examiner reaches the second GS-13 classification and GSlevel 14, she attains more authority of her own to sign off on decisions, thus representing a decline in the level of scrutiny placed on her by her superiors. One may be concerned that the increase in grant rates observed upon promotion in Figure 1 are merely a reflection of this 
lightening of scrutiny. The fact that this pattern of increasing granting tendencies occurs over earlier promotions, which do not come with the formal extension of greater authority and less oversight, lends support to the idea that the documented pattern of results may not simply arise from changes in the degree of oversight. We acknowledge, however, the possibility of informal lightening of scrutiny as examiners are promoted at earlier grades. That is, supervisors may lessen the extent they review an examiner's work as she gets promoted from GS-7 through GS13, even though there is no formal policy by the Patent Office to do so. If this occurs, our results would still hold but their interpretation would differ. Examiners may grant more patents upon promotion not because they become more time constrained but instead because the work is subject to less review, enabling examiners to increasingly shirk their responsibilities.

Nevertheless, one may take our findings as being more consistent with increasing time constraints rather than a lightening of scrutiny for several reasons. First, as implied by Table 4 and Figure 5 and as shown more explicitly by Figures A10-A12 in the Online Appendix, we find that the basis of rejection that falls the most upon grade-level changes-both in terms of consistency and magnitude-relates to the obviousness of the application. In other words, the reductions in rejections that may correspond to the observed increase in application allowances are those that are most sensitive to the amount of time allocated to examiners. With respect to the other rejection types-i.e., § 101 rejections (utility/patentable subject matter), § 112 rejections (written description/enablement/definiteness) and $\S 102$ rejections (novelty)—we actually do not observe a decline in grant rates upon the promotions of interest at all (only a leveling out). Ultimately, if examiners are truly shirking work upon promotion, it is less clear why obviousness rejections would receive the emphasis of their reduced attention. The observed pattern is arguably more consistent with time-management developments. 
Second, consider our results in Figure 3 and 4, which suggest that an examiner's grant rate initially increases upon promotion and then falls with each additional year an examiner spends at the grade level in question. If these findings were driven by a lightening of informal scrutiny, supervisors would arguably have to lessen their review of an examiner's work immediately upon promotion but then slowly increase their review as the examiner garners more experience within a particular grade level. This is perhaps less plausible than the binding time constraint explanation-i.e., an examiner's grant rate increase upon promotion and then gradually decreases as she learns to adjust to her new time allocation.

\section{Investigation of Prior Art Citations}

To further illuminate whether the above patterns of rising grant rates and falling obviousness rejections upon the relevant promotions are indeed a reflection of reduced examination effort stemming from binding examination-time constraints, we next estimate the relationship between GS-level promotions and the share of total prior-art citations listed in the final patent that are provided by the examiner as opposed to the applicant, a proxy (even if crude) for the search effort of the examiner. In Columns 3 and 4 of Table 4, we estimate this relationship over the full sample of patents issued between 2002 and 2012. This specification is, of course, somewhat compromised by the fact that it relies only on issued patents, the incidence of which we already know (as above) is likely to increase upon the promotions of interest, leading to possible selection concerns. With this caveat in mind, we note that the findings parallel those of the obviousness-rejection analysis above. 


\section{TABLE 5. RELATIONSHIP BETWEEN ALLOWANCE RATE AT EPO AND JPO AND U.S. EXAMINER Grade AND ExPERIENCE LEVEls, AMONG SET OF U.S. PATENTS LiKEWISE SEEKING PROTECTION AT EPO AND JPO}

\begin{tabular}{|c|c|c|c|}
\hline & (1) & (2) & (3) \\
\hline & $\begin{array}{c}\text { INCIDENCE OF } \\
\text { ALLOWANCE } \\
\text { AT BOTH EPO } \\
\text { AND JPO }\end{array}$ & $\begin{array}{c}\text { INCIDENCE OF } \\
\text { ALLOWANCE } \\
\text { AT EPO }\end{array}$ & $\begin{array}{c}\text { INCIDENCE OF } \\
\text { ALLOWANCE } \\
\text { AT JPO }\end{array}$ \\
\hline \multicolumn{4}{|l|}{ Omitted: GS-7 } \\
\hline GS-9 & $\begin{array}{l}-0.024 \\
(0.018)\end{array}$ & $\begin{array}{l}-0.030 * \\
(0.018)\end{array}$ & $\begin{array}{l}-0.019 \\
(0.017)\end{array}$ \\
\hline GS-11 & $\begin{array}{c}-0.048^{* * * *} \\
(0.019)\end{array}$ & $\begin{array}{c}-0.048^{* * *} \\
(0.018)\end{array}$ & $\begin{array}{l}-0.031 * \\
(0.017)\end{array}$ \\
\hline GS-12 & $\begin{array}{c}-0.056^{* * *} \\
(0.019)\end{array}$ & $\begin{array}{c}-0.057^{* * * *} \\
(0.018)\end{array}$ & $\begin{array}{l}-0.033^{*} \\
(0.018)\end{array}$ \\
\hline GS-13 & $\begin{array}{c}-0.063^{* * * *} \\
(0.020)\end{array}$ & $\begin{array}{c}-0.059 * * * \\
(0.019)\end{array}$ & $\begin{array}{c}-0.042^{* *} \\
(0.019)\end{array}$ \\
\hline GS-13 (with partial signatory authority) & $\begin{array}{c}-0.065^{* * * *} \\
(0.020)\end{array}$ & $\begin{array}{c}-0.061^{* * *} \\
(0.020)\end{array}$ & $\begin{array}{c}-0.040 * * \\
(0.020)\end{array}$ \\
\hline GS-14 & $\begin{array}{c}-0.070^{* * * *} \\
(0.021)\end{array}$ & $\begin{array}{c}-0.063^{* * *} \\
(0.020)\end{array}$ & $\begin{array}{c}-0.048 * * \\
(0.02)\end{array}$ \\
\hline \multicolumn{4}{|l|}{ Omitted: 0-1 Years Experience } \\
\hline 2-3 Years Experience & $\begin{array}{c}0.010 \\
(0.009)\end{array}$ & $\begin{array}{c}0.007 \\
(0.010)\end{array}$ & $\begin{array}{l}0.029 * * \\
(0.009)\end{array}$ \\
\hline 4-5 Years Experience & $\begin{array}{l}0.022^{*} \\
(0.013)\end{array}$ & $\begin{array}{c}0.015 \\
(0.013)\end{array}$ & $\begin{array}{l}0.029 * * \\
(0.012)\end{array}$ \\
\hline 6-7 Years Experience & $\begin{array}{c}0.024 \\
(0.016)\end{array}$ & $\begin{array}{c}0.020 \\
(0.016)\end{array}$ & $\begin{array}{l}0.034^{* *} \\
(0.015)\end{array}$ \\
\hline 8-9 Years Experience & $\begin{array}{c}0.025 \\
(0.020)\end{array}$ & $\begin{array}{c}0.023 \\
(0.019)\end{array}$ & $\begin{array}{l}0.037 * * \\
(0.019)\end{array}$ \\
\hline $\begin{array}{l}\text { 10-11 Years } \\
\text { Experience }\end{array}$ & $\begin{array}{c}0.029 \\
(0.024)\end{array}$ & $\begin{array}{c}0.024 \\
(0.023)\end{array}$ & $\begin{array}{l}0.039^{*} \\
(0.023)\end{array}$ \\
\hline $\begin{array}{l}\text { 12-13 Years } \\
\text { Experience }\end{array}$ & $\begin{array}{c}0.029 \\
(0.028)\end{array}$ & $\begin{array}{c}0.023 \\
(0.027)\end{array}$ & $\begin{array}{c}0.041 \\
(0.026)\end{array}$ \\
\hline 14+ Years Experience & $\begin{array}{c}0.016 \\
(0.034)\end{array}$ & $\begin{array}{c}0.022 \\
(0.032)\end{array}$ & $\begin{array}{c}0.023 \\
(0.033)\end{array}$ \\
\hline $\mathrm{N}$ & 172103 & 172103 & 172103 \\
\hline \multicolumn{4}{|c|}{$\begin{array}{l}* \text { significant at } 10 \% ; * * \text { significant at } 5 \% ; * * \text { significant at } 1 \% \text {. Standard errors are reported in } \\
\text { parentheses and are clustered to correct for autocorrelation within given examiners over time. } \\
\text { Each observation is from the sample of applications that (1) were filed after March, } 2001 \text { and (2) } \\
\text { that reached a final disposition and that were published in the PAIR records between March, } 2001 \\
\text { and July, 2012. The sample is further restricted to those applications that actually culminated in a } \\
\text { patent grant and whose underlying inventors also sought patent protection at the JPO and EPO. }\end{array}$} \\
\hline
\end{tabular}




\section{Assessment of Marginal Nature of Increased Grants}

The analysis above suggests that, as time constraints tighten, examiners will grant some patents that they might have otherwise rejected if given sufficient time. Assuming an otherwise competent examination process, these additional patent grants should be of marginally questionable validity-i.e., they should fail to satisfy a proper application of patentability standards. It is inherently difficult to systematically assess the underlying legal validity of each of the patents issued in our sample. Nonetheless, to test this prediction, we rely upon the fact that many U.S. applicants likewise file for patent protection with the European Patent Office (EPO) and the Japan Patent Office (JPO), two offices that are known to invest substantially more resources per application in the examination process, while having essentially similar patentability standards (Picard and van Pottelsberghe de la Potterie, 2011). Accordingly, we consider the sample of issued patents in which the relevant U.S. applicant likewise sought protection at the EPO and the JPO and follow Jaffe and Lerner (2004) and Lemley and Sampat (2012) in using outcomes at these foreign offices as a benchmark-albeit an imperfect one-to assess what the outcome at the U.S. Patent Office would have been (at least generally speaking) if the U.S. examiners were to be given more time and resources to determine the patentability of the relevant invention.

For these purposes, we note that it is not possible to pinpoint the exact marginal patents that are issued as a result of binding time constraints. Nonetheless, with the above (admittedly, rough) proxy for validity in mind, one can arguably identify the quality of such marginal patents by looking at the full sample of patents that were issued in the U.S. and that sought protection in the EPO and the JPO and then estimating how the mean incidence of such patents likewise being 
granted by the EPO (and/or JPO) changes as examiners experience the examination-timereducing promotions of interest. The above analysis demonstrated that the pool of issued patents will rise upon such promotions. To the extent that average quality levels among the set of issued patents fall upon these events, it must be the case that the marginal patents being issued as a result of these promotions are of an increasingly below-average level of quality (Frakes 2013). ${ }^{29}$

In Table 5, we test for the presence of falling mean rates upon promotion for the indicated patent quality metric. Consistent with expectations, we indeed estimate monotonically (generally) declining patterns of this nature, suggestive of marginal patent issuances of weakening validity. Relative to the patents issued at GS-7, the patents issued at GS-14 are 7 percentage-points—or roughly 16 percent—less likely to be allowed by both the EPO and the JPO (when using success at both foreign offices to signify the strongest benchmark of quality). Whether or not those additional patent grants arising from such promotions have truly crossed the invalidity threshold, the evidence suggests that they are at least of a more questionable nature than the typical issuance.

\section{DisCuSSION AND CONCLUSION}

\section{A. Summary and Magnitude of Findings}

Our analysis finds that as examiners are given less time to review applications upon certain types of promotions, the less prior art they cite, the less likely they are to make time-consuming obviousness rejections, and the more likely they are to grant patents. Moreover, our evidence suggests that these marginally issued patents are of weaker-than-average quality. These findings demonstrate that a factor other than the true patentability of applications may be a determinant of granting decisions and may be pushing grant rates upwards. All else equal, they thus support the

29 After all, if one adds some object to an existing set of objects and the average value of the overall set of objects falls, it must be case that the object added on the margin is of below-average value. 
general sentiment that the Patent Office may be biased towards allowing patents. Of course, all else is not necessarily equal and we cannot say definitively that the net effect of all features of the Patent Office pushes in this direction. Nonetheless, we stress that the feature that we do emphasize in this analysis is one that may meaningfully alter the granting landscape of the Agency. Combining the estimated impacts of GS-level changes on grant rates depicted in Column 1 of Table 3 with the distribution of applications examined across the various grade levels, as depicted in Column 1 of Table A1 in the Online Appendix, our analysis implies that if all examiners were allocated as many hours as are extended to GS-7 examiners, the Patent Office's overall grant rate would fall by roughly 14 percentage points, or nearly 20 percent. $^{30}$ Based on the number of annual disposals by the patent office in recent years, this would amount to approximately 40,000-45,000 fewer issued patents per year.

To facilitate an alternative interpretation of the magnitude of the above findings, Table A7 in the Online Appendix presents results from an examiner fixed effects specification that likewise draws upon promotion-related changes in time allocations but that replaces the grade level dummy variables with a single variable for the number of hours allocated to the application at hand (and that includes Patent Office class dummies to account for fixed differences in hour allotments across classes). This exercise suggests that a doubling of the amount of hours given to all examiners is associated with a 9 to 24 percentage point (or a 13 to 34 percent) reduction in the grant rate, representing roughly 40,000-100,000 fewer patents being issued each year.

B. Quality / Production Tradeoff

30 For example, roughly 35 percent of applications are disposed of by GS-14 examiners, whom we have estimated to grant at a nearly 19 percentage-point (or 28 percent) higher rate than GS-7 examiners, accounting fully for examiner heterogeneity. This implies that if, those applications disposed of by GS-14 examiners were granted at the same rate applied by GS-7 examiners, the Agency would experience a reduction in its grant rate of roughly 7 percentage points $(=0.19 * 0.35)$ or by roughly 10 percent $(0.28 * 0.35)$. Extending this exercise to the remaining grades and aggregating the amounts delivers the indicated 20 percent effect. 


\section{Basic Framework}

Of course, increasing the number of hours allotted to examiners in such a manner would not be without consequence. To understand the tradeoffs at play here, consider a Patent Office with the following objective function:

$W_{t}=\sum_{t=1}^{\infty} V\left(x_{t}, g_{t}-\delta_{t}\right) \beta^{-t}$

where $x_{t}$ is the number of applications processed by the Agency at time $t, g_{t}$ is the rate by which the Agency grants applications at time $t$ and $\delta_{t}$ is the rate by which the Agency would grant applications if given sufficient time to properly follow the patentability standards. First, we assume that $V^{\prime}\left(x_{t}\right)>0$-i.e., that the Patent Office's utility is enhanced the greater it is able to satisfy its obligation to process incoming applications. It could of course decline to satisfy all such obligations immediately and review some applications at a later date; however, pursuant to the above objective function, the Patent Office will discount a delayed review $\left(\beta^{-t}\right)$. That is, we assume that the Agency values a timely review of all incoming applications. Long patent delays, after all, can postpone the deployment of valuable inventions to the marketplace and increase uncertainty surrounding the rights of potential patents, which in turn limit a company's ability to license or engage in related activity. Moreover, to the extent future inventions are based on prior ones, a backlog of patent applications may deter cumulative innovation. ${ }^{31}$

As theorized above (and as supported by the empirical analysis), $g_{t}-\delta_{t}$ increases as the time allocated to review an individual application in year $t, a_{t}$, decreases. In other words, time constraints lead to a bias in the Patent Office's granting practices. ${ }^{32}$ Moreover, we assume that the Agency disvalues the presence of any such bias-i.e., $V^{\prime}\left(g_{t}-\delta_{t}\right)<0$. As stated in our

\footnotetext{
31 Based on these costs, one study has estimated that an additional year of patent pendency could cost the global economy close to 12 billion dollars (London Economics 2010).

32 In light of our focus in this paper on determinants of a pro-granting bias and in light of our theoretical predictions of such a bias, we only consider the situation where $g_{t} \geq \delta_{t}$ - that is, where grant rates may be set higher than the unbiased rate.
} 
introductory remarks, the granting of invalid patents on the margin may stunt follow-on innovation and impose related harms on society.

Finally, it is critical to note that the Patent Office will maximize this objective function subject to a resource constraint that must be satisfied at each time period (according to a fixed budget, $R$ ): $R_{t} \geq a_{t} h_{t} x_{t}, \forall t$, where $h_{t}$ equals the cost per hour of examination time to the Agency. It is beyond the scope of this paper to evaluate whether the Agency is properly optimizing its constrained objectives with its choice over how many hours to allocate to each individual application; rather, we simply set forth this structure in order to demonstrate the trade-offs associated with this choice. The Patent Office may increase the amount of time, $a$, allocated to review given applications in an attempt to reduce its grant bias-i.e., bring $g_{t}$ closer to $\delta_{t}$ - and thereby increase its utility, $V$. However, to the extent that the budget constraint binds (and in light of the fixed $R$ ), it can be readily shown that an increase in $a$ in period $t$ must come at the expense of a reduction in the amount of applications processed in period $t, x$, a development that would, in turn, inhibit the objectives of the Patent Office and result in the above specified harms associated with delayed examinations. ${ }^{33}$

As such, the Agency's choice over how many hours to extend to examiners implicates a possible tradeoff between the benefits of improved patent quality and the harms of reduced examination capacity. Our empirical analysis suggests that the above specified budget constraint may indeed be binding and that this tradeoff is presently in action. However, the above analysis does not necessarily demonstrate that the way in which the Patent Office executes this tradeoff is suboptimal given its budgetary limitations. Of course, to the extent that the Agency overly favors examination capacity concerns in performing this calculus (beyond the weight that may be applied to such concerns by a social planner), which is possible given that application throughput

33 In the case of a binding budget constraint, $x_{t}=\mathrm{R}_{\mathrm{t}} /\left(a_{t} h_{t}\right)$, in which case $\mathrm{d}\left(x_{t}\right) / \mathrm{d}\left(a_{t}\right)<0$. 
(and associated backlog) is a more highly visible and easily measured feature of the Agency relative to the quality of its review (Holmstrom and Milgrom, 1991), the Patent Office's execution of this tradeoff may indeed deviate from optimality-i.e., it may be setting examination time allotments insufficiently low. ${ }^{34}$

\section{Examiner Heterogeneity in Productivity}

Figure 3 suggests that examiners may undergo productivity gains as they accumulate experience over time within the Patent Office. That is, for a given time allotment, $a$, examiners may be able to bring $g_{t}$ closer to $\delta_{t}$ as they spend more time at the Agency. With these gains in mind, the Agency may desire to set different time allocations for examiners with different levels of productivity (e.g., provide less time to examiners with experience). ${ }^{35}$ The above framework can be readily extended to account for examiner heterogeneity along such lines, such that the Patent Office will maximize

$$
W_{t}=\sum_{m} \sum_{t=1}^{\infty} V\left(x_{t m}, g_{t m}-\delta_{t}\right) \beta^{-t}
$$

s.t.

$$
R_{t} \geq \sum_{m} a_{t m} x_{t m} h_{t m}, \forall t
$$

where $m$ signifies different productivity groups. In the unitary examiner framework set forth above, increases in application throughput, $x$, could only come at the expense of driving grant rates above their unbiased point, $\delta$ (i.e., at the expense of quality), when constraints bind. If all examiners experienced productivity gains, one might expect to observe a relaxation of the budget

\footnotetext{
34 In its own annual reports, the Patent Office's rhetoric suggests an especially strong emphasis on promoting examination throughput. In its 2008 Performance and Accountability Report, the Patent Office stated that its "biggest challenge" is to decrease its patent pendency (the time between the filing of an application and the receipt of a substantive communication from the Agency) and to decrease the backlog of applications awaiting review (United States Patent and Trademark Office, 2008). Moreover, the Office of Inspector General recently issued a report concluding that the Patent Office's policies in place to review the quality of patent examiner decisions were largely ineffective. (Office of Inspector General, 2015).

35 While the Patent Office does not necessarily make such adjustments over years of experience itself, they do, as discussed above, time-allocation adjustments upon certain specified promotions.
} 
constraint and a resulting first order condition in which examination quality is marginally less compromised-i.e., a reduction in grant rates. If only some examiners experience productivity gains, the Patent Office may experience similar relief and set time allocations such that its overall grant rate goes down. However, without knowing more about the structure of the Patent Office's objective function, it is difficult to predict how any such desired quality improvements will be split among the different productivity types. For instance, to the extent the Agency places significant value on horizontal application equity, it may try to adjust time allotments in a way that still leaves $g_{t m}-\delta_{t}$ similar across different examiner types, $m$-i.e., in a way that leaves an applicant's outcome unaffected by the examiner she randomly receives.

We leave it for future research to assess the optimality of the particular relationship between examination time-allocation adjustments and grant rates that we observe in Figure 1. Nonetheless, we emphasize that the relationship we do observe is, interestingly, one in which grant rates increase strongly as examiners experience time-allocation adjustments associated with productivity gains. To the extent that the solution to this maximization problem is one in which grant rates are either expected to fall with time-allocation adjustments upon seniority or stay roughly flat—which, again, might be desirable in the event that we place sufficient value on horizontal equity - these results would suggest that the present examination time schedule is not calibrated optimally (or equitably) to reflect actual productivity improvements. ${ }^{36}$

\section{Ex-Ante / Ex-Post Investment in Quality}

One feature of the patent system arguably missing from the framework set forth above is the judiciary. If examiners are given less time, $a$, to review applications, examiners may begin to issue legally invalid patents on the margin (pushing $g$ above $\delta$ ). As above, this may benefit

36 Cockburn, Kortum, and Stern (2003) and Lemley and Sampat (2012) each suggested that the findings of substantial examination heterogeneity raised concerns over the equity of the examination process, suggesting than an applicant's outcome with the process comes down to a luck of the draw with respect to which examiner she is randomly assigned. 
welfare to the extent it allows the Agency to process more applications on a limited budget; but it may be detrimental to the extent it results in the issuance of invalid patents. However, the welfare losses associated with such issuances may not be as large as originally envisioned to the extent the courts may subsequently correct this outcome and invalidate these patents (albeit with a delay). Of course, this legal backdrop is not without welfare consequences of its own. Litigation, when it arises, carries substantial administrative expenses, lawyer fees, and related costs.

As such, given that both the Patent Office and the courts assess the patentability of claimed inventions, the tradeoffs at play here take on yet another dimension: the balance in society's utilization of these two institutions to apply the patentability standards. Any such analysis will likely involve an assessment of the relative administrative expenses associated with these separate systems. Though far more expensive on a per-unit basis, litigation ultimately arises in the case of a small fraction of those applications before the Patent Office. Consider the decision to increase the amount of examination time given to examiners. Though carrying added payroll expenses, this policy decision may decrease the number of invalid patents that the Agency issues and potentially reduce the number of lawsuits moving forward (and associated litigation expenses). Making particular assumptions about the various parameters in play with this analysis-e.g., the costs of litigation, the costs of examination, the frequency of litigation, etc.Lemley (2001) suggests that increasing the hours to review applications may not be cost effective. The present analysis affords us an opportunity to revisit Lemley's claim. In the Online Appendix, we apply certain conservative assumptions and perform a back-of-theenvelope calculation—supported by novel estimates of the reduction in legal challenges that may result from increasing examination hours-demonstrating that the savings in future litigation 
costs associated with giving all examiners the amount of time given to GS-7 examiners more than outweigh the added payroll expenses to the Patent Office.

At the least, this exercise supports the relevance of the Patent Office in this larger welfare calculus. That is, the presence of the courts and the fact that they are invoked in rare and important cases may not render inconsequential the decision as to how many examination hours to extend to patent examiners.

\section{REFERENCES}

Alcacer, Juan, Michelle Gittelman, and Bhaven Sampat, "Applicant and Examiner Citations to Patents: An Exploration and Overview," Research Policy (2009), 415-427.

Asch, Beth J., "Do Incentives Matter? The Case of Navy Recruiters," Industrial and Labor Relations Review 43 (1990), 89S-106S.

Baker, George, Robert Gibbons, and Kevin Murphy, "Subjective performance measures in optimal incentive contracts," Quarterly Journal of Economics, 109 (1994), 1125-1156.

Burk, Dan and Mark A. Lemley, The Patent Crisis and How the Courts Can Solve It (2009).

Chan, David, "Teamwork and Moral Hazard: Evidence from the Emergency Department," Journal of Political Economy, forthcoming (2015 a).

Chan, David, "The Efficiency of Slacking Off: Evidence from the Emergency Department," mimeo, Stanford University (2015 b).

Cockburn, I., S. Korum, and S. Stern, “Are All Patent Examiners Equal? Examiners, Patent Characteristics, and Litigation Outcomes," in W. M. Cohen and S.A. Merril (Eds.), Patents in Knowledge-Based Economy (Washington, DC: National Academies Press, 2003). 
Cohen, Wesley M., Richard R. Nelson, and John P. Walsh, "Protecting Their Intellectual Assets: Appropriability Conditions and Why U.S. Manufacturing Firms Patent (or Not)," NBER working paper 7552 (2000).

Cotropia, Christopher, Mark Lemley, and Bhaven Sampat, "Do Applicant Patent Citations Matter?", Research Policy, 42 (2013), 844-54.

Courty, Pascal and Gerald Marshke, "An Empirical Investigation of Gaming Responses to Performance Incentives,” Journal of Labor Economics, 22 (2004), 23-56.

de Ree, Joppe, and Rob Alessie, "Life Satisfaction and Age: Dealing with Underidentification in Age-Period-Cohort Models," Social Science and Medicine, 73 (2011), 177-82.

Frakes, Michael D. "The Impact of Medical Liability Standards on Regional Variations in Physician Behavior: Evidence from the Adoption of National-Standard Rules." American Economic Review, 103(1) (2013), 257-76.

Frakes, Michael D. and Melissa F. Wasserman, "Does Agency Funding Affect Decisionmaking?: An Empirical Assessment of the PTO's Granting Patterns," Vanderbilt Law Review, (2013), 67-147.

Frakes, Michael D. and Melissa F. Wasserman, "The Failed Promise of User Fees: Empirical Evidence from the United States Patent and Trademark Office," Journal of Empirical Legal Studies, 11(4) (2014), 602-36.

Frakes, Michael D. and Melissa F. Wasserman, "Does the U.S. Patent and Trademark Office Grant Too Many Bad Patents?: Evidence from a Quasi-Experiment," Stanford Law Review, 67(3) (2015), .

Galasso, Alberto and Mark Schankerman. "Patents and Cumulative Innovation: Causal Evidence from the Courts," Quarterly Journal of Economics, forthcoming (2014). 
Griliches, Zvi, "Patent Statistics as Economic Indicators: A Survey," Journal of Economic Literature, 28 (1990), 1661-1707.

Hall, B. H., A. Jaffe, and M. Trajtenberg, "The NBER Patent Citations Data File: Lessons, Insights and Methodological Tools," NBER Working Paper 8498 (2001).

Hall, B. H., A. Jaffe, and M. Trajtenberg, "Market Value and Patent Citations," Rand Journal of Economics, 36 (2005), 613-76.

Harhoff, D., F. Narin, F. M. Scherer and K. Vopel, "Citation Frequency and the Value of Patented Innovation," Review of Economics and Statistics, 81 (1999), 511-515.

Heckman, J. and Robb, R, "Using Longitudinal Data to Estimate Age, Period and Cohort Effects in Earnings Equations," pp. 137-150 in WM. Mason and SE. Fienberg (eds.) Cohort Analysis in Social Research: Beyond the Identification Problem, Springer-Verlag: New York (1985).

Holmstrom, Bengt, and Paul Milgrom, "Multitask Principal-Agent Analyses: Incentive Contracts, Asset Ownership, and Job Design.” Journal of Law, Economics, and Organization 7 (2) (1991), 201-228.

Jaffe, A. B., M. Trajtenberg, and R. Henderson, "Geographic Localization of Knowledge Spillovers as Evidence by Patent Citations," The Quarterly Journal of Economics, 108 (1993), 577-598.

Jaffe, A. B. and Josh Lerner, Innovation and Its Discontents: How our Broken Patent System is Endangering Innovation and Progress, and What to Do about It (Princeton, NJ: Princeton University Press, 2004).

Larkin, Ian, "The Cost of High-Powered Incentives: Employee Gaming in Enterprise Software Sales," Journal of Labor Economics, 32 (2014), 199-227. 
Lanjouw, Jean O. and Josh Lerner, "The Enforcement of Intellectual Property Rights: A Survey of the Empirical Literature," NBER working paper 6296 (1997).

Lemley, Mark A. and Bhaven Sampat, "Examiner Characteristics and Patent Office Outcomes," The Review of Economics and Statistics, (2012), 817-827.

Lemley, Mark A., "Rational Ignorance at the Patent Office," Northwestern University Law Review, (2001), 1495-1532.

Lichtman, Douglas, "Rethinking Prosecution History Estoppel," University of Chicago Law Review, (2004), 151-82.

London Economics, "Economic Study on Patent Backlogs and System of Mutual Recognition: Final Report to the Intellectual property Office," available at http://www.ipo.gov.uk/pbacklog-report.pdf. (2010).

Mann, Ronald, "The Idiosyncrasy of Patent Examiners: Effects of Experience and Attrition," Texas Law Review, (2014), 2149-76.

Mansfield, Edwin, "Patents and Innovation: An Empirical Study," Management Science, 32 (1986), 173-181.

Moser, Petra, "How Do Patent Laws Influence Innovation? Evidence from Nineteenth-Century World's Fair," American Economics Review, (2004), 1214-1236.

Nordhaus, William, Invention, Growth, and Welfare (Cambridge, MA: MIT Press, 1969).

Office of Inspector General, USPTO Needs to Strengthen Patent Quality Assurance Practices, Final Report No. OIG-15-026-A (2015).

Oyer, Paul, "Fiscal Year Ends and Nonlinear Incentive Contracts: The Effect on Business Seasonality," Quarterly Journal of Economics, 113 (1998), 149-185. 
Pakes, Ariel, "Patents as Options: Some Estimates of the Value of Holding European Patent Stocks," Econometrica, 54 (1986), 755-784.

Picard, Pierre M., and Bruno van Pottelsberghe de la Potterie, "Patent Office Governance and Patent System Quality,” CEPR Discussion Paper No. DP8338 (2011).

Sampat, Bhaven, "When Do Applicants Search for Prior Art?" Journal of Law and Economics 53 (2010), 399-416.

Sampat, Bhaven and Heidi L. Williams, "How do Patents Affect Follow-on Innovation? Evidence from the Human Genome," available athttp://economics.mit.edu/files/9778 (2014).

Scotchmer, Suzanne, "Standing on the Shoulder of Giants: Cumulative Research and the Patent Law," Journal of Economic Perspectives, 5 (1991), 29-41.

United States Patent and Trademark Office, "Performance and Accountability Report for Fiscal Year 2008," (2008), available at: http://www.uspto.gov/about/stratplan/ar/USPTOFY2008 PAR.pdf. 


\section{ONLINE APPENDIX TO}

\section{Is THE TIME Allocated to REVIEW PATENT APPLICATIONS INDUCING EXAMINERS TO GRANT INVALID PATENTS?: EVIDENCE FROM MICRO-LEVEL APPLICATION DATA}

\section{A. Background on Patent Examiner Workload Expectations}

Examiners are generally expected to meet certain workload goals, whereby they are expected to attain a certain number of credits, often referred to as "counts". Credits, however, have historically been earned only upon the issuance of a first office action and at final disposal, which occurs when a patent application is allowed by the examiner or abandoned by the applicant (often after receipt of a final rejection or in anticipation of such a rejection). ${ }^{1}$ By setting expectations regarding the number of credits examiners should attain, the Patent Office contemporaneously sets expectations regarding the amount of time examiners should spend on applications. ${ }^{2}$ The number of expected hours allocated to review a patent application depends on both the technological field in which the examiner is working and on her position in the general schedule (GS) pay scale. A patent examiner in a more complex field is allocated more hours to review an application than an examiner of the same grade who is working in a less complex field.

\footnotetext{
$1 \quad$ Since 2010 examiners can also earn partial credits for final office actions and examiner-initiated interviews with the patent applicant or her attorney. Under either system, a patent examiner earns a maximum of two credits per patent application examined. While examiners are free to average these time allotments over their caseload, they are strongly encouraged to meet their credit quota on a biweekly basis. Examiner's performance appraisal plan (PAP) was also modified in 2010 in order to better align patent examiner incentives with those of the agency. These modifications were largely uniform across examiner pay grade, with the exception of SPEs (GS-15) who PAP changes differed from those of GS-5 through GS-14 patent examiners.

$2 \quad$ These time allotments have largely remained unchanged since 1976. The Patent Office has created new patent classifications as a result of new and emerging technology. Once the Agency has set the time allotments for a new technology these allocations also have largely remained unchanged. In 2010, however, the Patent Office increased the time allotments for every application by two hours.
} 
The higher the pay grade of an examiner within a technology area the fewer number of hours the Patent Office allocates to earn two credited work units.

\section{B. Background on Collection of Rejection Types in USPTO PAIR Data}

Through reading of a number of office actions in the PTO PAIR data, we identified the following phrases that were either (1) likely to be associated with the examiner rejecting a claim as failing to meet the patentability standards, (2) likely to be associated with the examiner objecting to the form of the claim (as distinguished from its substance), (3) likely to be associated with an examiner objecting to other aspect of the application or making additional requirements of the patentee (e.g., objection to drawings, objection to the abstract, restriction requirement, etc.). To be clear, the focus of this article is claim rejections not objections. However, for completeness we reproduce the list of phrases we searched, including phrases that are directed only at identifying objections, below.

rejected under; rejected are under; rejected as unpatentable; as being unpatentable; rejected as failing to define; objected to; election of species; fails to define a statutory; antecedent basis; new title is required; title of the application will; notice to comply; part of paper; prior art made of record and; rejected as being based; rejected as being directed; rejected on the ground; restriction to one of the fol; restriction is required under; status identifiers; fail to meet; fail to comply; fail to contain; fail to provide; fail to identify; fail to include; do not comply with; not in accordance with; cannot be patented; defective because; non-compliant because; renders the claim indefinite; not of sufficient quality; filed after the issue fee was; filed after publication; drawings in compliance with; declaration is missing; are not consistent; is not a proper submission; not include a support; claim rejections; this is a provisional obvious; because it is unsigned; not filed a certified copy; is non-responsive; required to furnish; introduce new matter; not contain a concise explan; the following omission; request for information; requirement for information; abstract exceeds 150 words; elect a single disclosed spec; elect disclosed species; not properly annotated; not signed by an; not authorized to sign; not been submitted; not appear to be relevant to; non-elected subject matter in; terminal disclaimer needs to; associate poa are no longer; include common ownership as; other copending United States; application conflict with cla; contain every element of cla; believed to interfere; has not been met; not 
indicated the appropria; contain(s) every element of; claimed invention is differe; contains every element of $\mathrm{cl}$; declaration in compliance wi; does not have publication da; do not have corresponding pa; filed well after the applica; list of all patents. Publica; notice of non-compliant amen; reference relevant to the ex; required information for the; requires that the summary of; restriction is hereby require; the appropriate statement ac; Website is not considered a.

After compiling this list of phrases we then searched for approximate matches to each of the above listed phrases in office actions. Once such a match was identified we captured (or excerpted) the matched phrase and a small amount of surrounding text (approximately the sentence that contained the phrase). After this list of excerpts was compiled, we wrote a simple program that allowed us to perform an iterative procedure to match an excerpt containing a phrase listed above to a specific rejection type (e.g., $101,102,103$, etc.) or objection type (e.g., 37 C.F.R. 1.121(d)). The program began by displaying all excerpts containing a phrase listed above that had not yet been assigned to a rejection or objection type. By inspection of this list, we choose a string of text (e.g., "35 USC 103") appearing in at least one excerpt that ought to be associated with a particular rejection type (e.g., obviousness). We then identified all excerpts containing an exact match of the string of text that also contained a match to the same phrase listed above and assign each of them to the identified rejection or objection type. That is, each time we matched rejection or objection type to an excerpt we did so for only for that group of excerpts containing the same above-listed phrase (e.g., "rejected under," "rejected are under," etc.). We continued this iterative process until there were no more unassigned excerpts.

\section{B. Supplementary Notes Regard Data Collection}

Our sample includes all 1,956,493 utility applications that were filed on or after March 2001 and were published in the PAIR database by July 2012. ${ }^{3}$ By the end of 2012, 49

3 In November 2000, there was a change in the law that required newly filed patent applications to be published 18 months after they were filed. 35 U.S.C. § 122(b). Applicants abandoned within the first 18 months of filing, Id. $\S 122(\mathrm{~b})(2)(A)(i)$ and applications wherein the applicant filed a special exemption to maintain confidentiality are exempted from this requirement, Id. § 122(b)(2)(B)(i). Such applications are thus absent from the PAIR database. When some or all of an applicant's claims are not allowed by the Patent Office, the aggrieved party will sometimes file a continuation application. This application is given a new serial number and may be assigned to a different examiner. Continuation applications are treated as unique applications in the PAIR database. A related and now far more commonly used device, known as a Request for a Continued Examination (RCE), does not receive a new application serial number and effectively allows 
percent of these applications had resulted in patents, 25 percent were not patented because they had been abandoned by the applicant, ${ }^{4}$ and the remainder were still pending. Applicants may elect to abandon their applications when they are unable to overcome an examiner's rejection or for other business-related reasons. Our study focuses on the 1.4 million utility applications filed from 2001 onwards that received a final disposition -those that were granted of abandoned-by July, 2012.

Critical to our analysis is determining the experience (in years) and the GS-level for each of the 9,000 examiners represented in our sample. For these purposes, we match the examiner field in the PAIR data with the two sets of examiner rosters received pursuant to separate FOIA requests. In order to calculate the relevant examiner's experience, we take the difference between the year at the time of disposal of the application and the first year at which the examiner joined the Patent Office, as determined by observing when each examiner was first represented in annual examiner lists that we received from the Patent Office. To ensure that this approach accurately captures the experience of long-tenure examiners, we began collecting these annual rosters in 1992-that is, nearly ten years prior to the commencement of our sample period. Naturally, this cannot ensure complete precision in the experience assignment given that some examiners may have joined the Patent Office long before 1992 (making it difficult to distinguish between 10-year examiners and 20-year examiners for those applications disposed of in 2002). To alleviate these final censoring concerns, we simply focus the empirical analysis on those examiners who joined the Office in 1993 and beyond, though the results are entirely robust to disregarding this restriction (available upon request). On average, this restricted set of examiners stays at the Patent Office for roughly 6.8 years with roughly 25 percent of such examiners staying at least 10 years.

Pursuant to a second FOIA request, we received an additional set of annual rosters from 2001 to 2012 indicating the GS level associated with each examiner on staff over those years. Furthermore, a third and final FOIA request allowed us to determine whether GS-

an aggrieved applicant to keep the application on the examiner's docket for further prosecution. RCEs are not treated as new, unique filings in the PAIR database; rather, they are treated as a continuation in the prosecution of original applications.

$4 \quad$ A small portion of these applications were actually abandoned after being allowed by the examiner. 
13 examiners did or did not have partial signatory authority at that time, a distinction, as above, that bears on the hours allocated to the examiner for review. ${ }^{5}$

The examiner field in PAIR had a number of typographical errors and variations in the spelling or formatting of names, complicating efforts to perform the above matches. To overcome this difficulty, we utilized the reclink Stata module, a "fuzzy" matching program designed to deal with variations in names over time (e.g., inclusions of full middle names versus middle initials, name changes upon marriage, etc.). Having performed this match, we then ensured the creation of a stable set of examiner field effects. All told, our analytical file contained roughly 9,000 examiners.

In Columns 1 of Table A1, we set forth the percentage of applications in our sample that are disposed of by examiners in each of the relevant GS-levels and experience groups. Examiners spend considerably more time in higher GS ranges, especially GS-level 14, thus accounting for the higher percentage of applications associated with high GS-level examiners. Also contributing to the relatively weaker presence of GS-levels 7 and 9 in the data is the fact that many examiners (nearly $1 / 3$ of new examiners) begin at GS-level 11. In Column 2, we further illuminate this breakdown by taking all of the examiner rosters over the 2002-2012 period and indicating what percentage of these total examiner years were represented by examiners in the various GS-level and experience categories. For the reasons just discussed, this representation also tends to be weighted near the higher GS ranges.

Finally, we exclude those few applications-roughly 3 percent of the raw sampleexamined by individuals at GS-15 given uncertainty over the examination time allocated to those reaching this final, largely supervisory level from our sample. Published time allocation schedules suggest that GS-15 examiners should receive 67 or 71 percent of the time extended to their GS-12 counterparts. However, the specific time allocation amounts that we received from the PTO for each GS-15 examiner in our sample differ markedly and erratically from this generally published schedule. ${ }^{6}$ In any event, as

${ }^{5}$ There were slight inconsistencies in the treatment of within-year promotions between the examiner roster data employed above and the secondary roster of GS-13 examiners we received pursuant to our second FOIA request. That is, many of those examiners receiving this within-GS13 promotion were registered as doing so during the year in which our primary roster indicated that they ascended to GS-level 14. We give priority to the timings of promotions set forth in this secondary data source.

$6 \quad$ Hoping that the difference in time allotments to GS-15 examiners would provide another within-GS-level degree of variation, we filed an additional FOIA request with the PTO asking for the specific examination-time allotments associated with each GS-15 examiner, for each year from 
demonstrated by this Online Appendix, our results are robust to likewise tracking changes in grant rates upon the ascension to GS-15.

TABLE A1: REPRESENTATION OF GS-LEVEL AND EXPERIENCE GROUPS

\begin{tabular}{ccc}
\hline GS-level \& Experience & (1) & (2) \\
Group & $\begin{array}{c}\text { Percentage of Applications } \\
\text { Disposed of by Examiner in } \\
\text { Indicated Group (\%) }\end{array}$ & $\begin{array}{c}\text { Percentage of Total } \\
\text { Examiner Years } \\
\text { Spent in Indicated } \\
\text { Group Between } \\
\text { 2002 and 2012 (\%) }\end{array}$ \\
\hline GS-7 & 1.8 & 5.0 \\
GS-9 & 5.7 & 9.9 \\
GS-11 & 9.9 & 12.2 \\
GS-12 & 15.4 & 15.2 \\
GS-13 & 19.7 & 17.2 \\
GS-13, partial signatory & 13.5 & 10.3 \\
GS-14 & 33.9 & 30.2 \\
\hline 0-1 Years & 10.5 & 19.8 \\
2-3 Years & 18.8 & 19.2 \\
4-5 Years & 20.0 & 15.8 \\
6-7 Years & 16.2 & 11.6 \\
8-9 Years & 13.4 & 7.6 \\
10-11 Years & 10.2 & 8.5 \\
12-13 Years & 6.4 & 6.7 \\
14+ Years & 4.2 & 10.8 \\
\hline
\end{tabular}

On a final note, we exclude 2001 from our analytical sample, since the PAIR database only began collecting application data for filings commencing in March of 2001, leaving very few final dispositions of such applications in 2001 and thus leaving us with a weak

2002-2012. The provided data, however, list the majority of such GS-15 examiners as having the same amount of time allocated to GS-12 and GS-13 examiners, as opposed to the anticipated 67 percent and 71 percent values. In the Online Appendix, we estimate specifications that treat all GS-15 examiners alike under the assumption, as expected from their published schedule, that GS15 examiners would receive even less time than their GS-14 counterparts. However, the uncertainties in the data received pursuant to this final FOIA request leaves us inclined to treat this as a supplementary exercise only. 
ability to assess the determinants of granting decisions at such time (after all, patent prosecution durations are generally longer than a year). Similarly, we note that only 0.2 percent of the original sample were examined by GS-5 examiners. Given such a small level of representation, we exclude these applications from the analysis, though again we note that this exclusion is of little significance to our findings.

C. Ex-Ante Investments in the PTO vs. Ex-Post Investments in Litigation

Both the Patent Office and the courts are tasked with the job of applying the patentability standards and assessing the validity of inventions seeking patent protection. Some have proposed that investing greater resources at the Patent Officee.g., more examination hours -is less cost effective than simply allowing the courts to correct the issuance of an invalid patent (Lemley, 2001). The present analysis affords us an opportunity to provide some back-of-the-envelope calculations that may illuminate this ex-ante / ex-post debate. For these purposes, we compare the increase in expenditures at the Patent Office associated with increasing examination hours by a certain specified amount with the decrease in litigation expenses that may ensue from such an investment as a result of the invalidation of weak patents at the Patent Office (as opposed to letting them issue at the Patent Office and be challenged at the courts).

To guide this discussion, consider the simulation contemplated in the paper: giving all patent examiners the same amount of examination time extended to GS-7 examiners. Based on the results from Table 3 and the numbers provided in Table A1 and assuming 300,000 application disposals per year, we predict that an expansion in hours of this nature would lead to roughly 40,000 fewer patents being issued each year. Based on the calculations in Table A2, we predict that this expansion in hours will cost the Patent Office roughly $\$ 130$ million in additional salary expenses.

How much litigation expense will this investment in additional hours subsequently save in return? The results of our main exercises (as supported by the marginal quality analysis set forth in Table 4) may suggest that the additional patents being issued on the margin as a result of binding time constraints may be of questionable validity. To the extent that these marginal patents continue to be issued under current time allotments, they may indeed generate additional litigation expenses to the extent that their questionable validity invites legal challenge. Hence, it is possible that such expenses can be avoided to the extent that such patents are not issued by the Patent Office in the first place. It is of course unfounded to assume that all litigation can be circumvented by investing more at the Patent Office (or to assume, in the first place, that the litigation 
system is able to effectively target the marginal patents in question). The presence and extent of any litigation consequences are empirical questions.

To confront these questions, we have collected information on the litigation outcomes associated with the applications considered in our sample using data obtained from the Lex Machina database. Primarily, for each individual application, we have collected information on the number of times any patent resulting from that application has been asserted in litigation. With this information, we estimate specifications allowing us to determine the relationship between the grade level of the examiner and the number of times the relevant application is ultimately asserted at court. Increases in grade levels may lead to more litigation in two ways: (1) somewhat mechanically, the greater number of patents issued as a result of grade level changes (per the main analysis of the paper) will lead to a greater probability of litigation to the extent that only issued patents can be the subject of litigation in the first place and (2) to the extent that the additional patents being issued on the margin as a result of the increased time pressures are of more questionable validity, such marginal patents will invite greater legal challenge. Since our goal is to understand how giving all examiners GS-7 hours may lead to a reduction in overall litigation (to match such gains against the extra payroll expenditures calculated above), we attempt to capture both such mechanisms by estimating the relationship between grade levels and mean numbers of patent cases associated with the claimed inventions using the sample of applications as the base. In alternative specifications (Columns 4-6 of Table A3), we estimate this relationship using only the sample of issued patents-similar to the JPO and EPO specifications in the text-allowing us to target the second mechanism in particular (the marginal validity component). ${ }^{7}$

Since patents are very rarely litigated (only 7,000 of the issued patents in our PAIR sample were asserted over the time frame of our analysis) and since cases only materialize a discrete number of times, we elect to approach this analysis from a countbased perspective and estimate negative binomial regressions of the number of times an individual application is ever asserted at court on the grade level of the associated patent examiner. With over a million observations and close to 9,000 examiners in our sample, it is beyond our computational means to include examiner fixed effects in this

\footnotetext{
7 That is, considering that the number of issued patents increases with GS levels of the examiners, if the mean number of future cases increases among the set of issued patents as GS levels increase, it would tend to suggest that the patents being issued on the margin as a result of GS-level increases are generating greater litigation than the average patent issuance.
} 
specification; nonetheless, we have included the following controls in an attempt to capture most of the concerns that motivated the examiner fixed effects specifications estimated throughout the paper: year fixed effects, examiner cohort fixed effects based upon the first year of entry with the Patent Office, examiner experience group dummies, examiner tenure group dummies based on total length of time with the Patent Office, and technology fixed effects. As demonstrated elsewhere in this Appendix, the inclusion of such controls in the grant rate specifications leads to results that are nearly identical to examiner fixed effects specifications in that context.

We present the results of this exercise in Table A3. As predicted, we find that as the grade levels associated with the underlying applications increase so does the mean frequency by which such applications ultimately lead to litigation. Relative to when an examiner was at GS-7, applications reviewed by examiners at GS-14 are litigated at a roughly 107 percent higher rate (Column 3). The results from Columns 4-6 likewise suggest that these effects may indeed partially be a response to the second mechanism identified above-that is, the results from Columns 4-6 imply that those patents being issued on the margin in connection with GS-level changes are, as expected, more likely to be asserted in court relative to the average issued patent.

With these estimates, we then perform a simulation analysis in Table A4 similar to that in $A 2$ in which we predict the reduction in patent litigation expenses that may result from giving all examiners the number of hours extended to GS-7 examiners. For these purposes we use information on the cost of patent litigation from the American Intellectual Property Law Association (AIPLA), capturing costs associated with: outside and local counsel; paralegal services; travel and living expenses; fees and costs for court reporters, copies, couriers, exhibit preparation, analytical testing, expert witnesses, and similar expenses. We stress that the estimated litigation costs savings presented here are likely underestimates. Importantly, the litigation expenses used are one-sided only-that is, we are only using costs associated with defending a suit, thereby omitting costs associated with the parties asserting the underlying patents (though we suggest what the total savings would be assuming that plaintiff costs match those of the defense). Further, the results are likely underestimates to the extent we are only using costs associated with bringing cases to the end of the discovery stage of trial. Those cases that see trials through to judgments naturally garner much greater expenses. The AIPLA data reports costs separately for cases in with different degrees of money in controversy: less than a $\$ 1$ million, $\$ 1$ to $\$ 10$ million, $\$ 10$ to $\$ 25$ million and over $\$ 25$ million. As Table A4 presents, even when we take the most conservative approach here, the amount of money saved through future litigation by giving all examiners GS-7 hours 
(\$161 million) is greater that the additional payroll expenses calculated in Table A3. The net savings are likely to be even greater when we account for the fact that many cases fall into different bins of the amount in controversy and when we account for the litigation costs associated with asserting litigation (see Column 5 of Table A4) and for the fact that some cases proceed beyond discovery. Moreover, this simple back-of-theenvelope comparison is just focusing on direct costs: payroll expenses at the Patent Office versus litigation expenses down the road. The net benefits of eliminating more invalid patents early in the process by investing more resources at the Patent Office are likely to be even larger should one quantify the additional social benefits that might come from such developments-e.g., the avoidance of impediments to cumulative innovation in the period of time prior to when a court may have invalidated the invalid patent anyway.

TABLE A2: SiMULATED INCREASE IN PAYROLl EXPENSES ASSOCIATED WITH GIVING ALL EXAMINERS THE NUMBER OF HOURS ALlOCATED TO GS-7 EXAMINERS FOR ONE YEAR OF APPLICATIONS

\begin{tabular}{cccccc}
\hline & $\mathbf{( 1 )}$ & $\mathbf{( 2 )}$ & $\mathbf{( 3 )}$ & $\mathbf{( 4 )}$ & $\mathbf{( 5 )}$ \\
\hline GS-level & $\begin{array}{c}\text { Number of } \\
\text { Annual } \\
\text { Dispositions by } \\
\text { Examiners }\end{array}$ & $\begin{array}{c}\text { Mean } \\
\text { Number } \\
\text { of Hours } \\
\text { Assigned }\end{array}$ & $\begin{array}{c}\text { Extra } \\
\text { Hours } \\
\text { Needed to } \\
\text { Give GS- } \\
\mathbf{7 ~ H o u r s}\end{array}$ & $\begin{array}{c}\text { Examiner } \\
\text { Pay Per } \\
\text { Hour }\end{array}$ & $\begin{array}{c}\text { Extra Costs } \\
\text { to Giving GS- } \\
\text { 7 Hours }\end{array}$ \\
\hline GS-7 & 5,400 & 27.54 & 0 & 18.82 & \\
GS-9 & 17,100 & 23.91 & 62,073 & 23.02 & $\$ 1,428,920$ \\
GS-11 & 29,700 & 21.28 & 185,922 & 27.86 & $\$ 5,179,787$ \\
GS-12 & 46,200 & 19.20 & 385,308 & 33.39 & $\$ 12,865,434$ \\
GS-13 & 59,100 & 16.66 & 643,008 & 39.70 & $\$ 25,527,418$ \\
GS-13, partial & 40,500 & 15.46 & 489,240 & 39.70 & $\$ 19,422,828$ \\
signatory & 101,700 & 14.09 & $1,367,865$ & 46.92 & $\$ 64,180,226$ \\
GS-14 & 300,000 & - & $3,133,416$ & & $\$ 128,604,613$ \\
\hline Total & & & & & \\
\hline
\end{tabular}

Notes: This table assumes that the Patent Office disposes of 300,000 applications each year (where each request for a continued examination-RCE—-does not constitute a new disposal). This amount is consistent with the most recent information available on the Patent Office's current aggregate disposal counts. The distribution of dispositions per grade levels follows Table A1. The mean number of hours per grade is calculated over the whole PAIR sample after assigning hour allotments to each application in the PAIR database based on the associated patent class and examiner grade level. The examiner pay per hour assumes that the examiner is at Step 5 within the relevant grade and is based on the 2015 payscale. 


\section{TABLE A3: RELATIONSHIP BETWEEN EXAMINER GS LEVELS AND THE NUMBER OF TIMES INDIVIDUAL APPLICATIONS (OR INDIVIDUAL ISSUED PATENTS) ARE Asserted in Litigation: NEGATIVE BINOMIAL REGRESSION RESUlts}

\begin{tabular}{|c|c|c|c|c|c|c|}
\hline & (1) & (2) & (3) & (4) & (5) & (6) \\
\hline \multicolumn{7}{|l|}{$\begin{array}{l}\text { Incident Rate Ratios for: } \\
\text { (Omitted: GS-7) }\end{array}$} \\
\hline GS-9 & $\begin{array}{c}1.100 \\
(0.215)\end{array}$ & $\begin{array}{c}1.115 \\
(0.218)\end{array}$ & $\begin{array}{c}0.952 \\
(0.121)\end{array}$ & $\begin{array}{c}1.039 \\
(0.204)\end{array}$ & $\begin{array}{c}1.052 \\
(0.206)\end{array}$ & $\begin{array}{c}0.879 \\
(0.215)\end{array}$ \\
\hline GS-11 & $\begin{array}{l}1.742^{* * *} \\
(0.325)\end{array}$ & $\begin{array}{l}1.589 * * \\
(0.294)\end{array}$ & $\begin{array}{c}1.254 \\
(0.285)\end{array}$ & $\begin{array}{l}1.580 * * \\
(0.292)\end{array}$ & $\begin{array}{l}1.522^{* *} \\
(0.280)\end{array}$ & $\begin{array}{c}1.133 \\
(0.257)\end{array}$ \\
\hline GS-12 & $\begin{array}{c}2.048 * * * \\
(0.383)\end{array}$ & $\begin{array}{l}1.581^{* *} \\
(0.292)\end{array}$ & $\begin{array}{c}1.279 \\
(0.292)\end{array}$ & $\begin{array}{l}1.681 * * * \\
(0.312)\end{array}$ & $\begin{array}{l}1.520^{* *} \\
(0.281)\end{array}$ & $\begin{array}{c}1.114 \\
(0.253)\end{array}$ \\
\hline GS-13 & $\begin{array}{l}3.193^{* * *} \\
(0.550)\end{array}$ & $\begin{array}{l}2.272^{* * *} \\
(0.425)\end{array}$ & $\begin{array}{l}1.857^{* *} \\
(0.454)\end{array}$ & $\begin{array}{c}2.454^{* * *} \\
(0.420)\end{array}$ & $\begin{array}{l}2.177^{* * *} \\
(0.400)\end{array}$ & $\begin{array}{l}1.599^{*} \\
(0.393)\end{array}$ \\
\hline $\begin{array}{l}\text { GS-13 (with partial signatory } \\
\text { authority) }\end{array}$ & $\begin{array}{l}4.206^{* * *} \\
(0.898)\end{array}$ & $\begin{array}{l}2.377 * * * \\
(0.499)\end{array}$ & $\begin{array}{l}2.043^{* * *} \\
(0.511)\end{array}$ & $\begin{array}{l}2.893^{* * *} \\
(0.598)\end{array}$ & $\begin{array}{l}2.207 * * * \\
(0.452)\end{array}$ & $\begin{array}{l}1.733^{* *} \\
(0.430)\end{array}$ \\
\hline GS-14 & $\begin{array}{l}4.542^{* * *} \\
(0.798)\end{array}$ & $\begin{array}{c}2.387 * * * \\
(0.454)\end{array}$ & $\begin{array}{l}2.071^{* * *} \\
(0.493)\end{array}$ & $\begin{array}{c}2.955^{* * *} \\
(0.512)\end{array}$ & $\begin{array}{l}2.178^{* * *} \\
(0.410)\end{array}$ & $\begin{array}{l}1.630 * * \\
(0.385)\end{array}$ \\
\hline $\mathrm{N}$ & 1158689 & 1158689 & 990940 & 784947 & 785947 & 645573 \\
\hline Experience Group Dummies? & NO & YES & YES & NO & YES & YES \\
\hline $\begin{array}{l}\text { Examiner Cohort Fixed } \\
\text { Effects? }\end{array}$ & NO & YES & YES & NO & YES & YES \\
\hline $\begin{array}{l}\text { Examiner Tenure Group } \\
\text { Dummies? }\end{array}$ & NO & YES & YES & NO & YES & YES \\
\hline $\begin{array}{l}\text { Technology-by-Year Fixed } \\
\text { Effects and Application } \\
\text { Covariates? }\end{array}$ & NO & NO & YES & NO & NO & YES \\
\hline Unit of Observation & $\begin{array}{l}\text { Applica- } \\
\text { tion }\end{array}$ & $\begin{array}{l}\text { Applica- } \\
\text { tion }\end{array}$ & $\begin{array}{l}\text { Applica- } \\
\text { tion }\end{array}$ & $\begin{array}{l}\text { Issued } \\
\text { Patent }\end{array}$ & $\begin{array}{l}\text { Issued } \\
\text { Patent }\end{array}$ & $\begin{array}{l}\text { Issued } \\
\text { Patent }\end{array}$ \\
\hline \multicolumn{7}{|c|}{$\begin{array}{l}{ }^{*} \text { significant at } 10 \% ;{ }^{* *} \text { significant at } 5 \% ;{ }^{* *} \text { significant at } 1 \% \text {. Standard errors are reported in parentheses and are clustered } \\
\text { to correct for autocorrelation within given examiners over time. Each observation in Columns } 1-3 \text { is a given application from } \\
\text { the PAIR database that reached a final disposition and that was published in the PAIR records between March, } 2001 \text { and July, } \\
2012 \text {. Each observation in Columns } 4-6 \text { is from a subset of those applications that ultimately issued as patents. Each negative } \\
\text { binomial regression includes an exposure variable equal to the difference between } 2014 \text { (when the Lex Machina litigation data } \\
\text { was collected) and the year of disposition. Technology-by-year effects are based on the } 37 \text { Hall et al. (2001) technology sub- } \\
\text { categories. Cohort fixed effects are based on the first year in which the relevant examiner joined the Patent Office, based on } \\
\text { historical rosters. Tenure group dummies capture the extent of the examiner's maximum experience level with the Patent } \\
\text { Office: } 0-3,4-6,7-9,10-12 \text {, or } 13-15 \text { years. }\end{array}$} \\
\hline
\end{tabular}


TABLE A4: SimUlated REDUCTION IN LiTIGATION EXPENSES AsSOCiATED WITH GIVING All EXAMiners the NuMBER OF HOURS AlLOCATED TO GS-7 EXAMINERS FOR ONE YEAR OF APPLICATIONS (ASSUMING CASES END IN DISCOVERY AND AMOUNTS IN CONTROVERSY $<\$ 1 \mathrm{MM})$

\begin{tabular}{|c|c|c|c|c|c|}
\hline & (1) & (2) & (3) & (4) & (5) \\
\hline \multirow[b]{2}{*}{$\begin{array}{l}\text { GS- } \\
\text { level }\end{array}$} & \multirow[b]{2}{*}{$\begin{array}{c}\text { Number of } \\
\text { Annual } \\
\text { Dispositions } \\
\text { by } \\
\text { Examiners }\end{array}$} & \multirow[b]{2}{*}{$\begin{array}{c}\text { Decrease in } \\
\text { Number of } \\
\text { Patent Cases } \\
\text { per } \\
\text { Application }\end{array}$} & \multirow[b]{2}{*}{$\begin{array}{c}\text { Decrease } \\
\text { (Increase) in } \\
\text { Future } \\
\text { Number of } \\
\text { Application- } \\
\text { Case Pairs }\end{array}$} & \multicolumn{2}{|c|}{$\begin{array}{c}\text { Decrease } \\
\text { (Increase) in } \\
\text { Future } \\
\text { Litigation } \\
\text { Costs: }\end{array}$} \\
\hline & & & & $\begin{array}{c}\text { Defense } \\
\text { Costs Only }\end{array}$ & $\begin{array}{l}\text { Defense and } \\
\text { Plaintiff } \\
\text { Costs } \\
\text { (Assuming } \\
\text { Equal) }\end{array}$ \\
\hline GS-7 & 5,400 & 0 & 0 & 0 & 0 \\
\hline GS-9 & 17,100 & $(0.0002)$ & (2.662) & $(\$ 522,560)$ & $(\$ 1,045,120)$ \\
\hline GS-11 & 29,700 & 0.0008 & 24.467 & $\$ 4,802,743$ & $\$ 9,605,486$ \\
\hline GS-12 & 46,200 & 0.0009 & 41.805 & $\$ 8,206,262$ & $\$ 16,412,524$ \\
\hline GS-13 & 59,100 & 0.0028 & 164.269 & $\$ 32,245,382$ & $\$ 64,490,764$ \\
\hline $\begin{array}{c}\text { GS-13, } \\
\text { partial } \\
\text { signato } \\
\text { ry }\end{array}$ & 40,500 & 0.0034 & 137.002 & $\$ 26,892,957$ & $\$ 53,785,914$ \\
\hline GS-14 & 101,700 & 0.0035 & 353.263 & $\$ 69,344,121$ & $\$ 138,688,242$ \\
\hline Total & 300,000 & - & 718.144 & $\$ 160,597,488$ & $\$ 321,194,976$ \\
\hline
\end{tabular}

Notes: This table assumes that the Patent Office disposes of 300,000 applications each year (where each request for a continued examination-RCE—does not constitute a new disposal). This amount if consistent with the most recent information available on the Patent Office's current aggregate disposal counts. The distribution of dispositions per grade levels follows Table A1. Figures in Column 2 are derived from the incident rate ratio results from Table A3 and account for the mean number of cases per application among GS-7 examiners. Litigation expense information is from the 2013 Annual Survey of the American Intellectual Property Law Association (AIPLA). Results from Columns 2 and 3 determine the reduction in application-case pairs, as distinct from the number of cases themselves, considering that patent cases generally have multiple patents at issue in each case. Litigation costs from the AIPLA, which are reported on a per case basis, are thus scaled by the mean number of patents per case (2.37), which we obtained from Ashtor et al. (2014). 


\section{Examiner Experience Analysis}

.TABLE A5. RELATIONSHIP BETWEEN GRANT RATES AND EXPERIENCE LEVELS of the Associated PATENT ExAMINER, INCLUDing YEAR EFFECTS, COHORT EFFECTS AND TENURE EFFECTS

\begin{tabular}{|c|c|c|c|c|c|}
\hline & (1) & (2) & (3) & (4) & (5) \\
\hline \multicolumn{6}{|c|}{ Omitted: 0-1 Years Experience } \\
\hline 2-3 Years Experience & $\begin{array}{c}0.120 * * * \\
(0.005)\end{array}$ & $\begin{array}{l}0.124^{* * *} \\
(0.006)\end{array}$ & $\begin{array}{c}0.094^{* * *} \\
(0.006)\end{array}$ & $\begin{array}{l}0.090 * * * \\
(0.005)\end{array}$ & $\begin{array}{c}0.073^{* * *} \\
(0.004)\end{array}$ \\
\hline 4-5 Years Experience & $\begin{array}{c}0.187 * * * \\
(0.006)\end{array}$ & $\begin{array}{c}0.185^{* * *} \\
(0.007)\end{array}$ & $\begin{array}{c}0.119 * * * \\
(0.009)\end{array}$ & $\begin{array}{c}0.102^{* * *} \\
(0.007)\end{array}$ & $\begin{array}{c}0.077^{* * *} \\
(0.006)\end{array}$ \\
\hline 6-7 Years Experience & $\begin{array}{c}0.247 * * * \\
(0.006)\end{array}$ & $\begin{array}{c}0.233^{* * * *} \\
(0.009)\end{array}$ & $\begin{array}{c}0.135^{* * * *} \\
(0.014)\end{array}$ & $\begin{array}{l}0.100 * * * \\
(0.009)\end{array}$ & $\begin{array}{c}0.072^{* * *} \\
(0.007)\end{array}$ \\
\hline 8-9 Years Experience & $\begin{array}{c}0.281^{* * *} \\
(0.007)\end{array}$ & $\begin{array}{l}0.264^{* * *} \\
(0.010)\end{array}$ & $\begin{array}{c}0.136^{* * *} \\
(0.019)\end{array}$ & $\begin{array}{c}0.088^{* * *} \\
(0.012)\end{array}$ & $\begin{array}{c}0.057 * * * \\
(0.009)\end{array}$ \\
\hline $\begin{array}{l}\text { 10-11 Years } \\
\text { Experience }\end{array}$ & $\begin{array}{c}0.306^{* * *} \\
(0.007)\end{array}$ & $\begin{array}{c}0.292^{* * * *} \\
(0.012)\end{array}$ & $\begin{array}{c}0.135^{* * *} \\
(0.024)\end{array}$ & $\begin{array}{c}0.079^{* * * *} \\
(0.015)\end{array}$ & $\begin{array}{c}0.045^{* * *} \\
(0.010)\end{array}$ \\
\hline $\begin{array}{l}\text { 12-13 Years } \\
\text { Experience }\end{array}$ & $\begin{array}{c}0.324 * * * \\
(0.008)\end{array}$ & $\begin{array}{c}0.316^{* * * *} \\
(0.014)\end{array}$ & $\begin{array}{c}0.124^{* * *} \\
(0.030)\end{array}$ & $\begin{array}{c}0.061^{* * * *} \\
(0.019)\end{array}$ & $\begin{array}{c}0.027^{* * *} \\
(0.012)\end{array}$ \\
\hline 14+ Years Experience & $\begin{array}{c}0.335^{* * *} \\
(0.011)\end{array}$ & $\begin{array}{c}0.344^{* * *} \\
(0.017)\end{array}$ & $\begin{array}{c}0.107 * * * \\
(0.037)\end{array}$ & $\begin{array}{c}0.033 \\
(0.024)\end{array}$ & $\begin{array}{l}-0.001 \\
(0.015)\end{array}$ \\
\hline $\mathrm{N}$ & 1170869 & 1170869 & 1170869 & 1158689 & 1158689 \\
\hline $\begin{array}{l}\text { Year Fixed Effects? } \\
\text { (Year of } \\
\text { Disposition) }\end{array}$ & YES & YES & YES & YES & YES \\
\hline $\begin{array}{r}\text { Examination Tenure } \\
\text { (Max Experience) } \\
\text { Group Dummies? }\end{array}$ & NO & YES & YES & YES & NO \\
\hline $\begin{array}{l}\text { Examiner Cohort } \\
\text { Dummies? (First } \\
\text { Year at Patent } \\
\text { Office) }\end{array}$ & NO & NO & YES & YES & NO \\
\hline $\begin{array}{l}\text { Examiner GS Level } \\
\text { Dummies? }\end{array}$ & $\mathrm{NO}$ & NO & NO & YES & YES \\
\hline $\begin{array}{l}\text { Examiner Fixed } \\
\text { Effects? }\end{array}$ & NO & NO & NO & NO & YES \\
\hline \multicolumn{6}{|c|}{$\begin{array}{l}\text { * significant at } 10 \% ;{ }^{* *} \text { significant at } 5 \% ; * * * \text { significant at } 1 \% \text {. Standard errors are reported in } \\
\text { parentheses and are clustered to correct for autocorrelation within given examiners over time. } \\
\text { Each observation is a given application from the PAIR database that reached a final disposition and } \\
\text { that was published in the PAIR records between March, } 2001 \text { and July, } 2012 \text {. Examiner tenure } \\
\text { effects are organized in the following groups: } 0-3 \text { years, } 4-6 \text { years, } 7-10 \text { years, } 11-13 \text { years, or } 14- \\
15 \text { years. }\end{array}$} \\
\hline
\end{tabular}


Additional notes regarding Table A5: to better capture tenure effects, we also estimate specifications that condition the sample on those observations reviewed by examiners that left the office prior to the end of the sample period. While we have omitted these findings for the purposes of brevity, the results from this alternative exercise mirror those presented in Table A5. While we omitted the estimated coefficients for the cohort dummies and tenure group dummies in Table A5, we present such coefficients in Figures $A 1$ and $A 2$, where such effects are derived from the specification in Column 4 in Table A5, in which we control simultaneously for cohort, tenure, year and grade-level effects.

Figure A1: Estimated Cohort Effects from Regression of Grant Rates on Cohort Effects, Year Effects, Tenure Effects, Grade-Level Groups and Examiner Experience Groups

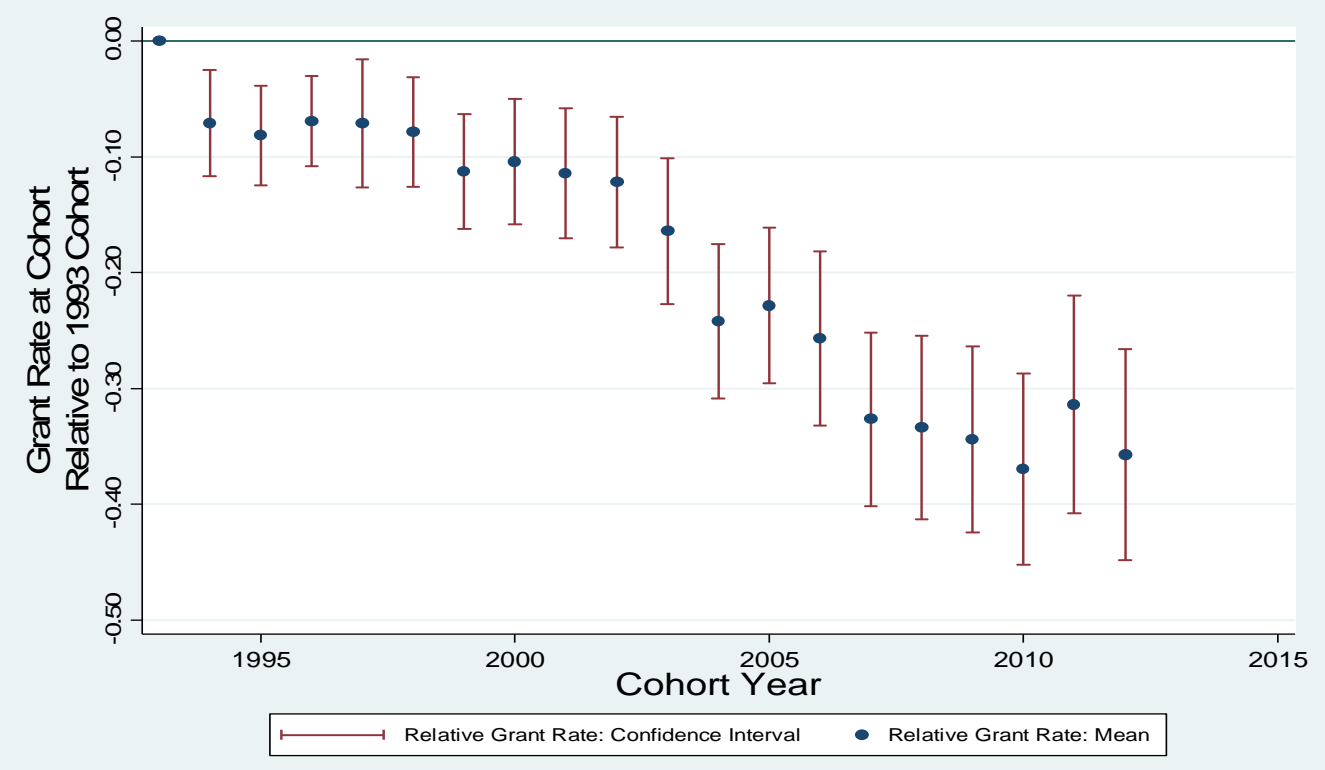

Notes: this figure presents estimated coefficients of the cohort year dummies from the specification estimated in Column 4 of Table A5. 
Figure A2: Estimated Tenure Effects from Regression of Grant Rates on Cohort Effects, Year Effects, Tenure Effects, Grade-Level Groups and Examiner Experience Groups

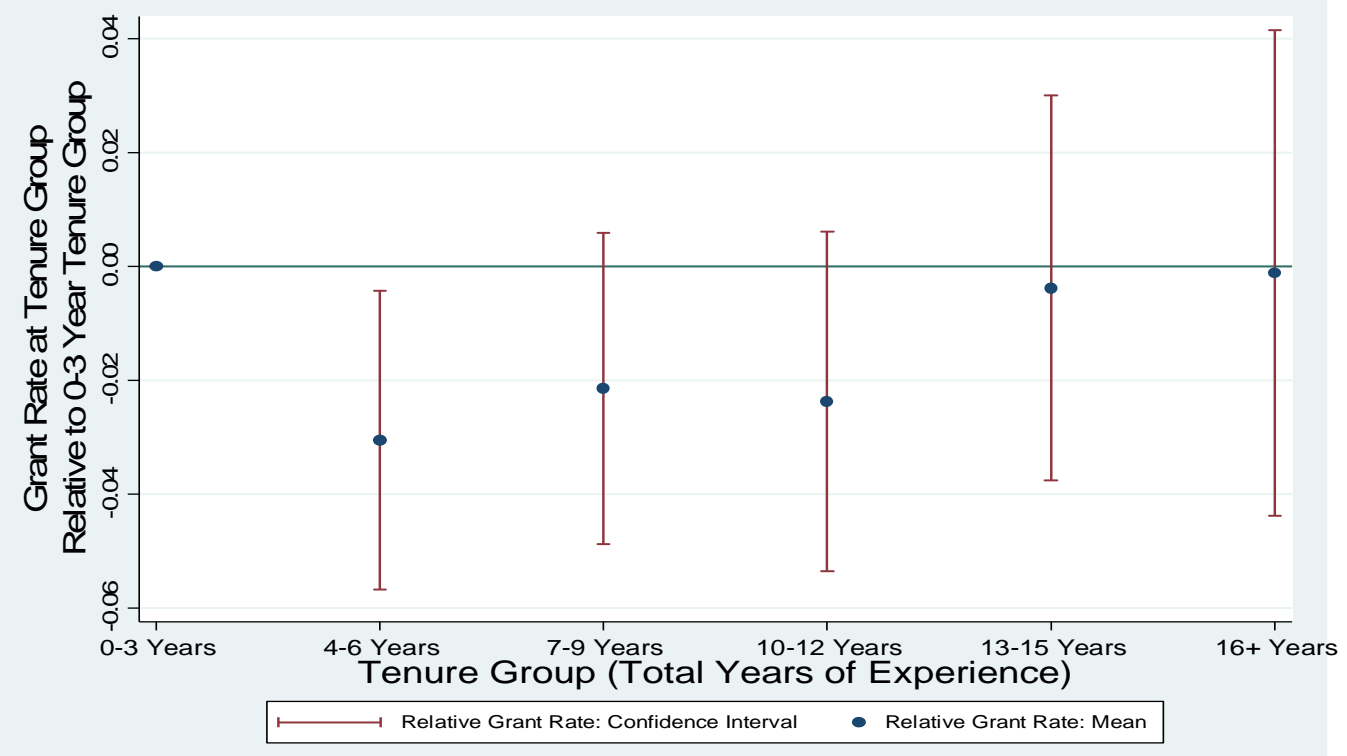

Notes: this figure presents estimated coefficients of the tenure group dummies from the specification estimated in Column 4 of Table A5. 


\section{E. Additional Robustness Checks}

Examination Duration Imbalance. Given that we only observe applications filed after March 2001, one may also be concerned that applications reaching a final disposition in the early years in the sample will be disproportionately comprised of quicker moving applications, whereas those observed in the later years in the sample represent a richer mix of quick- and slow-moving applications. This may be of consequence considering that prosecution durations may impact grant rates due to the higher likelihood of applicants abandoning their applications during long durations. However, an increased incidence of longer-duration prosecution periods later in the sample does not necessarily confound the above analysis considering (1) the imposition of year fixed effects to capture any general trends in granting practices over the sample, (2) that we observe overlapping cohorts of examiners, in which event examiners are moving among each of the various grade (and experience) levels during every year of the sample and (3) that controls are available for the time between filing and disposition of each application. Nonetheless, to more comprehensively address any inconsistency in the set of applications under investigation, we also estimate an alternative specification in which we begin the period of observation in 2004 and confine the sample of applications to those that are disposed of within a three-year period. By focusing only on applications of limited prosecution duration, we ensure consistency in the relative mix of application durations observed. ${ }^{8}$ In Figure A3, we demonstrate that the above results are likewise robust to this alternative sampling approach.

$8 \quad$ Of course, imposing this duration limitation forces us to exclude 2002 and 2003 as there will be few applications disposed of in these years that fall near the 3-year duration mark, despite the fact that we would observe more of such applications in the later sample years, which could otherwise undercut the balancing impulse of this exercise. 
Figure A3: Relationship between Examiner GS-Level and Grant Rates, Restricted Duration-Window Approach

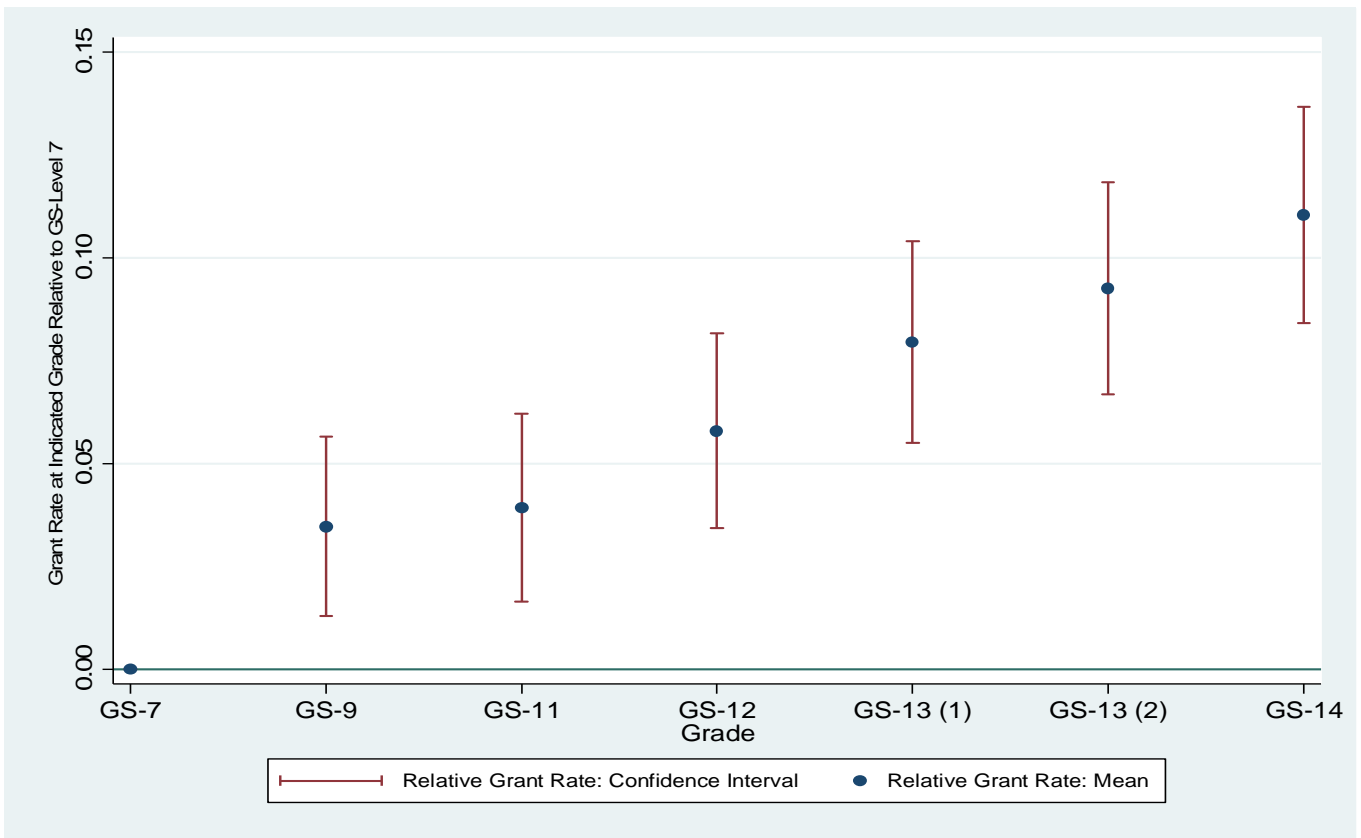

Notes: this figure presents estimated coefficients of a regression of the incidence of the application being granted on a set of dummy variables capturing the incidence of the relevant examiner falling into each general schedule pay grade. This figure also includes year fixed effects and examiner fixed effects. The sample is limited to those applications that reach a disposition within three years from filing and that were filed in 2004 and beyond. Standard errors are clustered at the examiner level. 
RCE Controls. As demonstrated by Figure A4, the results are also robust to the inclusion of a control for the incidence of a request-for-continued examination (RCE) associated with the application, which is a device used by applicants to continue the examination process in the face of an examiner's final rejection. Given the tendency of RCEs to prolong the examination process, it is not surprising that the percentage of an examiner's dispositions that involve an RCE filing will grow with experience. With this in mind, one may be concerned that grant rates may rise with experience and/or promotions given the possibility that continuation devices such as RCE filings increase the ultimate chances that the underlying application will be allowed. Alleviating this concern, we find that the estimated pattern of results persists (though with slightly smaller magnitudes) when controlling for the incidence of an RCE filing in the underlying application and, alternatively, when conditioning the analysis on those applications without an RCE filing. The results remain essentially unchanged with alternative parameterizations of these RCE controls (available upon request), including those that count the total number of RCEs employed (as distinct from the incidence of any RCE presence) and those that include separate dummy variables capturing different bins of RCE counts.

Figure A4: Relationship between Examiner GS-Level and Grant Rates, Controlling for the Incidence of a Request for Continued Examination

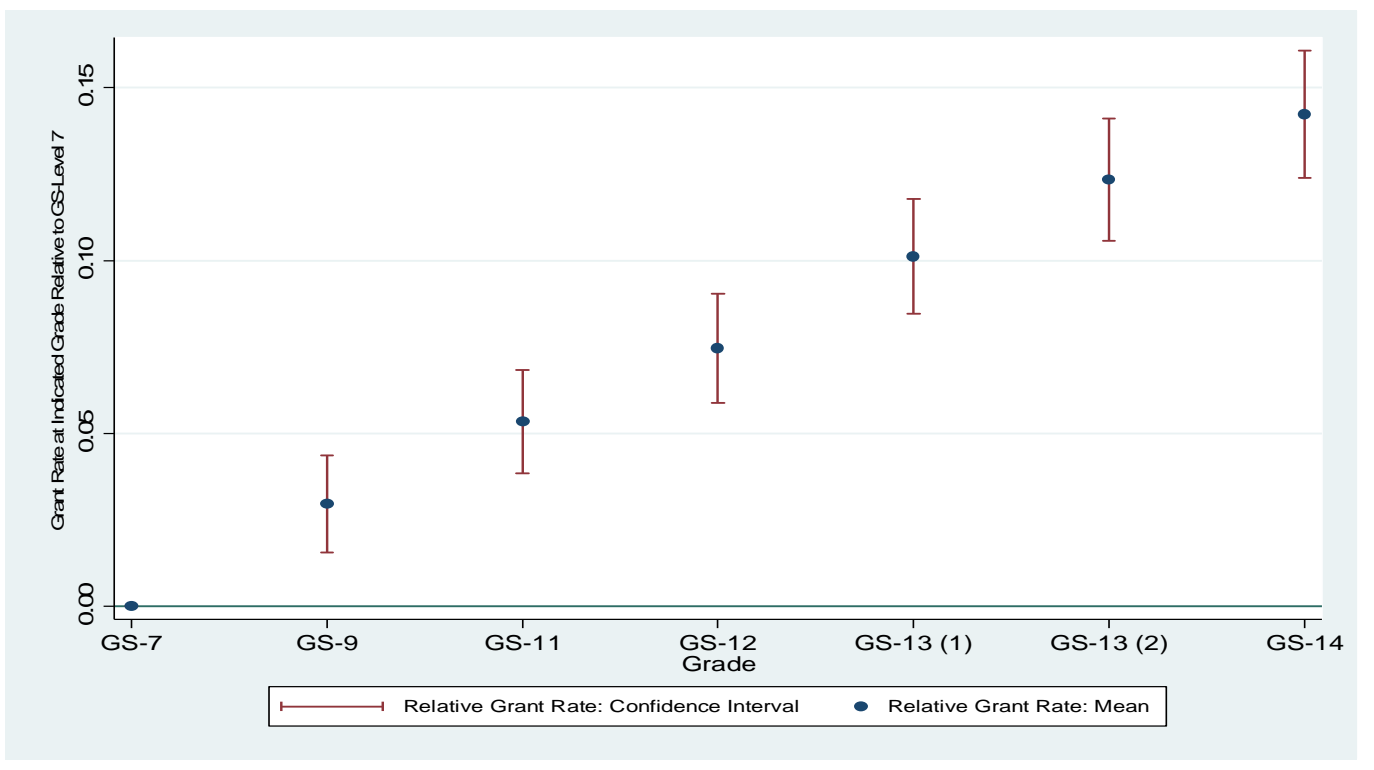

Notes: the specification underlying this figure replicates that of Figure 1, except that it includes a control for the incidence of the application undergoing at least one Request for Continued Examination. 
Additional Robustness Checks on Specifications that Nest Experience Years within Grade Levels

Figure A5: Relationship between Grant Rates and Experience Years within Distinct Grade Levels, Including GS-15

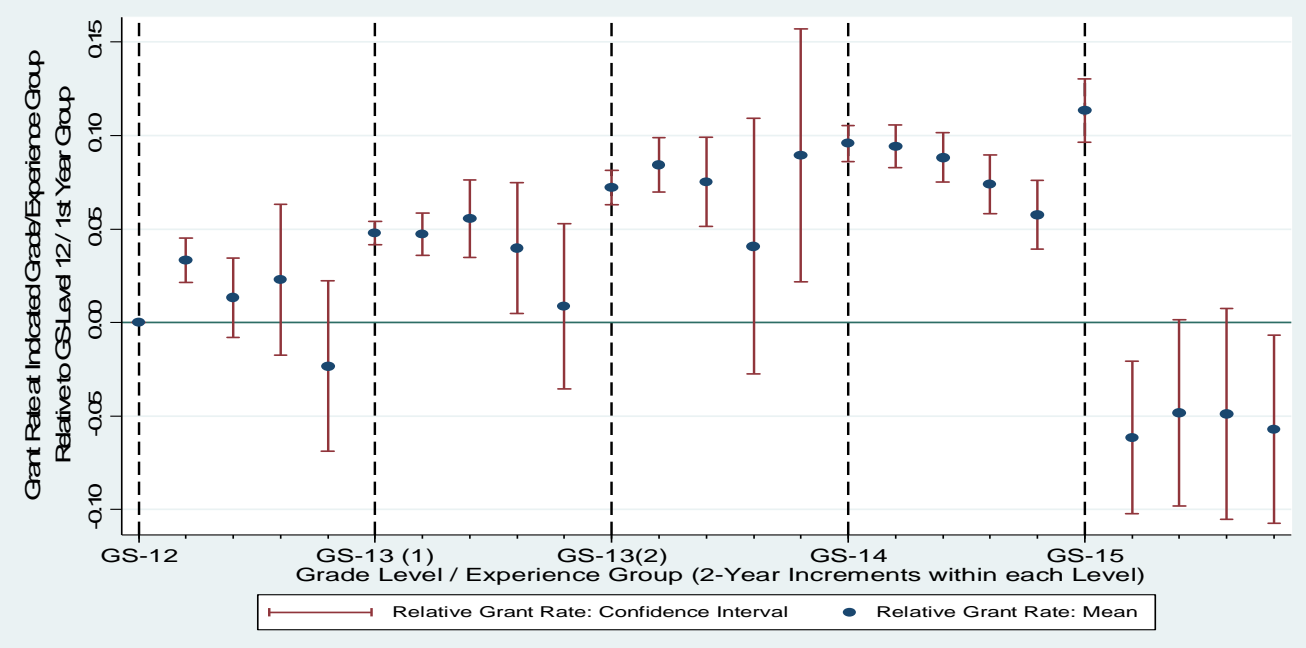

Notes: this figure replicates that of Figure 3 in the text except that it includes examiners at GS-15.

Figure A6: Relationship between Grant Rates and Experience Years within Distinct Grade Levels, Including GS-15 and Conditional on Examiner Starting at least Below GS-12 During Sample Window

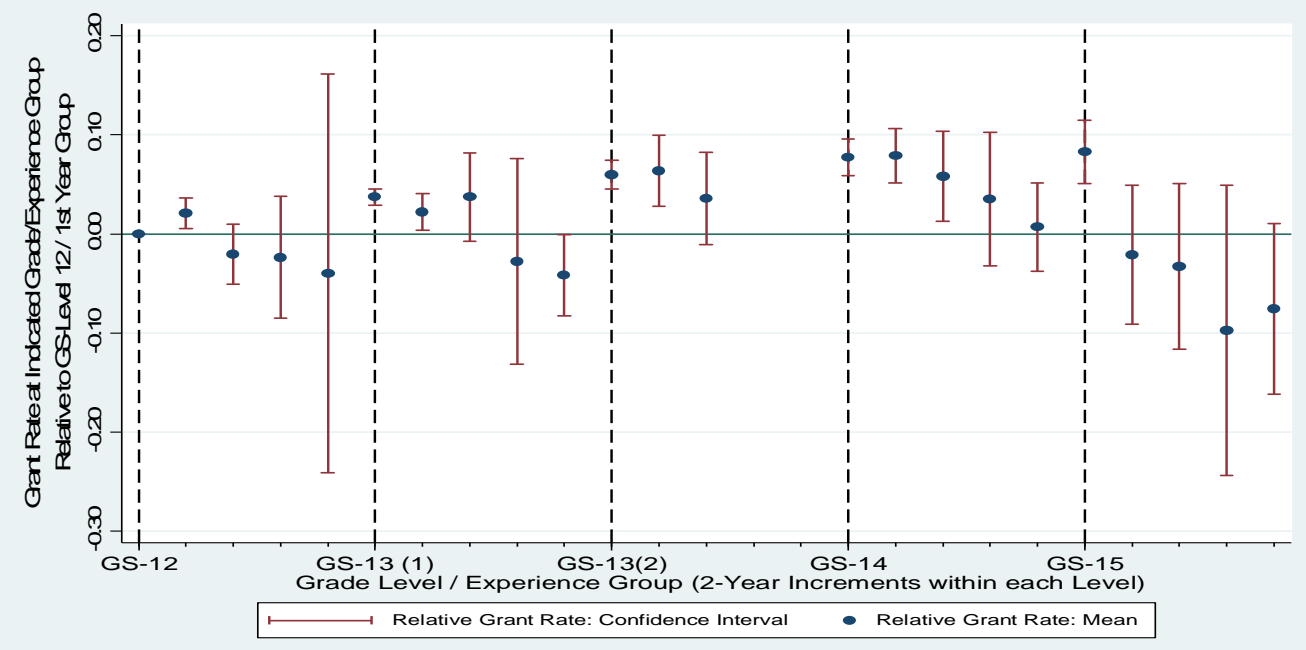

Notes: this figure replicates that of Figure A5 except that it excludes examiners that start the sample period at GS-12 and higher (that is, it excludes those examiners whose pre-sample-period tenures within the relevant grade are unobservable). Within this restricted sample, there are no observations (and thus no reported results) for examiners in the $4^{\text {th }}$ and $5^{\text {th }}$ period groups within the second GS-13 category. 
Figure A7: Relationship between Obviousness Rejection Rate and Experience Years within Distinct Grade Levels, Conditional on Examiner Starting at least Below GS-12 During Sample Window

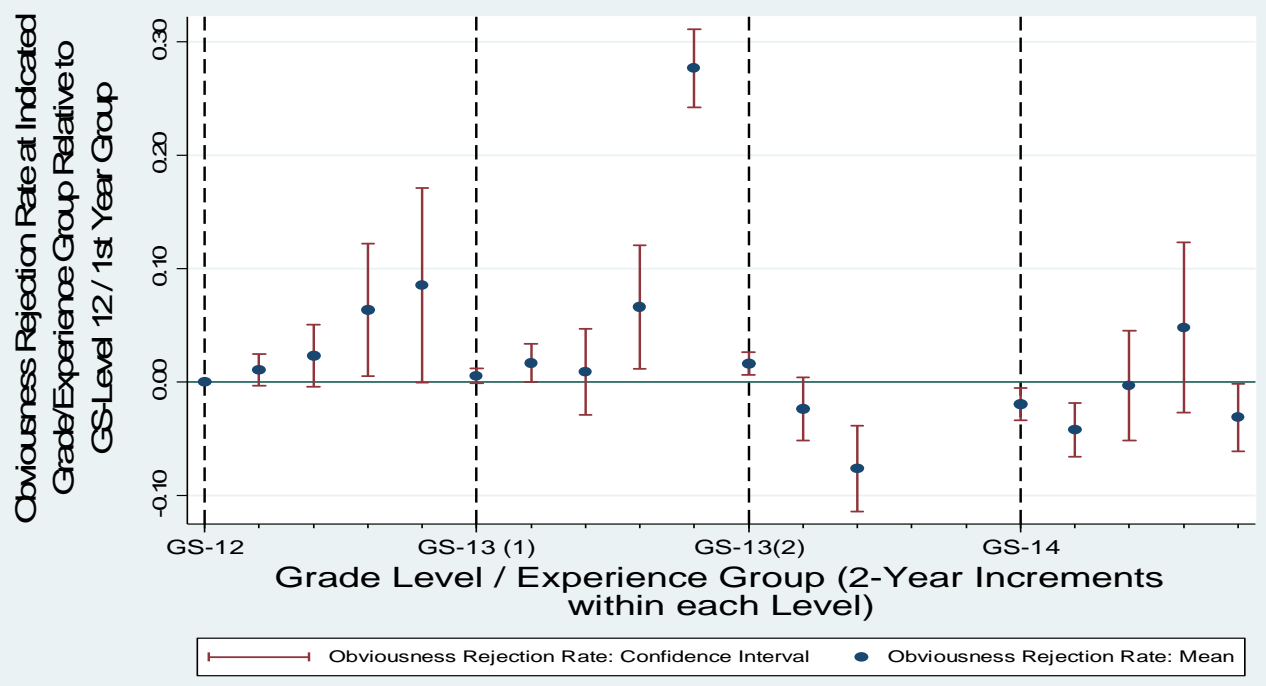

Notes: this figure replicates that of Figure 6, except that it excludes examiners that start the sample period at GS-12 and higher (that is, it excludes those examiners whose pre-sample-period tenures within the relevant grade are unobservable). Within this restricted sample, there are no observations (and thus no reported results) for examiners in the $4^{\text {th }}$ and $5^{\text {th }}$ period groups within the second GS-13 category.

Figure A8: Relationship between Obviousness Rejection Rate and Experience Years within Distinct Grade Levels, Including GS-15 Examiners

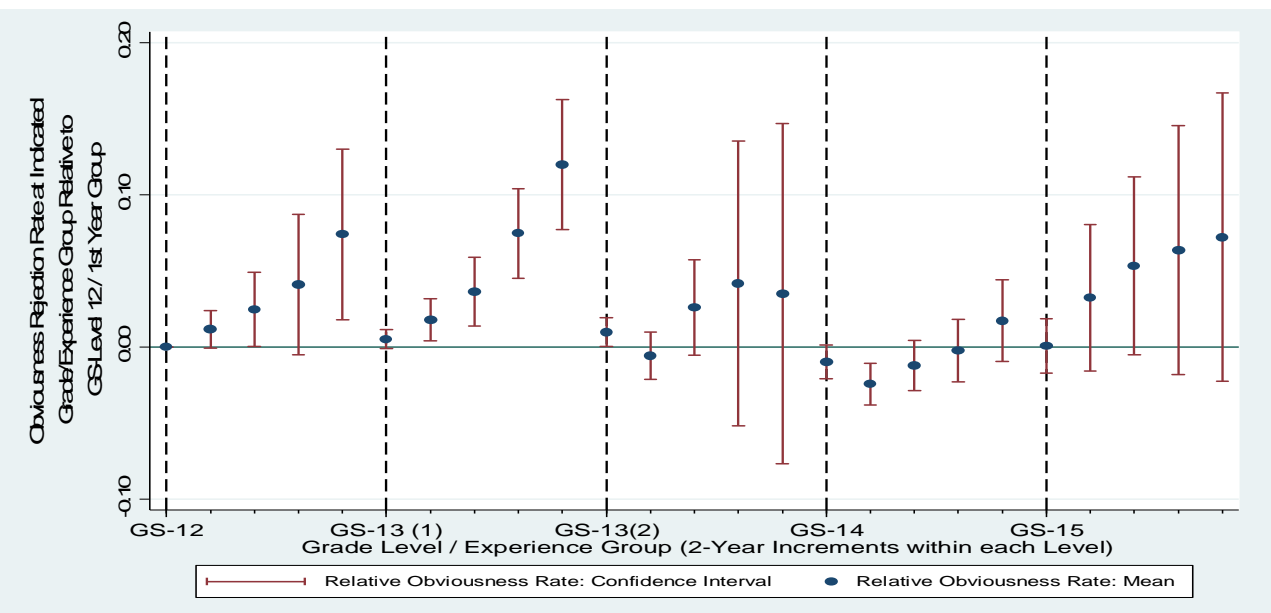

Notes: this figure replicates that of figure 6 except that it includes GS-15 examiners. 
Figure A9: Relationship between Obviousness Rejection Rate and Experience Years within Distinct Grade Levels, Including GS-15 and Conditional on Examiner Starting at least Below GS-12 During Sample Window

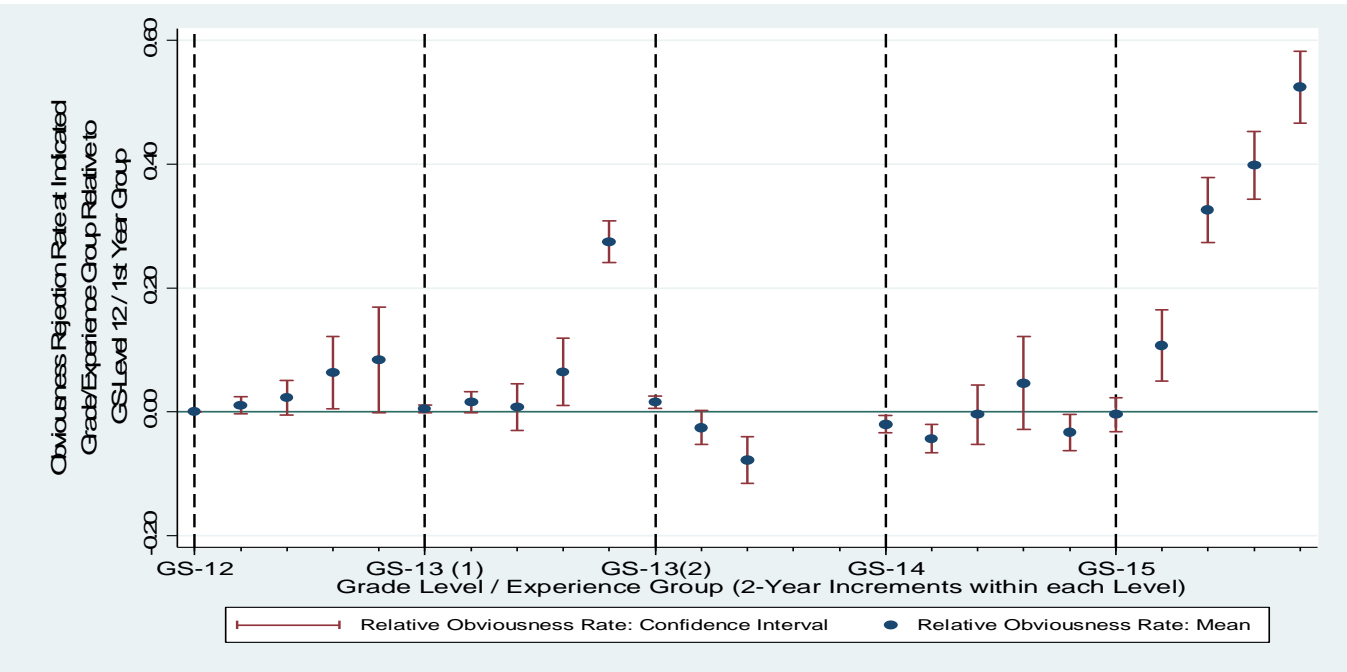

Notes: this figure replicates that of Figure A8, except that it excludes examiners that start the sample period at GS-12 and higher (that is, it excludes those examiners whose pre-sample-period tenures within the relevant grade are unobservable). Within this restricted sample, there are no observations (and thus no reported results) for examiners in the $4^{\text {th }}$ and $5^{\text {th }}$ period groups within the second GS-13 category. 


\section{Graphs of Relationship between Each Rejection Type and GS-Level}

Figure A10: Relationship between Incidence of each of Section 101, Section 102, Section 103 and Section 112 Rejections and Examiner GS-Level (Percentage Results)

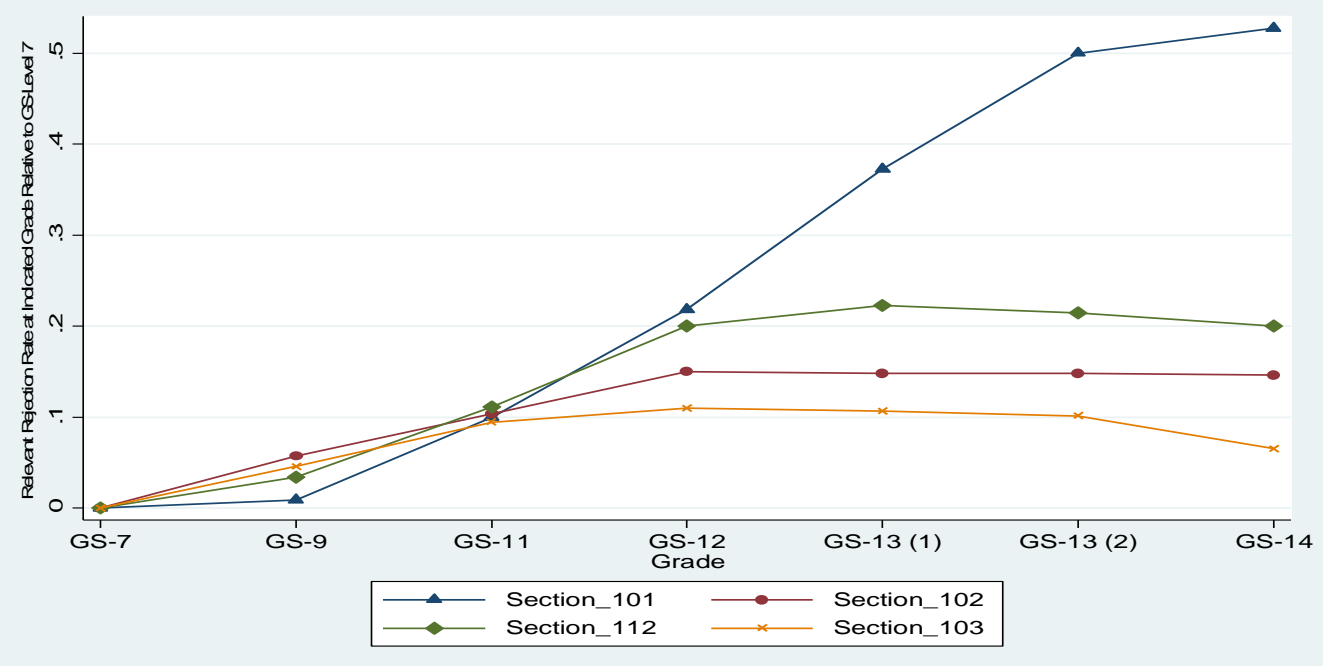

Notes: each line represents the estimated mean coefficients of a separate regression of the incidence of the indicated rejection type on set of dummy variables capturing the incidence of the relevant examiner falling into each general schedule pay grade. Coefficients are scaled by the mean incidence of each rejection type to facilitate an interpretation of this trend in percentage terms. This figure also includes year fixed effects and examiner fixed effects.

Figure A11: Relationship between Incidence of each of Section 101, Section 102, Section 103 and Section 112 Rejections and Examiner GS-Level (Percentage Results), Controlling for Application Characteristics and Technology-by-Year Fixed Effects

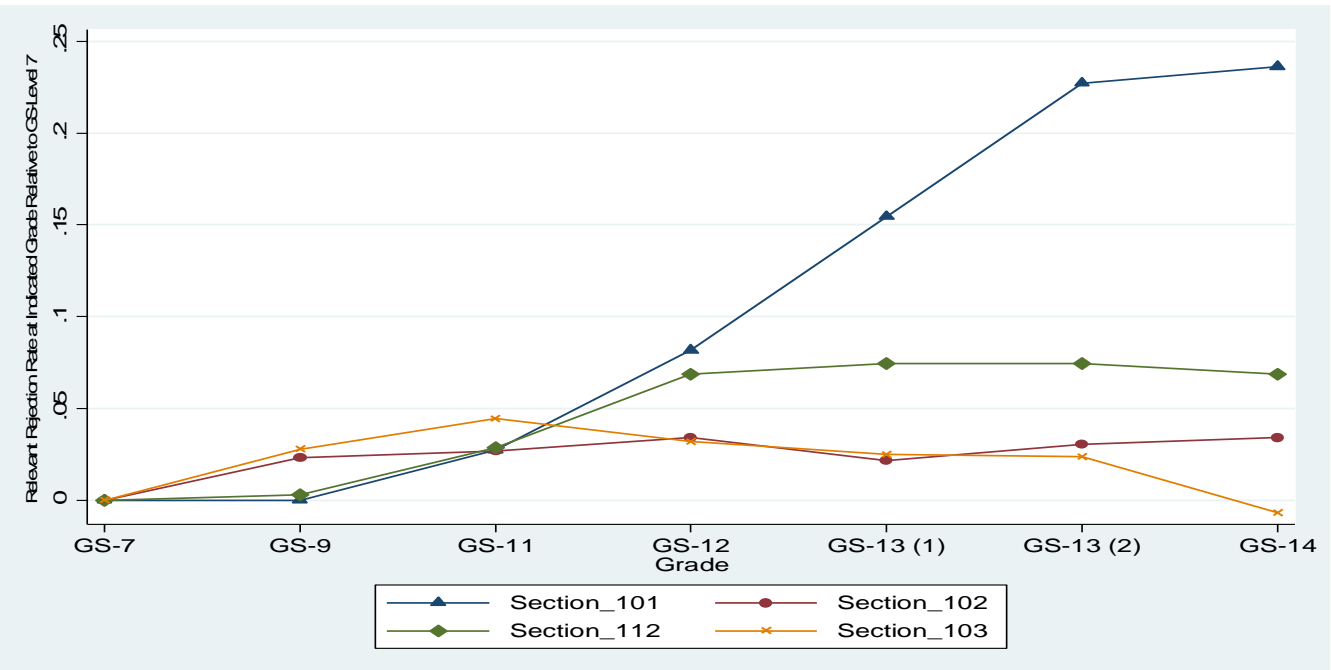

Notes: this figure replicates that of Figure A10, but it includes controls for application entity size, prosecution duration (and its square), and foreign priority, along with a full set of technology-by-year fixed effects. 
Figure A12: Relationship between Incidence of each of Section 101, Section 102, Section 103 and Section 112 Rejections and Examiner GS-Level (Percentage-Point Results), Controlling for Application Characteristics and Technology-by-Year Fixed Effects

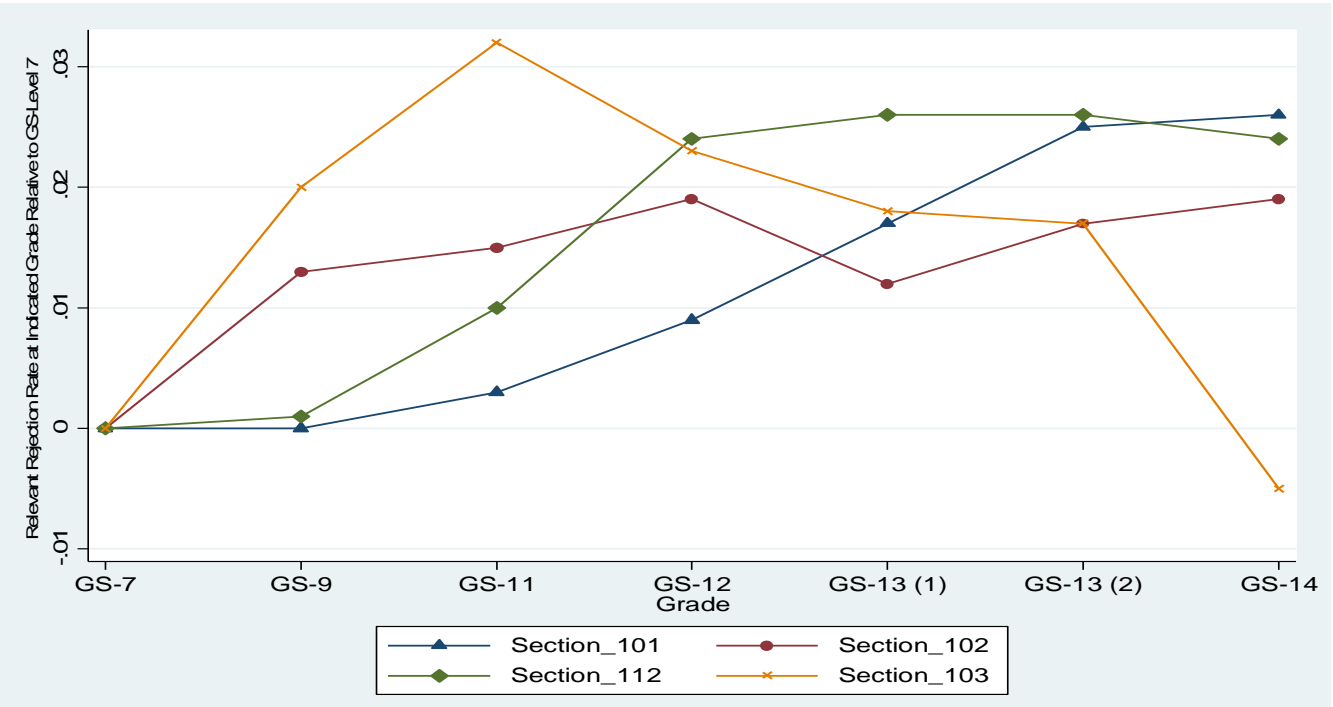

Notes: this figure replicates that of Figure A11, but it does not scale the coefficients by the mean incidence of the relevant rejection. 


\section{Prior Art Citation Figures}

Figure A13: Relationship between Number of Applicant-Provided Citations in Final Patents (Logged) and Examiner GS-Level

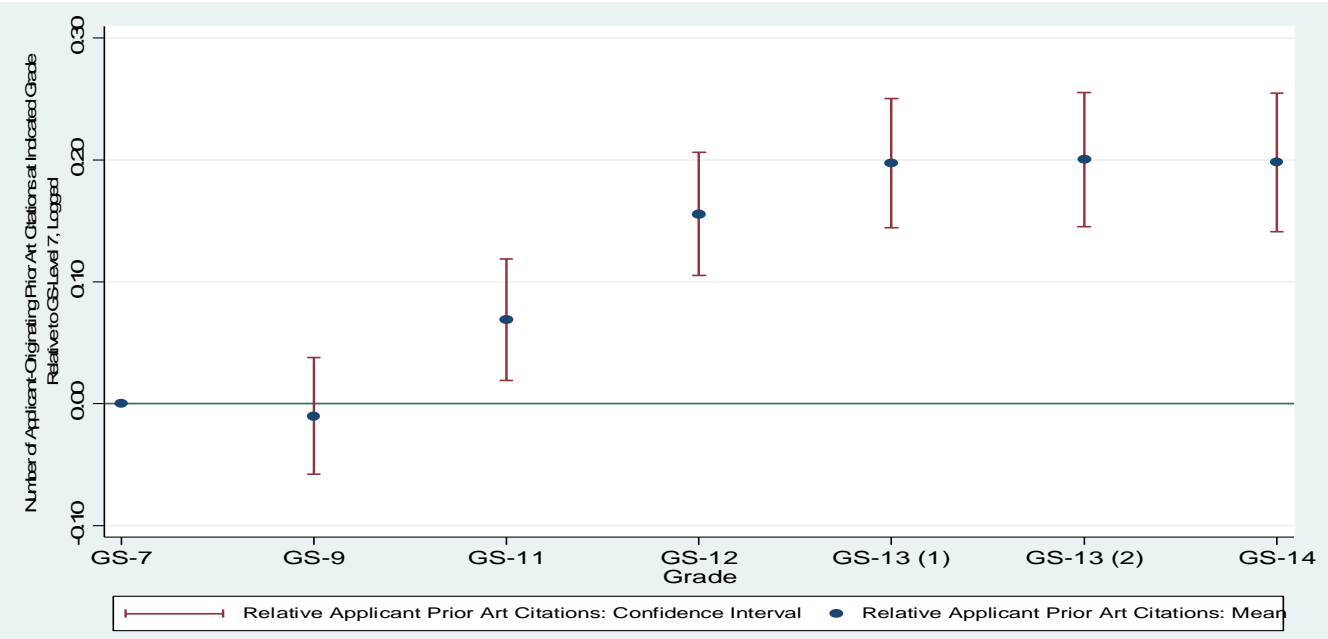

Notes: this figure presents estimated coefficients of a regression of the number of applicant-provided citations (logged) on a set of dummy variables capturing the incidence of the relevant examiner falling into each general schedule pay grade. This figure also includes year fixed effects and examiner fixed effects. Standard errors are clustered at the examiner level.

Figure A14: Relationship between Number of Examiner-Provided Citations in Final Patents (Logged) and Examiner GS-Level

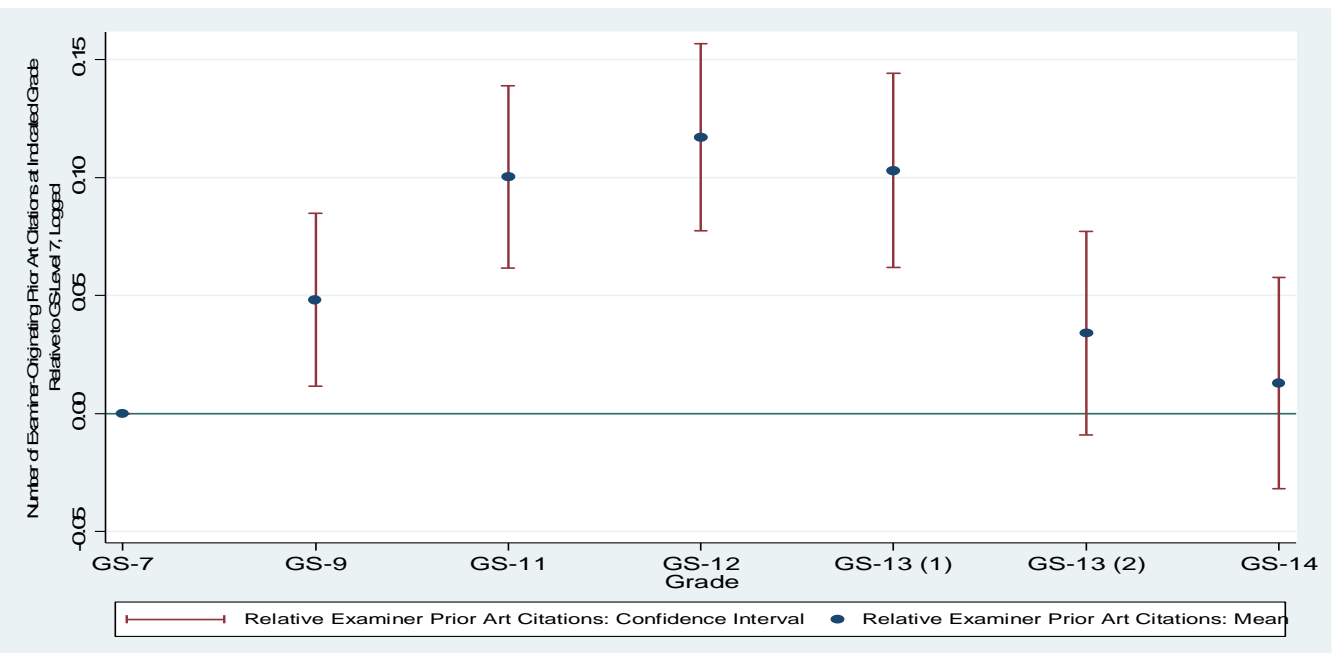

Notes: this figure replicates that of Figure A13 except that the dependent variable is the number of examiner-provided citations (logged). 


\section{Treatment of Examiners who Leave Agency and Return}

We note that 5 percent of the examiners in our sample left the Agency at some point only to return at a later point in time. With the possibility that this hiatus from the Agency may disrupt the learning / interruption story hypothesized in the text, we estimate alternative specifications that simply drop these examiners. The results are virtually identical in this alternative specification (results available upon request from the authors).

\section{Balanced Sample Analysis (Cont'd)}

Estimating balanced-sample counterparts to Figure 3 (which follows examiners over the course of years within grade levels from GS-12 to GS-14) is tricky insofar as it is not possible to follow individual examiners over the entire course of many years set forth in the figure given that (1) we are only following examiners over a 10-year period, as opposed to the longer period implicitly depicted in Figure 3 and (2) it is rare to find an examiner that stayed for a long period of time in every single grade. In Figure 4, we take a step in the direction of achieving better balance by focusing only on those examiners that at least stared the sample period prior to GS-12. As such, Figure 4 avoids drawing information from examiners that start our sample in the middle of the hypothetical trajectory set forth in the figure. In Figure A15, we take this one step further and condition the analysis on those examiners that at least start prior to GS-12 and that at least ascend to GS-14 during our sample window. The pattern previously demonstrated of declines in grant rates over the temporal dimension to this graph and of jumps in grant rates upon promotion is generally maintained over this restricted sample. 
Figure A15: Relationship between Grant Rate and Increases in Experience Years within Distinct Grade Levels, Conditional on Examiner Starting at least Below GS-12 and Rising to GS-14 During Sample Window

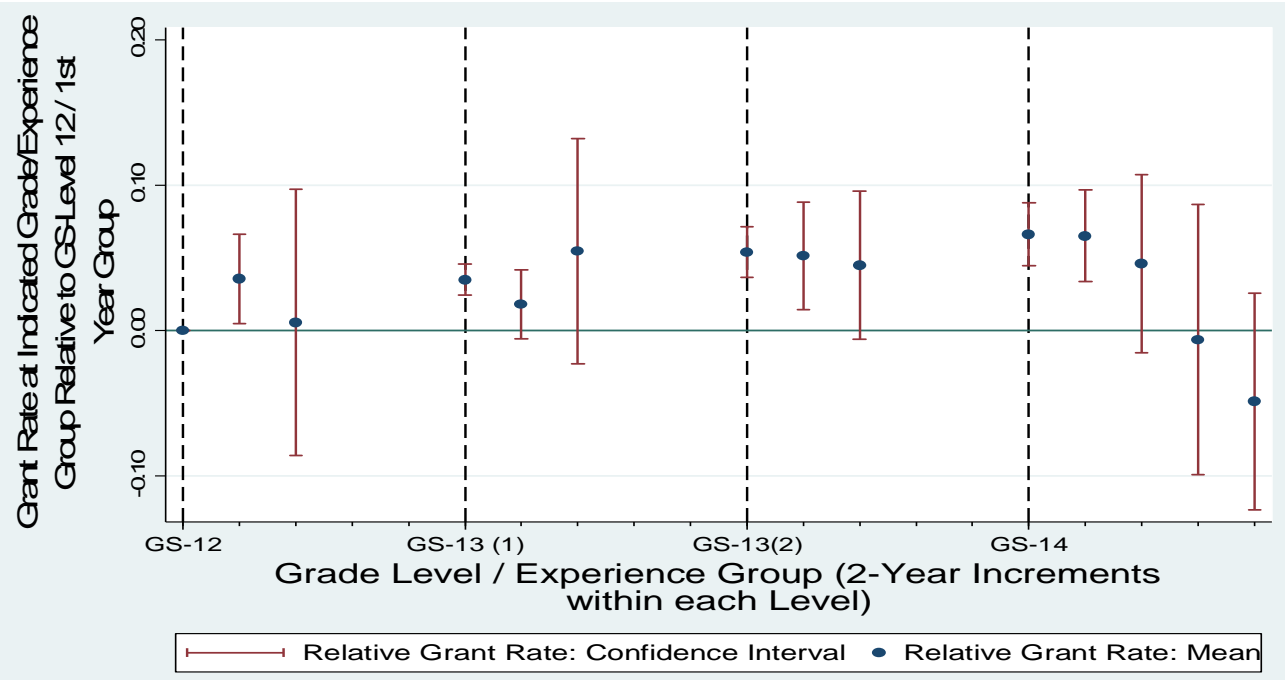

Notes: this figure replicates that of Figure 4, except that it further conditions the sample to those applications reviewed by examiners that are observed to rise all the way to GS-14 over the sample period.

As stated in the text, one of the concerns with Figure 3 is that there are a limited number of examiners that stay at least 7 years within grades 12, 13 (without signatory authority) and 13 (with signatory authority) that it may be difficult to generalize from the experiences of these examiners to predict what would happen if we forced all examiners (including those that rise in the ranks quickly) to stay that long within each grade. What is more common, however, is that those who at least rise to GS-14 will wind up staying at that level for many years. This motivates an alternative balanced sample approach. In Table A6, we focus on those examiners that (1) at least rise to GS14 from a lower grade during the sample period, (2) that at least stay at GS-14 for 4 years during the sample period and (3) that at least took 4 years during the sample to rise to GS-14. We then take an event-study approach in which we estimate how their grant rate changes in the period approaching the jump to GS-14 and the period following this promotion. Rather than only looking at the four years leading up to GS-14 while staying within GS-13 (with signatory authority)-among those who stay at GS13(2) that long-this alternative approach simply follows examiners over the four preceding years regardless of what pre-GS-14 grade they were in that time. Taking the former approach would simply be too restrictive to be of much generalized insight. Again, while it is very common for examiners to spend many years at GS-14 once they reach that level (which we are trying to take advantage of with this balanced approach), there is much variation in how fast or slow they take to get to GS-14 itself. 
Consistent with expectations and with Figure 3, we observe a distinct jump in the grant rates (relative to the grant rate in the preceding periods) upon the promotion to GS-14. Though the lagged coefficients are statistically insignificant, the point estimates suggest a subsequent decline in grant rates thereafter, consistent with Figure 3. Note that The coefficient represented in each row represents the mean change in the grant rate as an examiner moves into the indicated time period relative to the grant rate prevailing in the prior time period (in other words, the coefficients should not be interpreted as the cumulative effect of the indicated time period relative to the omitted time period), where time is measured with reference to years prior to and subsequent to a GS-14 promotion.

\section{TABLE A6: EVENT STUDY ANALYSIS OF GRANT RATES IN THE YEARS PRECEDING AND Following THE PROMOTION TO GS-14}

\begin{tabular}{|c|c|c|}
\hline & $(1)$ & $(2)$ \\
\hline \multicolumn{3}{|l|}{$\begin{array}{l}\text { (Omitted: } 4+\text { Years Prior to GS-14 } \\
\text { Promotion) }\end{array}$} \\
\hline 2-4 Years Prior to GS-14 Promotion & $\begin{array}{l}-0.016^{* *} \\
(0.006)\end{array}$ & $\begin{array}{l}-0.010^{*} \\
(0.006)\end{array}$ \\
\hline 0-2 Years Prior to GS-14 Promotion & $\begin{array}{l}-0.005 \\
(0.006)\end{array}$ & $\begin{array}{l}-0.004 \\
(0.006)\end{array}$ \\
\hline 0-2 Years Following GS-14 Promotion & $\begin{array}{l}0.018^{* * * *} \\
(0.005)\end{array}$ & $\begin{array}{l}0.018^{* * *} \\
(0.005)\end{array}$ \\
\hline 2-4 Years Following GS-14 Promotion & $\begin{array}{l}-0.006 \\
(0.005)\end{array}$ & $\begin{array}{l}-0.007 \\
(0.005)\end{array}$ \\
\hline 4+ Years Following GS-14 Promotion & $\begin{array}{l}-0.005 \\
(0.007)\end{array}$ & $\begin{array}{l}-0.009 \\
(0.007)\end{array}$ \\
\hline $\mathrm{N}$ & 145169 & 138811 \\
\hline $\begin{array}{l}\text { Sample restriction: minimum years of } \\
\text { observation of examiners prior to GS- } \\
14 \text { promotion }\end{array}$ & 4 & 4 \\
\hline $\begin{array}{l}\text { Sample restriction: minimum years of } \\
\text { observation of examiners following } \\
\text { GS-14 promotion }\end{array}$ & 4 & 4 \\
\hline $\begin{array}{l}\text { Technology-by-Year Fixed Effects and } \\
\text { Application Covariates? }\end{array}$ & NO & YES \\
\hline \multicolumn{3}{|c|}{$\begin{array}{l}{ }^{*} \text { significant at } 10 \% ;{ }^{* *} \text { significant at } 5 \% ;{ }^{* *} \text { significant at } 1 \% \text {. Standard errors are reported in } \\
\text { parentheses and are clustered to correct for autocorrelation within given examiners over time. } \\
\text { The specification underlying this Table focuses on those applications reviewed by examiners } \\
\text { that we observe being promoted to GS-14 during the sample and that stay at GS- } 14 \text { for at least } \\
4 \text { years during the sample period. With this sample, we then regress the incidence of the } \\
\text { application being granted on a series of lead and lag indicators for the timing of the associated } \\
\text { examiners GS-14 status (along with examiner and year fixed effects). The coefficient } \\
\text { represented in each row represents the mean change in the grant rate as an examiner moves } \\
\text { into the indicated time period relative to the grant rate prevailing in the prior time period, } \\
\text { where time is measured with reference to years prior to and subsequent to a GS-14 promotion. }\end{array}$} \\
\hline
\end{tabular}


Figure A16: Relationship between Grade Levels and Grant Rates by Technology
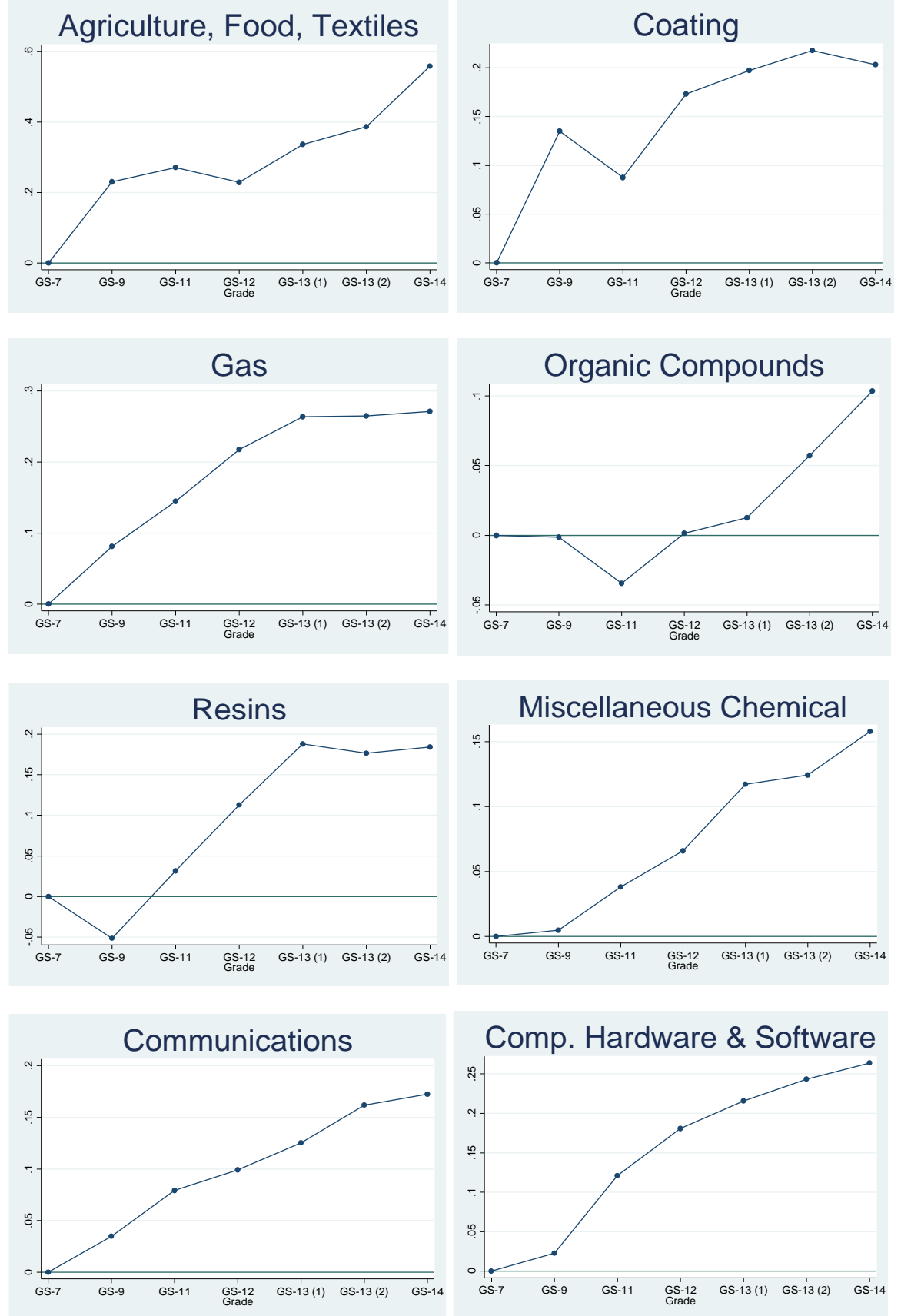

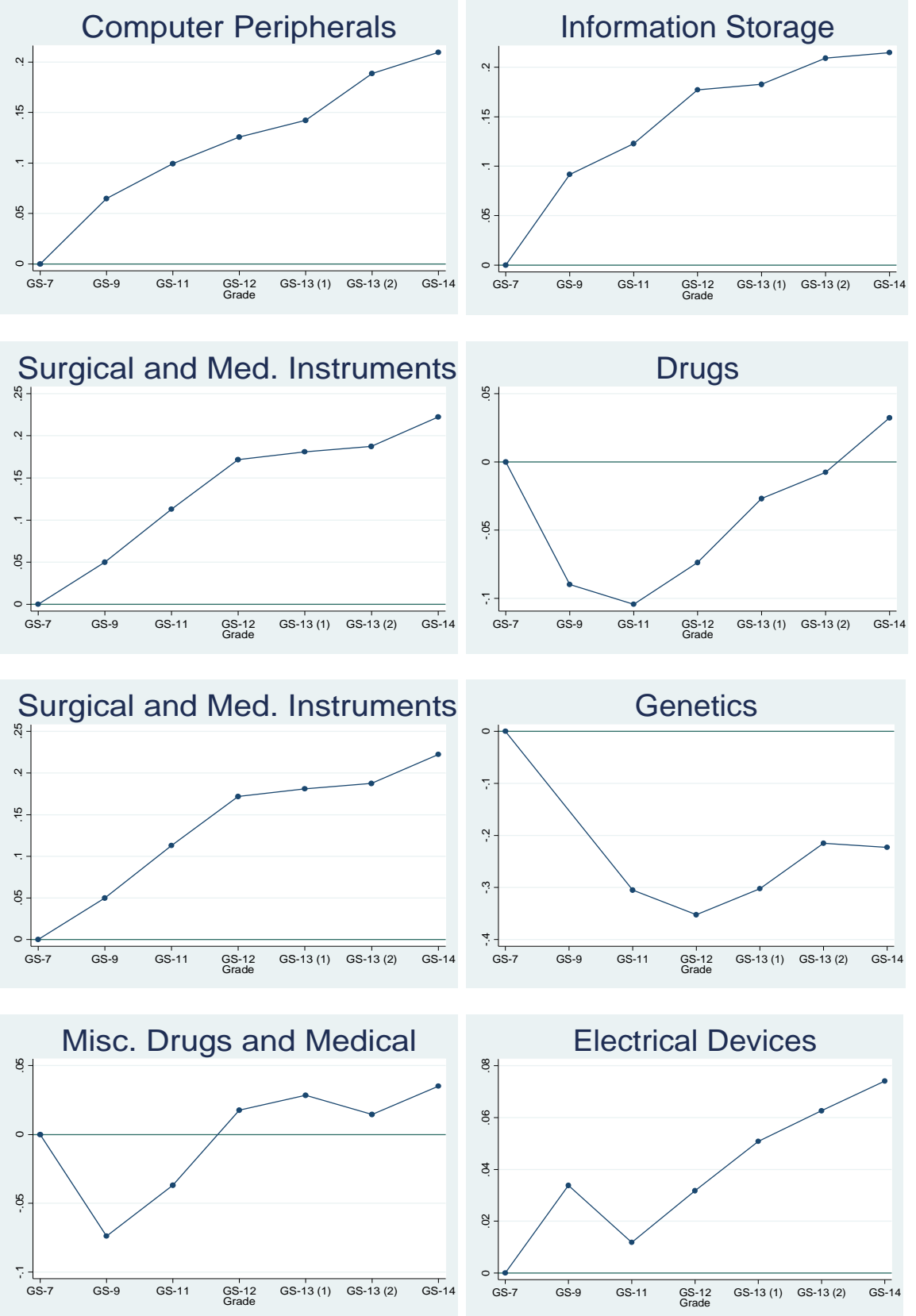

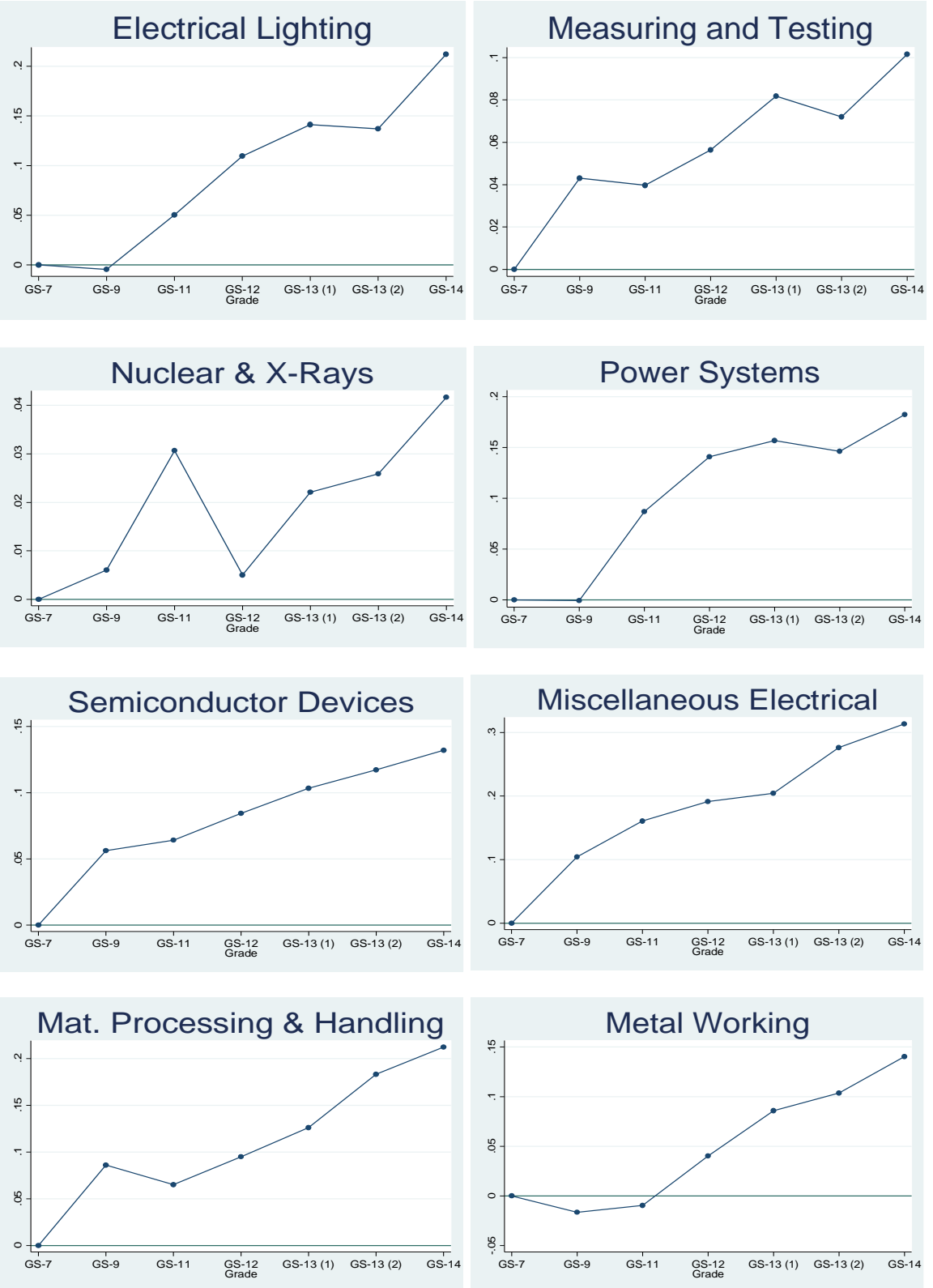

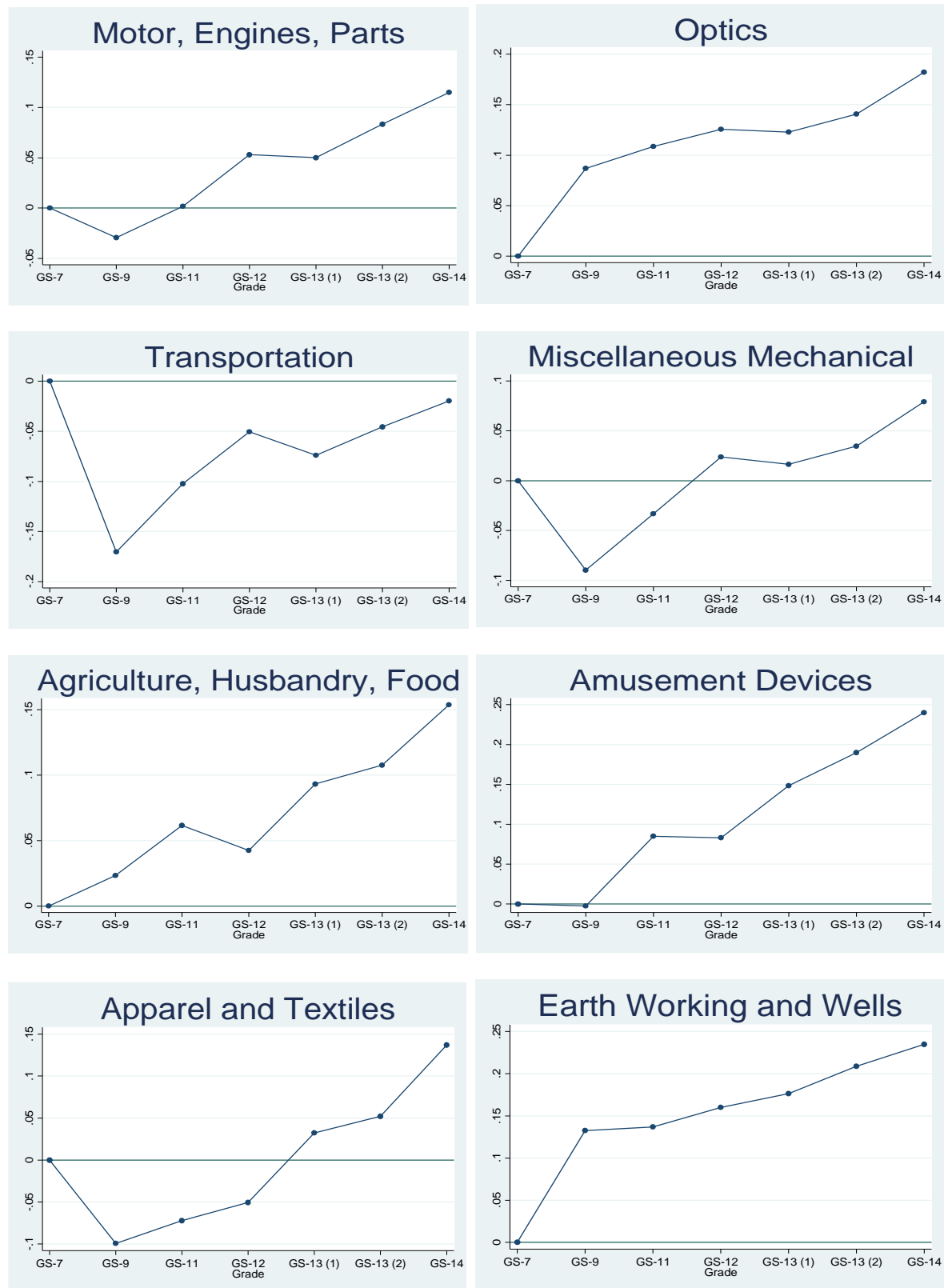

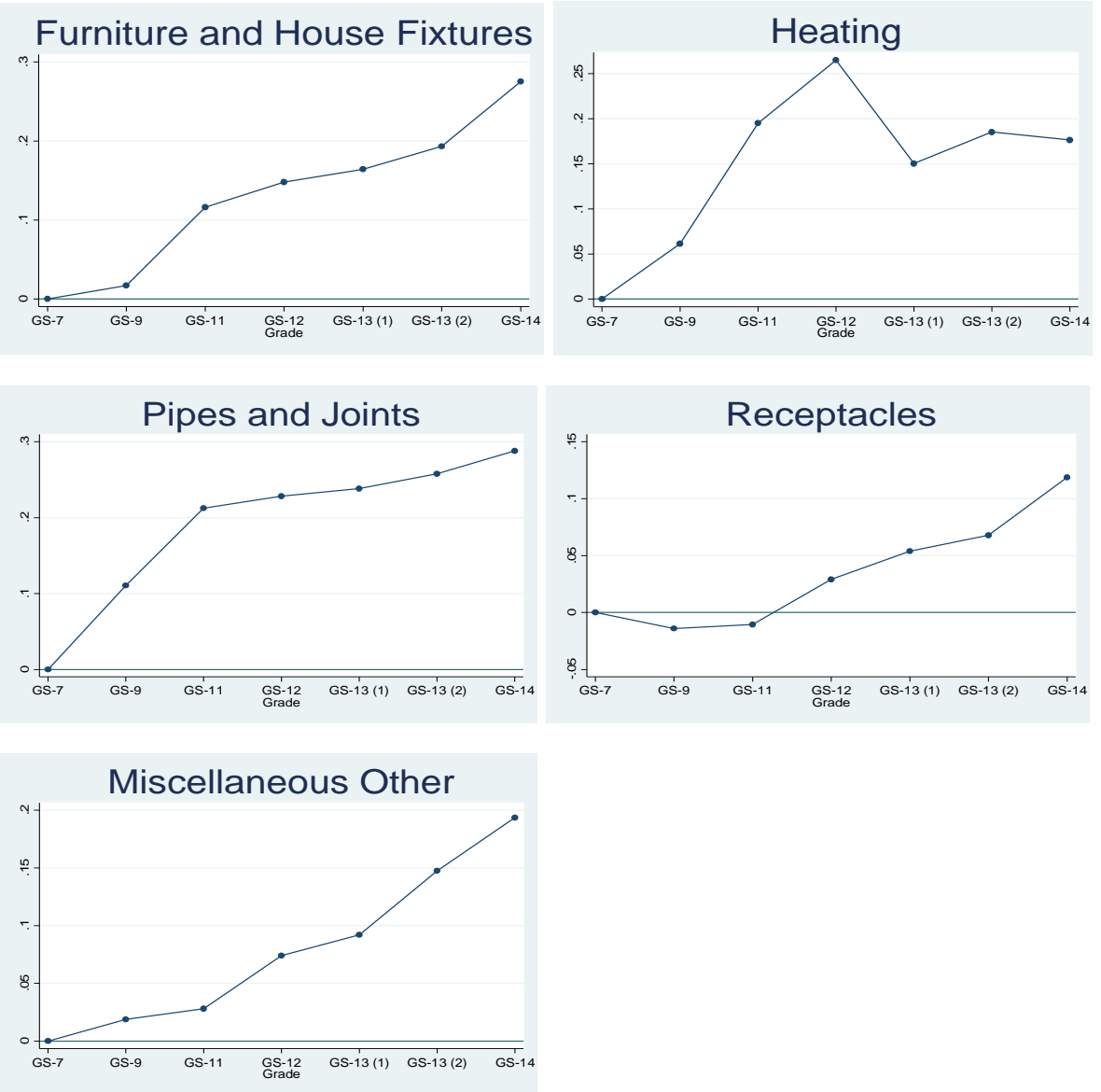

Notes: each figure replicates that of Figure 1 except focusing separately on applications within the indicated technology. Technology delineations follow the 37 Hall et al. (2001) sub-categories. 
Hours-specific Interpretation of Results

TABLE A7. RELATIONSHIP BETWEEN GRANT RATES AND ALLOCATED
EXAMINATION HOURS

\begin{tabular}{lcccc}
\hline & $\mathbf{( 1 )}$ & $\mathbf{( 3 )}$ & $\mathbf{( 4 )}$ & $\mathbf{( 5 )}$ \\
\hline Allocated Examination Hours & $-0.0060^{* * *}$ & $-0.0136^{* * *}$ & $-0.0097^{* * *}$ & $-0.0047^{* * * *}$ \\
N & $(0.0004)$ & $(0.0006)$ & $(0.0006)$ & $(0.0005)$ \\
Examiner and Year Fixed & 1158588 & 1158599 & 990889 & 990889 \\
$\quad$ Effects? & YES & YES & YES & YES \\
PTO Class Fixed Effects? & NO & YES & YES & NO \\
Application Covariates? & NO & NO & YES & YES \\
Technology-by-Year Fixed & NO & NO & NO & YES \\
\hline Effects? & & & &
\end{tabular}

* significant at $10 \% ; * *$ significant at $5 \% ; * * *$ significant at $1 \%$. Standard errors are reported in parentheses and are clustered to correct for autocorrelation within given examiners over time. Each observation is a given application from the PAIR database that reached a final disposition and that was published in the PAIR records between March, 2001 and July, 2012. Application covariates in this table include the incidence of a large entity applicant and the incidence of the filing of a Request for Continued Examination in connection with the application. Technology-by-year effects are based on the $37 \mathrm{Hall}$ et al. (2001) technology sub-categories. The allocated examination hours scheduled (which is a function of the PTO class of the application and the grade level of the examiner) was obtained from the PTO pursuant to a FOIA request.

Additional notes regarding Table A7: Time allotments are a function of both the grade level of the examiner and the technology of the application. Table 3 in the text is meant to capture fluctuations in one of these measures - that is, to capture the influence of changing grade levels on grant rates. Of course, it is important in that initial analysis to include technology dummies to account for the possibility that examiners will start reviewing different technologies following promotions. Table 3 approaches this using both fine-grained dummies for each Patent Office Class and the more aggregated technology subcategories (37 groups) delineated by Hall et al. (2001). In this hours specification, we likewise endeavor to draw upon differences in grade levels of the associated examiners to capture variation in examination hours, benefiting from the fact that applications are randomly assigned across examiners of different grades. ${ }^{9}$ In the case of the present table, however, it is arguably more critical to use the more finegrained PTO classification on which hour-allotments are based in order to isolate the

$9 \quad$ Any attempt to identify the effects of time allocation changes by drawing upon examiners switching across PTO Classes would be confounded by the difficulty in separating the time allocation effect and fixed differences in grant rates that may arise from technology effects more generally. 
influence of promotions on time allotments (given the direct linking between PTO Class and hour allotments). As such, the columns of greater interest here are Columns 2 and 3 which include PTO class dummies. The findings from these columns suggest that an increase of one hour in the amount of time allocated to review an application is associated with a 0.5 to 1.4 percentage point reduction in the grant rate. Considering a mean hours allocation across the applications in the analytical sample of roughly 17 hours, these results suggest that a doubling of examination hours-a benchmark used by Lemley (2001) to evaluate the merits of investing more in Patent Office examination resources-would lead to a 9 to 24 percentage-point decrease in the grant rate, or a roughly 13 to 34 percent decline.

One concern with this approach is the linear treatment of any time allocation effects. The main approaches taken in the paper, which specific the relationship between grant rates and a series of grade level dummies, are more flexible and nonparametric in nature.

\section{Treatment of Switching of Examiners during Applications.}

The PAIR dataset, allows us to identify, for each application, the dates upon which the application was docketed to an examiner, even if there are multiple docketing events over the course of a single application. In over 70 percent of the applications within this file, the records do not indicate any such docketing event after the period of time in which the first office action on the merits has taken place. In other words, a majority of time, the initial examiner sees the application through to its completion. There is often more than one "docketing" record in the period prior to the completion of the first office action, though our interviews with examiners suggest that these initial recordings may capture a separate docketing with the Art Unit itself and then with the ultimate examiner. To be clear, the fact that a minority of applications experience a switch in examiners between the first office action and the final disposal of the application is not overly problematic for our analysis. When an examiner takes over an application from a prior examiner (e.g., upon their departure from the Agency), the new examiner will still receive a "count" for bringing the application to its disposal. Considering that examiners face expectations over how many counts to process in a specified period of time, the new examiner is still subject to time pressures in completing the task of reviewing the application in question. Importantly, the degree of these time pressures will vary depending on the GS-level of the examiner, which we seek to capture in our specifications. Nonetheless, in Figure A17, we present results 
from an alternative specification in which we focus only on those applications in which there is no indication of an examiner replacement following the first office action.

Figure A17: Relationship between Examiner GS-Level and Grant Rates, Excluding Applications with Examiner Replacements

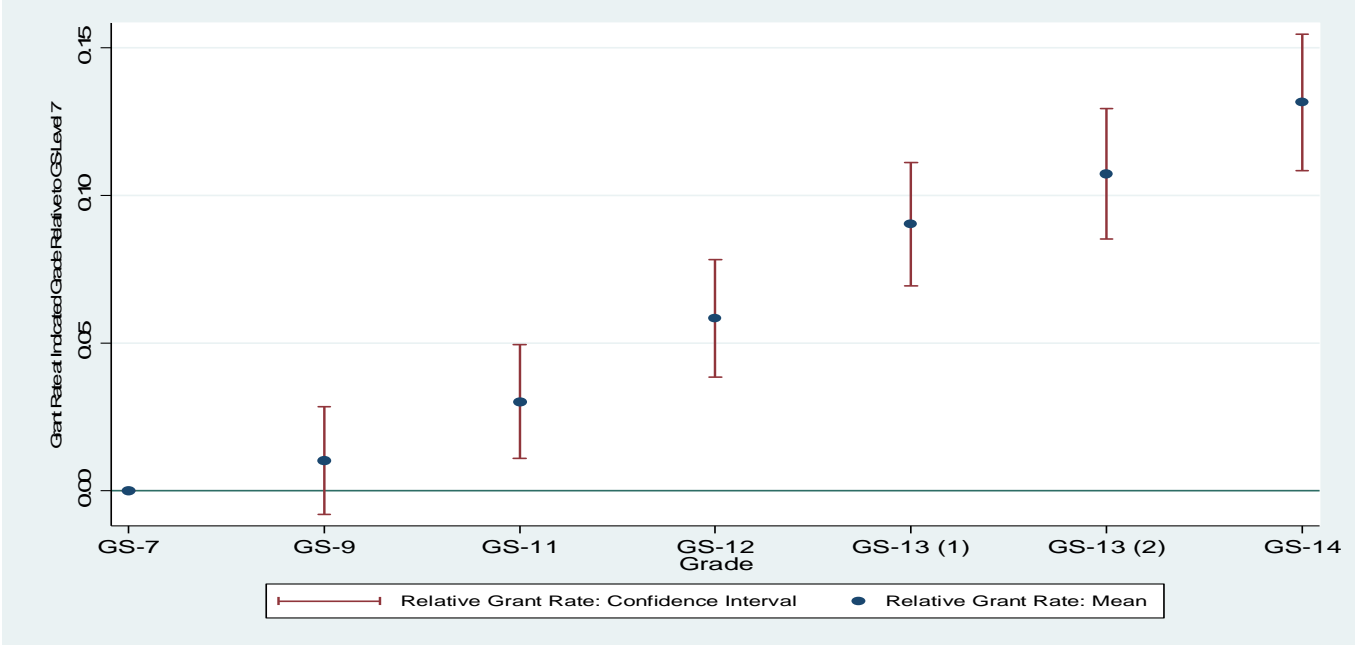

Notes: this figure replicates that of Figure 1 except that it focuses only on the 775,091 applications within our sample in which the examiner completing the first office action was the same examiner completing the disposition of the application.

\section{Alternative Treatments of Time}

The primary specifications capture the time at which the examiner reviews applications with reference to the time of disposition of the application in question. In the minority of cases in which the examiner producing the disposal differed from the examiner completing the first office action, this approach will ensure that we capture the time period in which the new examiner is exerting her efforts. For those situations in which the examiners stay with the same application to its completion, this approach will still ensure that we capture the period of time in which the examiner is exerting substantial effort on reviewing the application. In Figure A18, we take an alternative approach in which we set year fixed effects and merge examiner roster information with each application based on the time of the first office action. The pattern of results is robust to this alternative approach. Since times of first office action are naturally before times of disposition, this alternative approach may assign lower GS levels to some 
applications relative to the primary specifications - in those cases where the promotion occurs throughout the course of the application. As such, one might expect that this approach will attenuate any observed increases in grant rates upon promotion (relative to the primary results), to the extent that such promotions are not actually registered in the empirical specification. Consistent with these expectations, though the same pattern of results is observed with this alternative approach, the magnitude of the observed rise in grant rates upon GS-level changes is smaller in this alternative approach relative to the primary specifications. One can perhaps view these results as a lower bound estimate when these timing considerations in mind and the results presented in the text as upper bound estimates. We note that the full pattern of results-e.g., Figure 3-are likewise robust to this alternative timing (full results available upon request). We further note that, since we are merging examiner roster information to the PAIR database based on the moment of the first office action, the specification underlying this Figure focuses only on those applications in which the examiner completing the first office action is the same examiner producing the disposition, though the results are essentially identical when we make no such restriction. Finally, the results are also similar to Figure A18 when we assign time based on the moment of initial filing or initial docketing, even though such moments may be prior to the time when the examiner actually commences examination. 
Figure A_18: Relationship between Examiner GS-Levels and Grant Rates, Assigning Time Based on the Moment of the First Office Action and Excluding Applications with Examiner Replacements

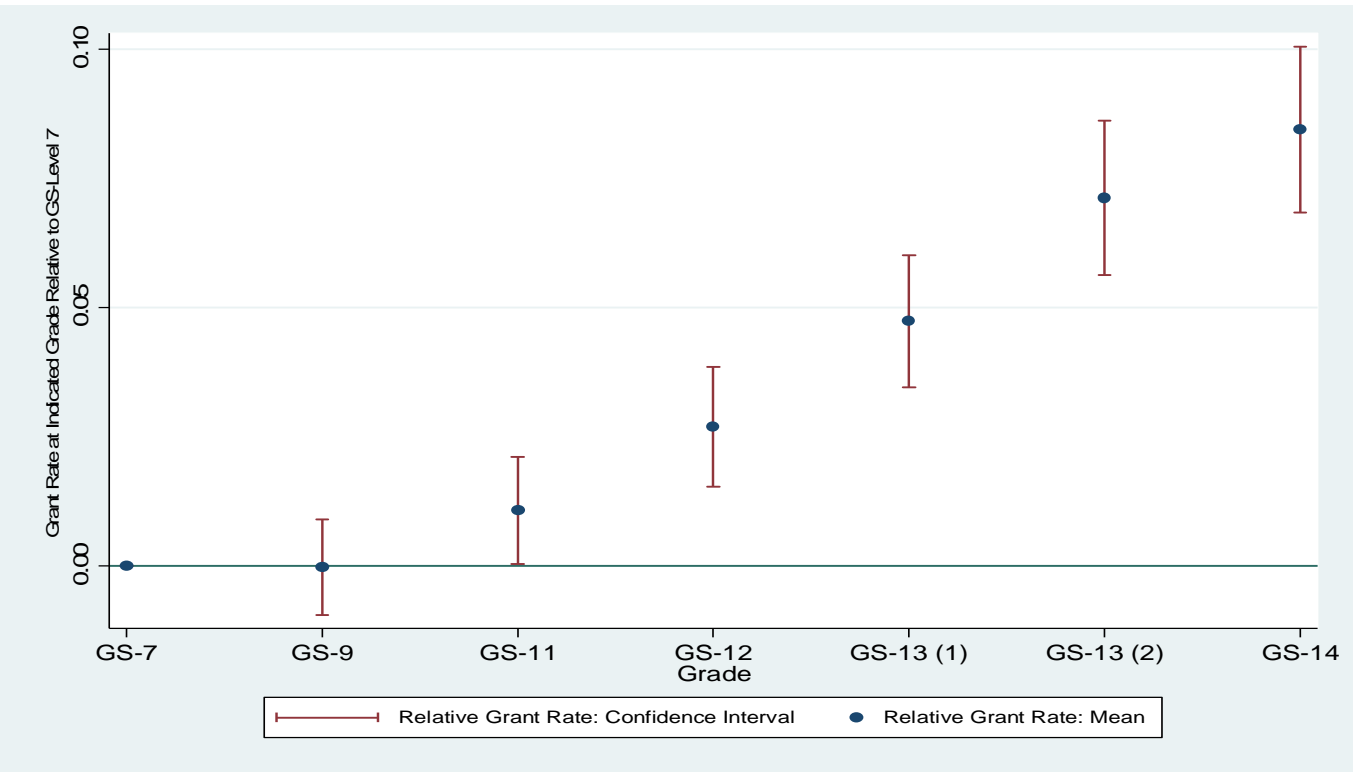

Notes: this figure replicates that of Figure 1 except that it assigns year effects and matches examiner roster information to the PAIR database based on the moment of completion of the first office action on the merits, while focusing only on the applications within our sample in which the examiner completing the first office action was the same examiner completing the disposition of the application. 


\section{Grant Rates of Fast vs. Slow Risers}

A simple observation of Figure 1 may lead to an endogeneity concern that the Patent Office is simply extending promotions once a given examiner's grant rates rise to a certain level. Figure 3 alleviates this concern by showing that grant rates are not increasing over time within each grade level. To take matters further, we also seek to explore the inherent granting tendencies of those who are promoted quickly within the Patent Office versus those who rise more slowly. For these purposes we focus on assessing promotion speed in the post-GS-11 range, where examiners began to spend more varied periods of time with each grade level. We look at those examiners that we can observe in our sample as starting below GS12 and that rose to GS-14. We then group this set of examiners into different bins depending on how quickly it took them to rise from GS-12 to GS-14. Column 1 of Table A8 compares the overall mean grants observed across these groups over the sample period. The slow risers actually grant at substantially higher rates relative to the fast risers, easing the above-stated concern. In Columns 2, we rule out that this observation can otherwise be explained by general year trends in the data. In Columns 3 and 4, we add yet additional controls, including, among others, the GS-level of the examiners. Since the goal of this exercise is to capture the inherent granting differences across these groups, it may benefit to account for the year-by-year change in other factors that also explain observed granting behaviors-e.g., time allocations. The coefficients of the slow-rising category fall in magnitude as we add these additional controls, leaving us with statistically insignificant differences in grant rates across the various speed groups. Nonetheless, the point estimates continue to suggest that fast risers grant at lower rates relative to the slow risers. At the least, this exercise does not find strong evidence suggestive of a story in which examiners are promoted for having demonstrated elevated granting behaviors. 
TABLE A8: RELATIONSHIP BETWEEN GRANT RATES AND SPEED BY WHICH EXAMINERS ASCEND FROM GS-12 TO GS-14, AMONG EXAMINERS STARTING AT LEAST BELOW GS12 AND RISING TO GS-14 DURING SAMPLE WINDOW

\begin{tabular}{|c|c|c|c|c|}
\hline $\begin{array}{l}\text { Speed in Rising from GS- } \\
12 \text { to GS-14 }\end{array}$ & (1) & (2) & (3) & (4) \\
\hline \multicolumn{5}{|l|}{$\begin{array}{l}\text { Omitted Category: Fast } \\
\text { Risers (Within } 3 \text { Years) }\end{array}$} \\
\hline Slower Risers (4-7 Years) & $\begin{array}{c}0.014 \\
(0.014)\end{array}$ & $\begin{array}{c}0.021 \\
(0.013)\end{array}$ & $\begin{array}{c}0.018 \\
(0.012)\end{array}$ & $\begin{array}{c}0.009 \\
(0.014)\end{array}$ \\
\hline Slowest Risers (8+ Years) & $\begin{array}{c}0.124 * * * \\
(0.272)\end{array}$ & $\begin{array}{c}0.116^{* * *} \\
(0.027)\end{array}$ & $\begin{array}{l}0.050^{*} \\
(0.027)\end{array}$ & $\begin{array}{c}0.037 \\
(0.029)\end{array}$ \\
\hline $\mathrm{N}$ & 292020 & 292020 & 291333 & 291333 \\
\hline Year Effects? & $\mathrm{NO}$ & YES & YES & YES \\
\hline $\begin{array}{c}\text { GS-Level and Experience } \\
\text { Effects? }\end{array}$ & NO & NO & YES & YES \\
\hline $\begin{array}{c}\text { Cohort Effects and Tenure } \\
\text { Effects (Total Years at } \\
\text { Agency)? }\end{array}$ & NO & NO & NO & YES \\
\hline
\end{tabular}




\section{Falsification Exercises}

\section{TABLE A9. RELATIONSHIP BETWEEN EXAMINER GRADE LEVELS AND CERTAIN IMMUTABLE CHARACTERISTICS OF INCOMING APPLICATIONS}

\begin{tabular}{|c|c|c|}
\hline & (1) & (2) \\
\hline & $\begin{array}{l}\text { INCIDENCE OF EPO } \\
\text { OR JPO PRIORITY }\end{array}$ & $\begin{array}{c}\text { LARGE ENTITY } \\
\text { STATUS OF APPLICANT }\end{array}$ \\
\hline \multicolumn{3}{|l|}{ Omitted: GS-7 } \\
\hline GS-9 & $\begin{array}{l}-0.001 \\
(0.003)\end{array}$ & $\begin{array}{l}0.012 * * \\
(0.005)\end{array}$ \\
\hline GS-11 & $\begin{array}{l}-0.002 \\
(0.003)\end{array}$ & $\begin{array}{l}0.026^{* * *} \\
(0.005)\end{array}$ \\
\hline GS-12 & $\begin{array}{l}-0.000 \\
(0.003)\end{array}$ & $\begin{array}{c}0.030 \\
(0.006)\end{array}$ \\
\hline GS-13 & $\begin{array}{l}-0.001 \\
(0.004)\end{array}$ & $\begin{array}{c}0.030 \\
(0.006)\end{array}$ \\
\hline $\begin{array}{l}\text { GS-13 (with partial signatory } \\
\text { authority) }\end{array}$ & $\begin{array}{c}0.003 \\
(0.004)\end{array}$ & $\begin{array}{c}0.031 \\
(0.008)\end{array}$ \\
\hline GS-14 & $\begin{array}{c}0.002 \\
(0.002)\end{array}$ & $\begin{array}{c}0.034 \\
(0.007)\end{array}$ \\
\hline $\begin{array}{l}\text { Omitted: 0-1 Years Experience } \\
\mathrm{N}\end{array}$ & 990939 & 990939 \\
\hline \multicolumn{3}{|c|}{$\begin{array}{l}{ }^{*} \text { significant at } 10 \% ;{ }^{* *} \text { significant at } 5 \% ;{ }^{* *} \text { significant at } 1 \% \text {. Standard errors are } \\
\text { reported in parentheses and are clustered to correct for autocorrelation within } \\
\text { given examiners over time. These specifications track those of Table } 3 \text { except } \\
\text { replacing the incidence of the application being granted as the dependent variable } \\
\text { with: (1) the incidence of the application having been previously filed in the EPO or } \\
\text { JPO (Column } 1 \text { ) or (2) the incidence of the applicant being of large entity status } \\
\text { (Column } 2 \text { ). }\end{array}$} \\
\hline
\end{tabular}


Figure A19: Scatter Plot of Frequency of Observations within Each GS-Level / Experience Combination

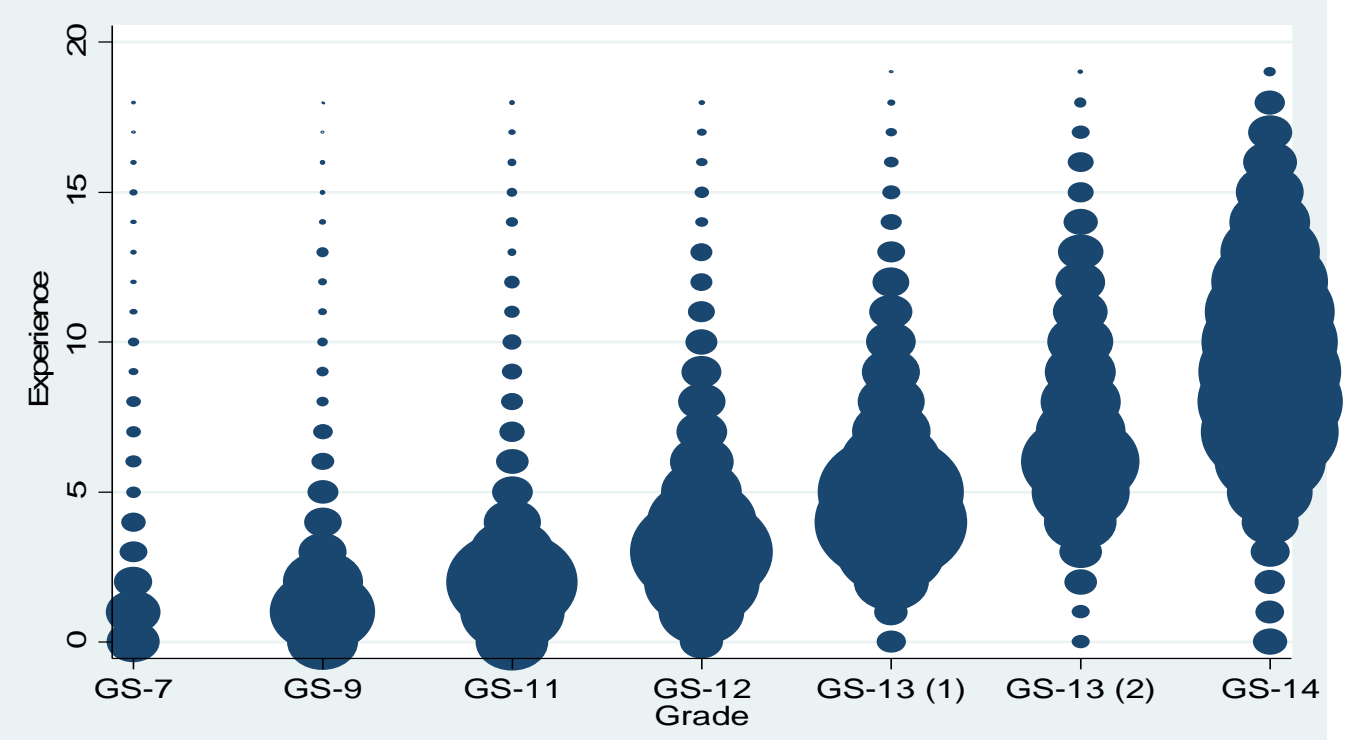

